Understanding human responses to wildlife in Malaysia

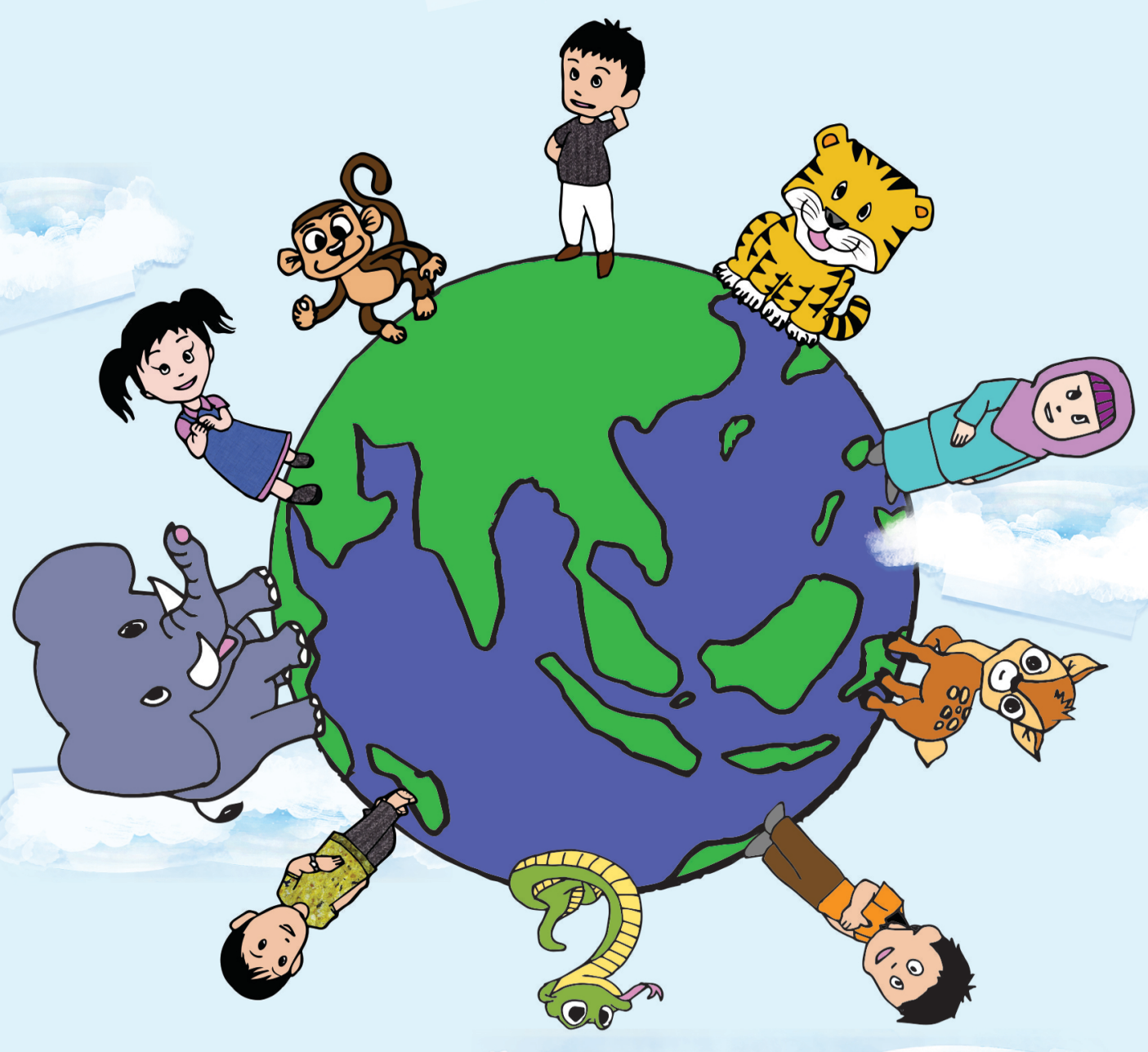

Zulkhairi Azizi Zainal Abidin 


\section{Propositions}

1. The domination orientation to wildlife is hard to measure, yet explains a lot about Malaysians.

(this thesis)

2. Emotions predict thought about actions beneficial to wildlife and not about actions harmful to wildlife.

(this thesis)

3. If people want to save the world from environmental degradation, ecotourism is not the answer.

4. Nuisance urban wildlife is created by irresponsible people.

5. A ban on palm oil exploitation will decrease biodiversity conservation efforts in Malaysia.

6. Conversations about environmental issues at dinner tables are equally important as experts' discussions at international conferences.

Propositions belonging to the thesis, entitled

Understanding human responses to wildlife in Malaysia

Zulkhairi Azizi Zainal Abidin

Wageningen, 28 August 2019 


\section{Understanding human responses to wildlife in Malaysia}




\section{Thesis committee}

\section{Promotor}

Prof. Dr V.R. van der Duim

Personal Chair at the Cultural Geography Group

Wageningen University \& Research

\section{Co-promotor}

Dr M.H. Jacobs

Assistant professor, Cultural Geography Group

Wageningen University \& Research

\section{Other members}

Prof. Dr B.J.M. Arts, Wageningen University \& Research

Prof. T. Haartsen, University of Groningen

Dr H. Wels, VU, Amsterdam

Dr S. de Vries, Wageningen University \& Research

This research was conducted under the auspices of the Wageningen School Social Sciences (WASS). 


\title{
Understanding human responses to wildlife in Malaysia
}

\author{
Zulkhairi Azizi Zainal Abidin
}

Thesis

submitted in fulfilment of the requirements for the degree of doctor

at Wageningen University

by the authority of the Rector Magnificus,

Prof. Dr A.P.J. Mol,

in the presence of the

Thesis Committee appointed by the Academic Board

to be defended in public

on Wednesday 28 August 2019

at 11 a.m. in the Aula. 
Zulkhairi Azizi Zainal Abidin

Understanding human responses to wildlife in Malaysia,

124 pages.

$\mathrm{PhD}$ thesis, Wageningen University, Wageningen, The Netherlands (2019)

With references, with summaries in English and Dutch

ISBN 978-94-6395-014-5

DOI https://doi.org/10.18174/494705 


\section{Acknowledgements}

"There are some four million different kinds of animals and plants in the world. Four million different solutions to the problems of staying alive".

David Attenborough, 1979 (Life on Earth)

Although this $\mathrm{PhD}$ journey has come to an end, the effort to protect wildlife will continue forever. This thesis probably makes only a very small contribution to the conservation of animals and wildlife. Small as it may be, I hope it will benefit the readers, people in general, and all wildlife species out there.

Writing this thesis is not something I did alone. There are many people that helped me throughout this adventurous and difficult journey. I would like to take this opportunity to convey my heartfelt gratitude and sincere appreciation to all the people who have supported and inspired me during my $\mathrm{PhD}$ journey.

First and foremost, I would like to express my deepest gratitude to my promoter and copromoter Rene and Maarten. Thank you Rene for the input and help during my PhD journey. Also, thanks from the bottom of my heart to Maarten for your guidance, input, feedback, and all your consideration, patience, and understanding in helping me to cross the finish line. It was a privilege for me to be a $\mathrm{PhD}$ student under your supervision for these four and half years. Thank you so much for believing in me in the first place and offering me the opportunity to embark on this journey. I always enjoyed the discussion we had, whether it was about this $\mathrm{PhD}$, life as academics, or family matters. I am also immensely grateful to Claudio, my previous promoter, for accepting me as a PhD student.

It would not have been possible to do this $\mathrm{PhD}$ project without sufficient financial support. Therefore, I would like to thank the Ministry of Higher Education, Malaysia and Universiti Putra Malaysia for financing my study in Wageningen University. My sincere gratitude is extended to the staff of the Department of Wildlife and National Parks of Peninsular Malaysia in Cheras (Headquarters), Kluang and Johor Bahru, particularly to Mr. Shamsul, for their technical and professional support during my fieldwork. My sincere thanks also go to all students and inhabitants who participated in this study. Special thanks also to Ivo van der Lans for his assistance in the data analysis process in chapter 5. I am also grateful to the anonymous 
journal reviewers for their thorough and critical assessments of some of the chapters in this thesis.

During my PhD journey, I have met many good and kind people. I would like to thank all staff and group members (current and former) of the Cultural Geography group. Alex, Amos, Ana, Arjaan, Aan, Chin Ee, Christine, Claudia, Clemens, Eugenie, Femke, Hamzah, Iulian, Karin, Karolina, Martijn, Maurice, Meghann, Michael, Nelly, Nowella, Rodrigo, Roy, Said, Tabitha, Trista, Xin Li, Yulia; and also to many people outside GEO: Arjen, Bas, Birgit, Catharina, Cindy, Fernanda, Ivo, Jim, Ruud, Sjerp, Susan, Tabitha; it was my pleasure to meet you all during this journey. I enjoyed the friendships, all lunch breaks and interesting discussions we had, whether in the $3^{\text {rd }}$ floor corridor, at the 'beach', during coffee breaks, or during walks. Special thanks to Maurice and Said for always being good company in the office. I would also like to acknowledge the support and help I received from the support staff of GEO: Keen, Carla, Stephan, Frank, and Paul.

Our Malaysian friends in Wageningen:

Aidil and Tihah, Ajak and Gee, Amin and Eiva, Amin and Izan, Amir and Zu, Ani, Azie, Hafeez and Nuyu, Hafiz and Yati, Huda K., Huda R., Loo Wee, Mus and Farhana, Nazri and Mira, Mas and Moritz, Mursyid and Umi, Sharul and Shikin, Shol, Su, Syak, Tarmizi, Teo, uncle Allen \& aunty Tony, Zulfakri and Syifa; I also would like to acknowledge all friends in MASNL and other Malaysians in the Netherlands, as well as my Indonesian friends in Wageningen, particularly pak Dikky. I owe you special thanks for your friendship and the very good makanmakan and membawang we spent together. Mohon halalkan semuanya, maaf atas kekurangan $k a m i$, and may our friendship last forever. Not forgetting my friends from afar: Aswad, Balkis, Hafizal, Jalilah, Muaz, Sham, Sheena. Thank you for all the discussions we had. I am so excited to get back to work with you guys again.

“Keredhaan Tuhan terletak pada keredhaan ibu bapa ....” Riwayat At-Tirmidzi.

Umi, terima kasih kerana melahirkan dan membesarkan bangah. Baba, bangah rindukan baba. Mimpi di malam terakhir pemergian baba masih segar dalam ingatan bangah. InsyaAllah bangah akan jaga dan tunaikan wasiat baba sebaik mungkin. Terima kasih juga kerana membesarkan dan mendidik bangah. Dan terima kasih tak terhingga atas doa yang tak putusputus untuk kejayaan bangah. Bangah mohon ampun atas semua salah silap dan kerana 
sentiasa tiada di sisi umi dan baba di saat susah dan payah. Semoga umi dan baba sentiasa dirahmatiNya.

Buat balong (kak long), kak cik, dan Zahirah. Terima kasih banyak mengambil tempat bangah untuk umi dan arwah baba selama bangah merantau. Buat keluarga mertua yang tersayang mak abah dan semua ipar duai, terima kasih kerana terus bersabar menanti kepulangan kami sekeluarga dari merantau mencari ilmu. Maafkan salah silap kami sekeluarga, dan semoga kita sekeluarga diberi kerahmatan dan kebahagiaan berkat kesabaran atas ujianNya.

Buat semua ahli keluarga yang lain, ibu dan bapa saudara, sepupu, anak buah, terima kasih kerana menyokong GG dan keluarga. Moga jasa baik kalian dibalas kebaikan.

Buat isteriku, Nur Adlini. Abang ucapkan berbanyak terima kasih menerima semua kerenah suamimu ini tanpa mengeluh dan penuh kesabaran. Terima kasih juga kerana sanggup korbankan peluang kerjaya untuk membantu abang menempuh kembara PhD ini. Abang cintakan sayang. Adam dan Zahrah. Terima kasih buat dua anak-anak abah yang tersayang sebab menjadi mangkin untuk abah terus bekerja dengan lebih kuat. Membesarkan kalian berdua semasa menuntut ilmu satu rahmat yang amat besar - abah dapat lebih memahami isi kandungan pengajian abah dengan memerhati hubungan abah dengan anak-anak abah. Moga momen kita sekeluarga di bumi Belanda memupuk kasih sayang yang erat antara kita. Atas semua pengorbanan yang kita semua lalui, PhD ini milik kita sekeluarga.

\section{Zulkhairi Azizi}

$28^{\text {th }}$ February 2019

Kuala Lumpur, Malaysia 


\section{Table of contents}

Acknowledgements $\quad \mathrm{v}$

Table of contents $\quad$ ix

$\begin{array}{lll}\text { Chapter } 1 \text { General introduction } & 1\end{array}$

$\begin{array}{lll}\text { Chapter } 2 & \text { The applicability of wildlife value orientations scales to a } & 13\end{array}$ Muslim student sample in Malaysia

Chapter 3 Abstract wildlife is nice, concrete wildlife less so: Salient thought about wildlife in a Malaysian sample

wildlife value orientations

Chapter 5 Understanding public acceptance of wildlife management interventions in Malaysia

$\begin{array}{lll}\text { Chapter 6 Discussion and conclusions } & 95\end{array}$

$\begin{array}{ll}\text { Summary } & 111\end{array}$

$\begin{array}{ll}\text { Samenvatting } & 117\end{array}$

$\begin{array}{ll}\text { About the author } & 119\end{array}$

$\begin{array}{ll}\text { Scientific contributions } & 121\end{array}$

Completed training and supervision plan 124 

Untuk baba, uni, sayang. Adam dan Zahrah 

Chapter 1

\section{General introduction}




\section{Wildlife conservation in Malaysia}

$\mathrm{W}$ ildlife is important to people in many different ways. Wildlife is a source of food, provides important ecological functions, influences economic livelihoods, and is a concern for safety and health (Manfredo, 2008). The importance of wildlife can be observed in Malaysia too, the country this $\mathrm{PhD}$ research is focused on. Wildlife can be a source of fascination and consequently foster economic development. In recent years, more than 800,000 domestic and international tourists per year visited Malaysian national parks, wildlife conservation centres and marine parks (Department of Marine Park Malaysia, 2016; Department of Wildlife and National Parks of Peninsular Malaysia [DWNP], 2015). For local inhabitants, wildlife-related tourism means a boost in the economy and new employment opportunities (Department of Statistics Malaysia, 2018). At the same time, people may also be concerned about wildlife, as wildlife presents safety issues and economic conflicts. For decades, plantation owners and farmers in Malaysia have experienced wildlife depredation with significant economic losses (Ahmad Zafir \& Magintan, 2016). Cases of human deaths caused by wildlife were also reported (Saaban et al., 2011). There are also reports of wildlife nuisance in residential areas (DWNP, 2015). On the other hand, increasing habitat loss and wildlife poaching are important threats to wildlife populations in Malaysia (Corlett, 2007; Sodhi et al., 2010; Sodhi, Koh, Brook, \& Ng, 2004).

The Malaysian government has fostered conservation through actions such as introducing new conservation laws, species conservation action plans, sustainable guidelines, and management strategies to protect Malaysia's wildlife and natural habitat as well as mitigating conflicts between humans and wildlife (Clements et al., 2010). While these efforts are important for wildlife conservation, they are predominantly based on the ecological contexts (e.g. predator-prey relationships), technical fixes (e.g. different management practices) and physical solutions (e.g. expansion of habitat). Knowledge about human relationships with wildlife has been given limited attention in wildlife conservation and management plans. Ideally, sound conservation strategies should also be based on social and psychological considerations (Bennett, 2016; Endter-Wada, Blahna, Krannich, \& Brunson, 1998).

The term "human dimensions of wildlife" denotes research on psychological and social aspects of human-wildlife relationships. It includes research on individual psychological attributes such as values, emotions, perceptions, and attitudes within the context of conservation (Bennett et al., 2017; Manfredo, 2008). As individuals may differ in the way they think about and respond to wildlife and wildlife issues, human dimensions of wildlife research aims to explore and understand the diversity of thought across individuals. Addressing public responses to wildlife conservation issues can contribute to the effectiveness and efficiency of conservation 
policies and management interventions (Endter-Wada et al., 1998; Manfredo, 2008; Sandbrook, Adams, Büscher, \& Vira, 2013).

In Malaysia, only a few studies have addressed human-wildlife relationships. Research has mainly been focused on human-wildlife conflicts (Hambali, Ismail, Zulkifli, Md-Zain, \& Amir, 2012; Hassan, Hambali, Wan Shaharuddin, \& Amir, 2017; Md-Zain, Ruslin, \& Idris, 2014). Local inhabitants' awareness of wildlife conservation in relation to demographic factors was also studied (Abd Mutalib, Fadzly, \& Foo, 2013; Shafie, Mohd Sah, Abdul Mutalib, \& Fadzly, 2017). One of the outcomes was that older people are more aware of the need to protect bats, while younger people are more aware of the need for turtle conservation. A few studies addressed students' attitudes towards native wildlife (Lim et al., 2013) and visitors' perceptions of and experiences with wildlife in one of the national parks in Malaysia (Aihara, Hosaka, Yasuda, Hashim, \& Numata, 2016).

Another study reported individual differences in values regarding urban wildlife based on Kellert's value typology (Baharuddin, Karuppannan, \& Sivam, 2013). The results indicated that people living closer to Kuala Lumpur's urban parks felt more of an ethical obligation to protect urban biodiversity than people living further away. Two studies examined individual residents' attitudes toward urban wildlife (Mohamad Muslim, Hosaka, Numata, \& Yahya, 2018; Nik Mohamad, 2011). Findings indicated that Malaysian people generally liked several insects and squirrels and liked mammals such as monkeys and wild boars less. Both studies highlighted the influence of past or childhood experiences with wildlife on individual willingness to live with wildlife. Yet another study examined human coexistence with the native flying fox (Aziz, Clements, Giam, Forget, \& Campos-Arceiz, 2017). Older male respondents, particularly fruit tree owners who had had negative experiences with native flying foxes eating the fruit, were more likely to support killing of the animals as part of a conflict solution.

Overall, these studies contributed to the understanding of human dimensions of wildlife in Malaysia by showing the salience of conflicts between humans and wildlife, and the significance of demographic factors for thoughts and actions. However, these studies did not address the underlying psychological mechanisms that are the basis of specific thought about wildlife.

The aim of this $\mathrm{PhD}$ research is to understand and explain how Malaysians think about and respond to wildlife, wildlife issues, and wildlife policy and management plans and interventions. This $\mathrm{PhD}$ project will focus on the concepts of wildlife value orientations, emotions towards wildlife, and wildlife risk perception. Since no single study has integrated these concepts together in one conceptual framework, this $\mathrm{PhD}$ project will make a new contribution to the literature by testing a new conceptual model that integrates the three concepts, thus paving the way for a more comprehensive theoretical understanding of human- 
wildlife relationships. In addition, this $\mathrm{PhD}$ project will add to the current understanding of public opinion about wildlife and wildlife issues in Malaysia.

Information about the public could inform policy-makers and wildlife managers, so they can have a better understanding of how the public thinks and feels about wildlife, as well as how the public would respond to management interventions and hence allow for ex ante evaluation and anticipation of potential public responses (Manfredo, 2008; Sijtsma, Vaske, \& Jacobs, 2012).

\section{Concepts to study human wildlife relationships}

The proposed research will combine three concepts - namely wildlife value orientations, valence towards wildlife, and wildlife risk perceptions - that have so far been applied in isolation only, to understand specific wildlife-related attitudes. These concepts are predominantly used to investigate human-wildlife relationships and are very useful to understand the variation in individual thought. A brief explanation of all the concepts is presented in this section. A detailed explanation of wildlife value orientations will be presented in chapters 2, 4, and 5. Chapter 4 and 5 will also describe the concept of valence towards wildlife, while more insights into wildlife risk perception are presented in chapter 5.

Wildlife value orientations are schematic networks of basic beliefs about wildlife and human-wildlife relationships (Fulton, Manfredo, \& Lipscomb, 1996). Studies in different countries suggest that the wildlife value orientations exist and can be measured reliably with a standardised quantitative scale. Apart from the United States, studies have been executed in the Netherlands (Vaske, Jacobs, \& Sijtsma, 2011), Germany (Hermann, Voß, \& Menzel, 2013), Denmark (Gamborg \& Jensen, 2016), and Italy (Cerri, Mori, Vivarelli, \& Zaccaroni, 2017), amongst other countries.

Valence refers to the pleasure-displeasure dimension of emotion. Emotion theory suggests that valence is the most important feature of emotion (Russell, 2003). This component is also labelled as "core affect" (Feldman Barrett, Mesquita, Ochsner, \& Gross, 2007). In the context of wildlife, valence was found to be a more important predictor of individual attitudes than other emotional measurements (Jacobs, Vaske, Dubois, \& Fehres, 2014).

Risk perception is defined as the subjective judgement that people make about potential danger in their surroundings. Perception of risk can involve value-based or emotionally influenced judgement (Finucane, Alhakami, Slovic, \& Johnson, 2000; Gore et al., 2009; Wildavsky \& Dake, 1990). Examining wildlife risk perception and its relationships with individuals' thought may improve our understanding of the diversity of responses to wildlife and wildlife issues. As researchers (Hanisch-Kirkbride, Riley, \& Gore, 2013; Jacobs, Vaske, Sijtsma, 2014; Riley \& Decker, 2000; Slagle, Bruskotter, \& Wilson, 2012) suggest, risk 
perceptions are shaped by social values and emotions. Wildlife value orientations and valence towards wildlife may therefore inform wildlife risk perceptions.

So far, three studies have examined wildlife value orientations amongst Malaysians. The first study on wildlife value orientations employed a qualitative approach to explore and identify the salient beliefs about wildlife among a group of East Malaysians (King \& Nair, 2013). The study findings suggested three different wildlife value orientations: caring, mutualism and materialism. The second study examined wildlife value orientations among the public in relation to demographic characteristics (Jafarpour \& Mariapan, 2014). Rural people were more utilitarian than urban dwellers, and men were more mutualistic than women. The third study investigated visitors' value orientations as regards to the Giant Panda in the National Zoo's Conservation Centre (Wan Mahamad \& Kunasekaran, 2016). Respondents were more mutualistic than domination-oriented toward the animal. All studies contributed to the understanding of Malaysians' wildlife value orientations. However, as the interview questions of the qualitative study centred on the topic of wildlife tourism, and the focus group sample of workers at tourism sites, the findings do not necessarily reflect the general beliefs of the Malaysian public about wildlife. The quantitative studies omitted some of the original wildlife value orientations items, yet included additional items without explanation, or focused on panda species instead of general wildlife. Also, these studies did not address the predictive potential of wildlife value orientations. Consequently, the studies provide limited information on the applicability of wildlife value orientations concepts and scales in Malaysia, a country with a different cultural context than that of Western countries.

To gain more insight into the wildlife value orientations of Malaysians, this $\mathrm{PhD}$ project will include both qualitative and quantitative studies among Malaysians with different demographic backgrounds. A qualitative study will explore salient beliefs about wildlife outside tourism contexts, and a quantitative study will examine relationships between wildlife value orientations and wildlife-related attitudes and norms. In addition, as there are no studies of emotions pertaining to wildlife in Malaysia, this $\mathrm{PhD}$ project will extend the current understanding of human-wildlife relationships beyond cognitive aspects, by addressing valence. Moreover, this research will investigate the influence of wildlife value orientations and valence towards wildlife on wildlife risk perception. The role of risk perception in understanding responses to management interventions will also be addressed.

\section{Conceptual model}

Two basic considerations underlie the conceptual model used for this $\mathrm{PhD}$ research (Figure 1.1). First, the principle of specificity, which is the notion that mental dispositions exist on different levels of abstraction, and that abstract mental dispositions inform specific ones. On 
the most abstract level, wildlife value orientations reflect cognitive aspects, and valence towards wildlife reflects affective aspects of general psychological dispositions towards wildlife. On the intermediate level, both wildlife value orientations and valence are hypothesised to inform wildlife risk perception. On a more specific level, these same wildlife value orientations, valence towards wildlife and wildlife risk perception are hypothesised to inform contextual attitudes and norms. Second, the conceptual model accounts for cognition and affection - two different mental capacities. Human dimensions of wildlife research is predominantly focused on cognition, such as wildlife value orientations and wildlife risk perceptions. Recently, attention has been paid to emotions. Studying both cognition and emotion may improve our general understanding of human responses to wildlife and wildlife issues.

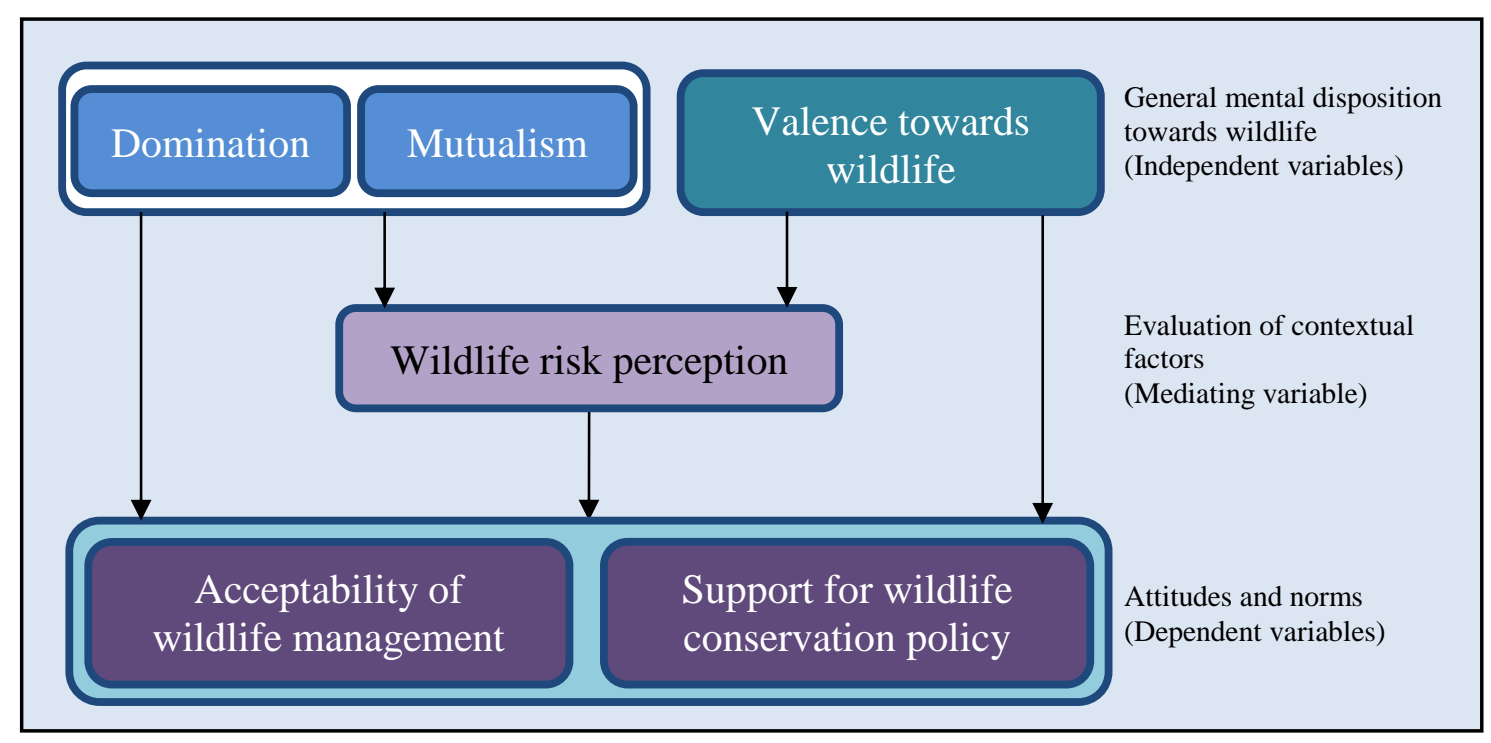

Figure 1.1. The conceptual model guiding this $\mathrm{PhD}$ research.

\section{Aim and research questions}

The main aim of this $\mathrm{PhD}$ research is to understand and explain how Malaysians think about, and respond to wildlife, wildlife issues, and wildlife policy and management plans and interventions. Specifically, the aim is to build on relevant social science theories to explain support for wildlife conservation policy and the acceptability of wildlife management interventions. The following four research questions guide this $\mathrm{PhD}$ project:

1. Are the wildlife value orientations scales applicable in Malaysia?

2. What are the predominant beliefs about wildlife amongst Malaysians?

3. Does valence have an additional predictive potential next to wildlife value orientations to explain wildlife-related evaluations?

4. To what extent do wildlife value orientations, valence towards wildlife, and wildlife risk perception explain acceptability of wildlife management interventions in Malaysia? 


\section{Organisation of the thesis}

This PhD thesis comprises six chapters: a general introduction (the current chapter), four empirical chapters (chapter 2 to 5), and a general discussion (final chapter) (Figure 1.2). Chapters 2 to 5 each address one of the research questions. For the empirical study described in chapter 2, data were obtained from a survey conducted among Malaysian university students $(n=391)$. The study described in chapter 3 used semi-structured interviews among 30 Malaysians of various demographic backgrounds - age group, gender, occupation, religion, cultural background, and place of residence. Data for the studies in chapter 4 and 5 were obtained from a drop-off survey distributed to households in several residential areas in the state of Johor, Peninsular Malaysia, Malaysia $(n=1062)$. The study area was selected based on the availability of natural habitats, population density, rapid economic development, and the nature of wildlife complaints. Finally, chapter 6 synthesises the results of this $\mathrm{PhD}$ project and discusses the implications of the results for future human dimensions of wildlife research in Malaysia and elsewhere.

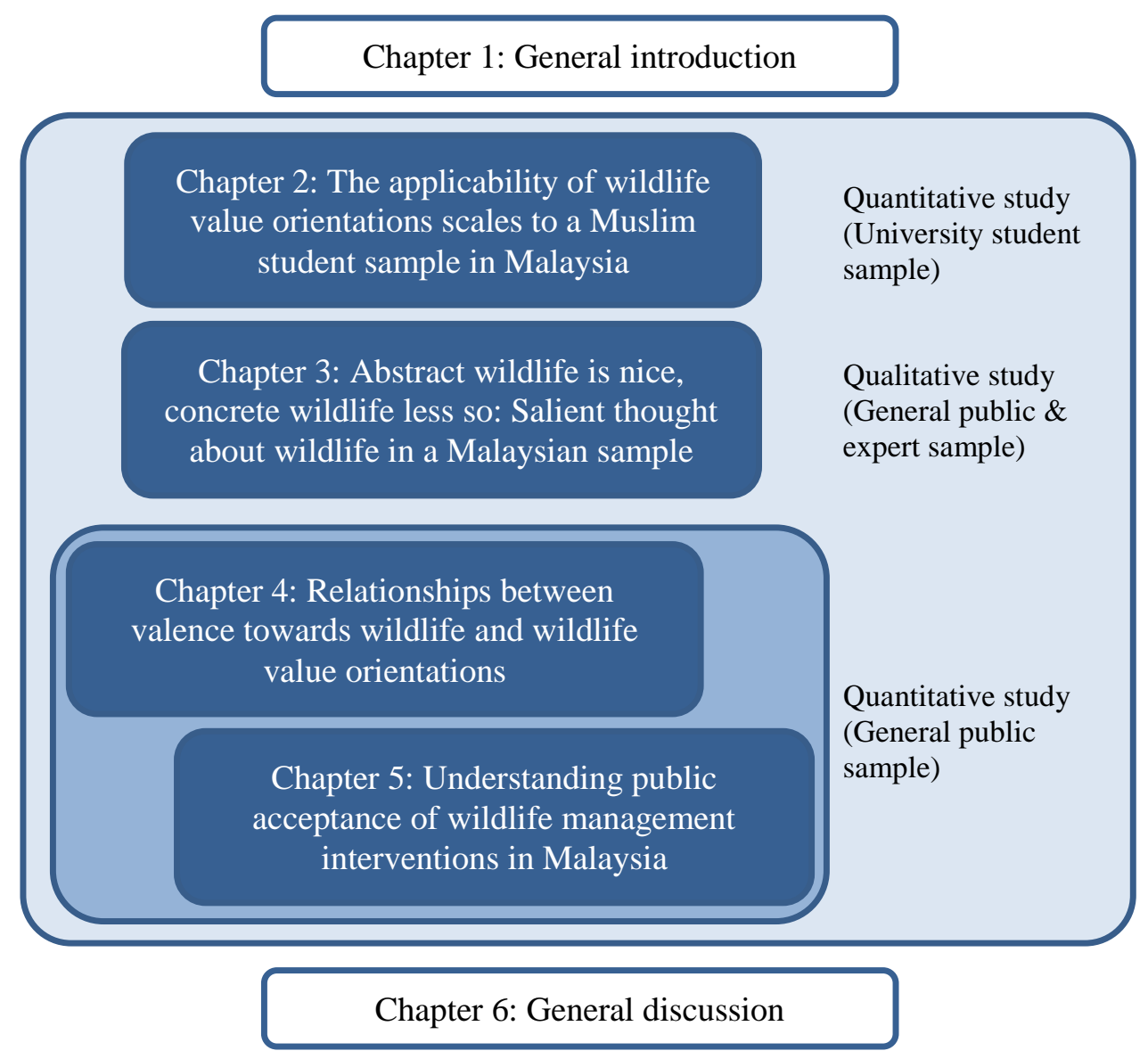

Figure 1.2. Organisation of the thesis. 


\section{REFERENCES}

Abd Mutalib, A. H., Fadzly, N., \& Foo, R. (2013). Striking a balance between tradition and conservation: General perceptions and awareness level of local citizens regarding turtle conservation efforts based on age factors and gender. Ocean and Coastal Management, 78, 56-63. doi: 10.1016/j.ocecoaman.2013.03.015

Ahmad Zafir, A. W., \& Magintan, D. (2016). Historical review of human-elephant conflict in Peninsular Malaysia. Journal of Wildlife and National Parks, 31, 1-19.

Aihara, Y., Hosaka, T., Yasuda, M., Hashim, M., \& Numata, S. (2016). Mammalian wildlife tourism in South-East Asian tropical rainforests: The case of Endau Rompin National Park, Malaysia. Journal of Tropical Forest Science, 28(2), 167-181.

Aziz, S. A., Clements, G. R., Giam, X., Forget, P.-M., \& Campos-Arceiz, A. (2017). Coexistence and conflict between the island flying fox (Pteropus hypomelanus) and humans on Tioman Island, Peninsular Malaysia. Human Ecology, 45, 377-389. doi: $10.1007 / \mathrm{s} 10745-017-9905-6$

Baharuddin, Z. M., Karuppannan, S., \& Sivam, A. (2013). Environmental attitude: Values on urban wildlife. Edinburgh Architectural Research Journal, 33, 25-46.

Bennett, N. J. (2016). Using perceptions as evidence to improve conservation and environmental management. Conservation Biology, 30(3), 582-592. doi: 10.1111/cobi.12681

Bennett, N. J., Roth, R., Klain, S. C., Chan, K., Christie, P., Clark, D. A., ... Wyborn, C. (2017). Conservation social science: Understanding and integrating human dimensions to improve conservation. Biological Conservation, 205, 93-108. doi: 10.1016/j.biocon.2016.10.006

Cerri, J., Mori, E., Vivarelli, M., \& Zaccaroni, M. (2017). Are wildlife value orientations useful tools to explain tolerance and illegal killing of wildlife by farmers in response to crop damage? European Journal of Wildlife Research, 63(4), 70-78. doi: 10.1007/s10344-017$1127-0$

Clements, R., Rayan, D. M., Zafir, A. W. A., Venkataraman, A., Alfred, R., Payne, J., ... Sharma, D. S. K. (2010). Trio under threat: Can we secure the future of rhinos, elephants and tigers in Malaysia? Biodiversity and Conservation, 19(4), 1115-1136. doi: 10.1007/s10531-009-9775-3

Corlett, R. T. (2007). The impact of hunting on the mammalian fauna of tropical Asian forests. Biotropica, 39(3), 292-303. doi: 10.1111/j.1744- 7429.2007.00271.x

Department of Marine Park Malaysia. (2016). Senarai kedatangan pelawat ke Pulau Taman Laut dari tahun 2000 sehingga tahun 2016.

Department of Statistics Malaysia. (2011). Population distribution and basic demographic characteristics. Putrajaya, Malaysia. 
Department of Statistics Malaysia. (2017). Gross Domestic Product Fourth Quarter 2016. Putrajaya, Malaysia.

Department of Statistics Malaysia. (2018). Economic census 2016-Tourism statistics. Putrajaya, Malaysia.

DWNP. (2013). Department of Wildlife and National Parks of Peninsular Malaysia Annual Report 2013. Kuala Lumpur, Malaysia.

DWNP. (2014). Department of Wildlife and National Parks of Peninsular Malaysia Annual Report 2014. Kuala Lumpur, Malaysia.

DWNP. (2015). Department of Wildlife and National Parks of Peninsular Malaysia Annual Report 2015. Kuala Lumpur, Malaysia.

Endter-Wada, J., Blahna, D., Krannich, R., \& Brunson, M. (1998). A framework for understanding social science contributions to ecosystem management. Ecological Applications, 8(3), 891-904.

Finucane, M. L., Alhakami, A., Slovic, P., \& Johnson, S. M. (2000). The affect heuristic in judgments of risks and benefits. Journal of Behavioral Decision Making, 13(1), 1-17.

Forestry Department of Peninsular Malaysia. (2016). Forestry Department of Peninsular Malaysia Annual Report 2016. Kuala Lumpur, Malaysia.

Fulton, D. C., Manfredo, M. J., \& Lipscomb, J. (1996). Wildlife value orientations: A conceptual and measurement approach. Human Dimensions of Wildlife, 1(2), 24-47. doi: $10.1080 / 10871209609359060$

Gamborg, C., \& Jensen, F. S. (2016). Wildlife value orientations: A quantitative study of the general public in Denmark. Human Dimensions of Wildlife, 21(1), 34-46. doi: 10.1080/10871209.2015.1098753

Gore, M. L., Wilson, R. S., Siemer, W. F., Wieczorek Hudenko, H., Clarke, C. E., Sol Hart, P., ... Muter, B. a. (2009). Application of risk concepts to wildlife management: Special issue introduction. Human Dimensions of Wildlife, 14(5), 301-313. doi: 10.1080/10871200903160944

Hambali, K., Ismail, A., Zulkifli, S. Z., Md-Zain, B. M., \& Amir, A. (2012). Human-macaque conflict and pest behaviors of long-tailed macaques (Macaca fascicularis) in Kuala Selangor Nature Park. Tropical Natural History, 12(2), 189-205.

Hanisch-Kirkbride, S. L., Riley, S. J., \& Gore, M. L. (2013). Wildlife disease and risk perception. J Wild Dis, 49(4), 841-849. doi: 10.7589/2013-02-031

Hassan, S., Hambali, K., Wan Shaharuddin, W. Y., \& Amir, A. (2017). Human-wildlife conflict: A study of local perceptions in Jeli, Kelantan, Malaysia. Malayan Nature Journal, 69(2), 113-125.

Hermann, N., Voß, C., \& Menzel, S. (2013). Wildlife value orientations as predicting factors 
in support of reintroducing bison and of wolves migrating to Germany. Journal for Nature Conservation, 21(3), 125-132. doi: 10.1016/j.jnc.2012.11.008

Jacobs, M. H., Vaske, J. J., Dubois, S., \& Fehres, P. (2014). More than fear: Role of emotions in acceptability of lethal control of wolves. European Journal of Wildlife Research, 60(4), 589-598. doi: 10.1007/s10344-014-0823-2

Jacobs, M. H., Vaske, J. J., \& Sijtsma, M. T. J. (2014). Predictive potential of wildlife value orientations for acceptability of management interventions. Journal for Nature Conservation, 22(4), 377-383. doi: 10.1016/j.jnc.2014.03.005

Jafarpour, M., \& Mariapan, M. (2014). Wildlife value orientations based on age, gender and education in Malaysia. Life Science Journal, 11(6), 194-201.

King, N., \& Nair, V. (2013). Determining the wildlife value orientation (WVO): A case study of lower Kinabatangan, Sabah. Worldwide Hospitality and Tourism Themes, 5(4), 377387. doi: 10.1108/WHATT-03-2013-0014

Lim, E. A. L., Mariapan, M., Ming, Y. A. S., Abi, J., Aziz, A., \& Zakaria, M. (2013). Rural students' attitudes toward the Malayan Tapir. Human Dimensions of Wildlife, 18(6), 469470. doi: 10.1080/10871209.2013.802398

Manfredo, M. J. (2008). Who cares about wildlife? Social science concepts for exploring human-wildlife relationships and conservation issues. New York: Springer.

Manfredo, M. J., Teel, T. L., \& Henry, K. L. (2009). Linking society and environment: A multilevel model of shifting wildlife value orientation in the western United States. Social Science Quarterly, 90, 407-427.

Md-Zain, B. M., Ruslin, F., \& Idris, W. M. R. (2014). Human-macaque conflict at the main campus of Universiti Kebangsaan Malaysia. Pertanika Journal of Tropical Agricultural Science, 37(1), 73-85.

Mohamad Muslim, H. F., Hosaka, T., Numata, S., \& Yahya, N. A. (2018). Nature experience promotes preference for and willingness to coexist with wild animals among urban and suburban residents in Malaysia. Ecological Processes, 7(18). doi: 10.1186/s13717-0180127-7

Nik Mohamad, N. H. (2011). Urban residents' attitudes toward wildlife in their neighbourhoods: The case study of Klang Valley, Malaysia. Journal of the Malaysian Institue of Planners.

Riley, S. J., \& Decker, D. J. (2000). Risk perception as a factor in wildlife stakeholder acceptance capacity for cougars in Montana. Human Dimensions of Wildlife, 5(3), 50-62. doi: 10.1080/10871200009359187

Saaban, S., Othman, N., Yasak, M. N., Mohd Nor, B., Ahmad Zafir, A. W., \& Campos-Arceiz, A. (2011). Current status of Asian Elephants in Peninsular Malaysia. Gajah, 35, 67-75. 
Sandbrook, C., Adams, W. M., Büscher, B., \& Vira, B. (2013). Social research and biodiversity conservation. Conservation Biology, 27(6), 1487-1490. doi: 10.1111/cobi.12141

Shafie, N. J., Mohd Sah, S. A., Abdul Mutalib, A. H., \& Fadzly, N. (2017). General perceptions and awareness level among local residents in Penang Island toward bats conservation efforts. Tropical Life Sciences Research, 28(2), 31-44. doi: 10.21315/tlsr2017.28.2.3

Slagle, K. M., Bruskotter, J. T., \& Wilson, R. S. (2012). The role of affect in public support and opposition to wolf management. Human Dimensions of Wildlife, 17(1), 44-57. doi: $10.1080 / 10871209.2012 .633237$

Sodhi, N. S., Koh, L. P., Brook, B. W., \& Ng, P. K. L. (2004). Southeast Asian biodiversity: An impending disaster. Trends in Ecology and Evolution, 19(12), 654-660. doi: 10.1016/j.tree.2004.09.006

Sodhi, N. S., Posa, M. R. C., Lee, T. M., Bickford, D., Koh, L. P., \& Brook, B. W. (2010). The state and conservation of Southeast Asian biodiversity. Biodiversity and Conservation, 19(2), 317-328. doi: 10.1007/s10531-009-9607-5

Vaske, J. J., Jacobs, M. H., \& Sijtsma, M. T. J. (2011). Wildlife value orientations and demographics in The Netherlands. European Journal of Wildlife Research, 57(6), 11791187. doi: 10.1007/s10344-011-0531-0

Wan Mahamad, W. A. B., \& Kunasekaran, P. (2016). Wildlife value orientations towards Giant Panda Conservation Centre (GPCC) at Zoo Negara, Malaysia. Asia-Pacific Journal of Innovation in Hospitality and Tourism, 5(3), 123-134.

Wildavsky, A., \& Dake, K. (1990). Theories of risk perception: Who fears what and why? Daedalus, 119(4), 41-60. 
1 General introduction 


\section{Chapter 2}

\section{The applicability of wildlife value orientations scales to a Muslim student sample in Malaysia}

This chapter has been published as:

Zainal Abidin, Z. A., \& Jacobs, M. H. (2016). The applicability of wildlife value orientations scales to a Muslim student sample in Malaysia. Human Dimensions of Wildlife, 21(6), 555566. doi: 10.1080/10871209.2016.1199745 


\begin{abstract}
This article addresses the applicability of quantitative wildlife value orientation scales in Muslim students in Malaysia. As Malaysian culture is deeply influenced by Islam ideology, this article presents a case for addressing the cross-cultural applicability of the scales. The current wildlife value orientation scales were reliable - all Cronbach's alphas $\geq .65$ - and had predictive validity -8 to 14 per cent of variance of acceptability of lethal control was explained. Yet, both reliability and predictive validity were of lesser magnitude than figures in previous western studies. Especially the hunting beliefs scale did not reflect basic thinking about wildlife in our sample, and our data suggest two different hunting dimensions - consequences of hunting for wildlife and human opportunities for hunting. For future cross-cultural comparisons of wildlife value orientations, amendment of the scales to better reflect salient beliefs in non-western nations is recommended.
\end{abstract}

Keywords: attitudes, basic beliefs, cross-cultural, ideology, lethal control 


\section{INTRODUCTION}

Concerns over wildlife often receive global attention. For instance, the killing of Cecil, Zimbabwe's best-known lion, by an American dentist in July 2015 sparked outcry and debate from people of different nationalities over acceptability of regulated trophy hunting as part of wildlife management and conservation approach. The concept of Wildlife Value Orientations (WVOs) is often suggested as a useful entry point for understanding humanwildlife issues in the global context (Manfredo \& Dayer, 2004). The concept addresses basic cognitions pertaining to wildlife that might exist across cultures (Teel, Manfredo, \& Stinchfield, 2007), and research has demonstrated that WVOs predict specific attitudes and behaviours (see Jacobs, Vaske, \& Sijtsma, 2014, for a recent overview). Yet, the usefulness of WVOs for understanding global or cross-cultural wildlife issues hinges on the applicability of the associated scales across cultures. This article addressed this issue by investigating the applicability of the current quantitative WVO scales amongst Muslim university students in Malaysia.

WVOs are core concepts within the 'cognitive hierarchy', a theoretical model suggesting that human cognitions form a hierarchical continuum from fundamental values, value orientations, attitudes, norms, to behaviour intentions and behaviours (Fulton, Manfredo, \& Lipscomb, 1996). More abstract cognitions inform more concrete cognitions (Whittaker, Vaske, \& Manfredo, 2006). Within the model, WVOs mediate between fundamental values and specific attitudes and behaviours towards wildlife (Jacobs, Vaske, Teel, \& Manfredo, 2012). The concept of WVO refers to patterns of basic beliefs that give meaning to fundamental values in the context of wildlife (Jacobs et al., 2012).

Research suggests that two predominant WVOs exist in western nations: domination reflected by underlying basic beliefs of appropriate use and hunting, and mutualism characterized by social affiliation and caring beliefs (Manfredo, Teel, \& Henry, 2009). Individuals who are more domination oriented prioritize human well-being over wildlife and are more likely to accept lethal wildlife control as part of management intervention (Teel \& Manfredo, 2009). In contrast, individuals who are more mutualist oriented are not likely to accept lethal wildlife control as they view wildlife as companions, deserving rights and care. These WVOs are thought to reflect the influence of general mastery and egalitarian ideologies in western nations (Teel \& Manfredo, 2009).

Qualitative (Dayer, Stinchfield, \& Manfredo, 2007) and quantitative measurement instruments (e.g., Fulton et al., 1996; Manfredo et al., 2009) have been developed to identify and measure WVOs. Cross-cultural studies using the qualitative measurement instrument suggest that these orientations might exist in China (Zinn \& Shen, 2007), Estonia (Raadik \& Cottrell, 2007), Mongolia (Kaczensky, 2007), The Netherlands (Jacobs, 2007) and Thailand 
(Tanakanjana \& Saranet, 2007). Hence, the concepts of domination and mutualism might reflect salient beliefs that exist worldwide.

Quantitative studies in the United States (Manfredo et al., 2009), Germany (Hermann, Voß, \& Menzel, 2013), The Netherlands (Jacobs et al., 2014) and Denmark (Gamborg \& Jensen, 2016) have all used the same measurement instrument. These studies demonstrated that the quantitative WVO scales are applicable in these four western nations, based upon their findings of the reliability of the scales and their predictive validity for more specific cognitions. In the studies conducted in the United States, Germany, and The Netherlands, Cronbach's alphas for domination and mutualism were in the range of .83 to .88 , indicating satisfactory reliability. The survey in Denmark revealed Cronbach's alphas for domination and mutualism of .68 and .86, respectively (Gamborg \& Jensen, 2016), thus indicating considerably lower, yet still adequate reliability for domination. Also, WVOs predicted wildlife related attitudes and behaviours (Manfredo et al., 2009), conservation support (Hermann et al., 2013), and acceptability of wildlife management interventions (Jacobs et al., 2014; Sijtsma, Vaske, \& Jacobs, 2012), with explained variability of up to 44 per cent. In a cross-cultural study, using a subset of WVO items in nine European countries (Teel et al., 2010), alphas for domination were low, probably due to the inclusion of only a subset of items. Alphas for mutualism still flagged adequate reliability. Overall, the literature suggests that WVO scales are reliable and have predictive validity in western samples.

Yet, these findings do not necessarily imply that the quantitative scales are applicable in other (most notably, non-western) nations. As cultures and ideologies diverge across nations (Schwartz, 2006), WVOs might vary as well, since WVOs are influenced by cultural ideologies. Because the concept of WVOs and the associated scales were developed within the United States, and the scales were satisfactorily applied in western nations only, the scales might not reflect all predominant basic patterns of thought about wildlife in nations with very different cultures and ideologies. As examples, a qualitative study amongst Mongolians suggested that WVOs might be different from those previously identified in the United States (Kaczensky, 2007), and a similar study in Thailand concluded that prohibition of consumptive use of wildlife might have shaped WVOs (Tanakanjana \& Saranet, 2007). Through a survey among Malaysian students, we sought to test the applicability of the current WVO scales beyond western nations, as a contribution to enhancing insights into the cross-cultural applicability of the WVO scales (and, by extension, of the concepts of domination and mutualism).

Malaysia is a non-western country where the religion of Islam is an important cultural feature. The influence of Islam can be seen in the Malaysian federal constitution (Federal Constitution, 2006), government policies (Syed Ismail, 2007), and it is central to everyday life for the Malay group, the majority ethnic group of the Malaysian population $(50.1 \%)$ 
(Department of Statistics Malaysia, 2011). Through the influence of Islam, general ideologies in Malaysia might be different from those in western nations, thus making Malaysia a feasible context for testing the applicability of WVOs. Recently, a survey that included WVO scales was conducted among the Malaysian public (Jafarpour \& Mariapan, 2014). The study identified relationships between gender, level of education, residence and WVOs. Yet, as this study did not present reliability figures for the standard scales of domination and mutualism, and did not examine predictive validity, this study was not tailored to evaluate the applicability of WVO scales in Malaysia.

We sought to extend current knowledge by addressing the applicability of the WVO scales in a Malaysian sample. Two research questions guided our study: (a) To what extent are the WVO scales reliable, and (b) To what extent do WVOs predict acceptability of lethal wildlife control across three human-wildlife problem situations? Acceptability of lethal control was chosen as the dependent variable as previous research suggest that this concept is especially well predicted by WVOs (Jacobs et al., 2014; Whittaker et al., 2006; Zinn, Manfredo, Vaske, $\&$ Wittmann, 1998). In addition, lethal control is one of the management practices conducted by responsible agencies (Department of Wildlife and National Parks of Peninsular Malaysia [DWNP], 2006, 2013; "Veterinary Services Department declares rabies outbreak in three states," 2015) as well as individuals (Azhar et al., 2013) in Malaysia to eradicate problem animals and hence, lethal control is likely to be a salient issue.

\section{METHODS}

A close-ended questionnaire consisting of questions to assess WVOs, acceptability of lethal control, and demographics such as age and religious affiliation was developed. The questionnaire form was prepared in English and Malay (on the same form). The original English survey was translated into Malay language and pre-tested among 17 students from two universities (Universiti Teknologi Mara and Pusrawi International College of Medical Science). All students were asked to identify confusing concepts or wording and to make suggestions for alternative wording. Upon their feedback, minor changes were made to the questionnaire, but no changes were needed on the English and Malay wording of questions. The translation/backtranslation method (i.e., an independent dual language speaker translated the Malay version back into English) revealed no problems pertaining to the Malay wording of WVO items and suggested consistency of the items across languages.

The self-administered questionnaire was distributed to Malaysian undergraduate students in 10 classes at Universiti Putra Malaysia. The questionnaire was handed out before class with a simple request to voluntarily participate in a study into human thought about wildlife. No further explanation was given. Completed questionnaires were collected by the 
lecturers within two days' time. From the 528 questionnaires distributed, 391 ones were returned, yielding an overall response rate of 74 per cent. The sample consists of $271(69 \%)$ Muslims, 54 (14\%) Buddhists, 37 (10\%) Christians, and 20 (5\%) Hindus. In this article, we focused on the Muslim subsample, as the numbers in the other subsamples are too low to make any substantial claims. Some comparisons with the other subsamples were made for illustrative purposes, to contemplate whether findings are Muslim-specific or rather pertaining to Malaysian students in general.

\section{Independent Variables}

Nineteen items were used to assess the WVOs of domination, composed of appropriate use (6 items) and hunting (4 items) beliefs, and mutualism, composed of social affiliation (4 items) and caring (5 items) beliefs (Table 2.1). All items were coded on continuous 7-point scales ranging from -3 "strongly disagree" to +3 "strongly agree" with zero as a neutral point. While the applicability of 7-points continuous scales might be problematic in some cultures, due to hesitance to opt for extreme answers, we did not detect this problem. Extreme answers were checked as well, and all variables were normally distributed as suggested by z-tests (Kim, 2013), as well as inspection of descriptive figures (skewness and kurtosis). We computed two composite indices of WVOs by summing the average scores of appropriate use and hunting beliefs for domination, and social affiliation and caring belief for mutualism (see Manfredo et al., 2009; Teel \& Manfredo, 2009).

\section{Dependent Variables}

To assess the acceptability of lethal control, responses to lethal control of four different species for three different scenarios that reflected different levels of problem contexts were elicited (i.e., 12 questions). The scenarios reflected realistic problems situations that actually occur or could probably occur in Malaysia and involved wildlife that regularly causes problems in Malaysia (python, elephant, panther, monkey), as reflected by complaints of the general public to the DWNP (2013), and by recent newspaper articles.

The first scenario was the possibility of an encounter with wildlife (encounter), without suggesting a direct problem for humans. The second and third scenarios described severe problems to humans: either wildlife damaging agricultural areas or killing domesticated animals (economic loss) or wildlife killing humans (human death). In all scenarios, lethal control (trapto-eliminate) was proposed as the management intervention by wildlife agencies. As an example, an actual question was: “A troop of monkey lives in a large nature area. There's a chance that hikers encounter them. How unacceptable or acceptable is it if wildlife agencies 
trap-to-eliminate the animal?" Acceptability of lethal control was coded similarly to the independent variables (i.e., 7-point scales).

\section{Analysis}

Reliability analyses (Cronbach's alpha) were used to check to what extent the items for the underlying basic beliefs and value orientations measure the same constructs, and to check if the acceptability items for different species could be combined into indices that reflect acceptability of lethal control for the three different levels of problem situations. To estimate the predictive validity of WVOs for acceptability of lethal control, we used two regression models. The first model used domination and mutualism as predictors and the second model used the four basic beliefs of appropriate use, hunting, social affiliation and caring as predictors. The same analyses were conducted for the Christian, Buddhist and Hindu samples.

\section{RESULTS}

\section{Reliability}

Reliabilities of the two WVO scales, as well as the four basic belief scales, were acceptable, as all Cronbach's alphas exceeded, or were equal to, the generally accepted cut-off point of .65 (Vaske, 2008) (Table 2.1). Almost all item-total correlations exceeded .40. The four items that did not exceed .40 , all belong to the domination scale.

The internal consistencies of the mutualism scale, as well as the associated basic beliefs of social affiliation and caring, were superior to the consistencies of the domination scale and the associated beliefs of appropriate use and hunting. As Cronbach's alpha for hunting beliefs was relatively low, we inspected the correlation matrix of the underlying items. The correlation between the items "Hunting is cruel and inhumane to the animals" and "Hunting does not respect the lives of animals" was .74. The correlation between the items "We should strive for a world where there's an abundance of wildlife and fish for hunting and fishing" and "People who want to hunt should be provided the opportunity to do so" was .35. All other correlations across the four hunting items were considerably lower. Subsequent exploratory factor analysis (Varimax rotation) over the four hunting belief items revealed two dimensions with Eigenvalues $>1$ (and items grouped together as the correlation figures suggest) and explained variances of 44 and 35 per cent, suggesting that hunting items might reflect a two-dimensional construct in the present sample. The first construct pertains to the consequences of hunting for wildlife ("Hunting is cruel and inhumane to the animals" and "Hunting does not respect the lives of animals"), while the second set pertains to hunting opportunities for humans ("We should strive for a world where there's an abundance of wildlife and fish for hunting and fishing" and "People who want to hunt should be provided the opportunity to do so"). Exploratory factor analyses 
over all other sets of basic beliefs (i.e., appropriate use, social affiliation, caring) revealed only one dimension with an Eigenvalue $>1$, suggesting that the associated items represent a onedimensional construct.

Table 2.1. Descriptive and reliability analyses of wildlife value orientation items ${ }^{\mathrm{a}}$ in the Muslim student sample.

\begin{tabular}{|c|c|c|c|c|c|c|}
\hline WVO and basic belief dimension & Mean & $\mathrm{SD}$ & $\begin{array}{l}\text { Inter-item } \\
\quad \text { total } \\
\text { correlation }\end{array}$ & $\begin{array}{l}\text { Alpha if } \\
\text { item } \\
\text { deleted }\end{array}$ & \multicolumn{2}{|c|}{$\begin{array}{l}\text { Cronbach's } \\
\text { alpha }\end{array}$} \\
\hline Domination & & & & & & .72 \\
\hline Appropriate use beliefs & & & & & .69 & \\
\hline $\begin{array}{l}\text { Humans should manage wildlife and fish } \\
\text { populations so that human benefit }\end{array}$ & 2.11 & 1.40 & .25 & .70 & & \\
\hline $\begin{array}{l}\text { The needs of humans should take priority over } \\
\text { wildlife and fish protection }\end{array}$ & -.14 & 1.75 & .38 & .66 & & \\
\hline $\begin{array}{l}\text { It is acceptable for people to kill wildlife if they } \\
\text { think it poses a threat to their life }\end{array}$ & .56 & 1.73 & .49 & .62 & & \\
\hline $\begin{array}{l}\text { It is acceptable for people to kill wildlife if they } \\
\text { think it poses a threat to their property }\end{array}$ & -.29 & 1.67 & .53 & .61 & & \\
\hline $\begin{array}{l}\text { It is acceptable to use wildlife and fish in } \\
\text { research even if it may harm or kill some } \\
\text { animals }\end{array}$ & .11 & 1.56 & .43 & .65 & & \\
\hline $\begin{array}{l}\text { Wildlife and fish are on earth primarily for } \\
\text { people to use }\end{array}$ & .16 & 1.70 & .44 & .64 & & \\
\hline$\underline{\text { Hunting beliefs }}$ & & & & & .65 & \\
\hline $\begin{array}{l}\text { We should strive for a world where there's an } \\
\text { abundance of wildlife and fish for hunting and } \\
\text { fishing }\end{array}$ & -.56 & 1.77 & .28 & .69 & & \\
\hline Hunting is cruel and inhumane to the animals ${ }^{\mathrm{b}}$ & -1.54 & 1.68 & .50 & .53 & & \\
\hline Hunting does not respect the lives of animals ${ }^{\mathrm{b}}$ & -1.31 & 1.71 & 60 & .46 & & \\
\hline $\begin{array}{l}\text { People who want to hunt should be provided } \\
\text { the opportunity to do so }\end{array}$ & -.59 & 1.49 & .38 & .61 & & \\
\hline Mutualism & & & & & & .87 \\
\hline$\underline{\text { Social affiliation beliefs }}$ & & & & & .72 & \\
\hline $\begin{array}{l}\text { We should strive for a world where humans and } \\
\text { wildlife and fish can live side by side without } \\
\text { fear }\end{array}$ & 1.44 & 1.52 & .46 & .69 & & \\
\hline I view all living things as part of one big family & 1.84 & 1.25 & .66 & .58 & & \\
\hline $\begin{array}{l}\text { Animals should have rights similar to the rights } \\
\text { of humans }\end{array}$ & .94 & 1.56 & .44 & .71 & & \\
\hline $\begin{array}{l}\text { Wildlife are like my family and I want to } \\
\text { protect them }\end{array}$ & 1.30 & 1.40 & .51 & .66 & & \\
\hline Caring beliefs & & & & & .86 & \\
\hline $\begin{array}{l}\text { I care about animals as much as I do other } \\
\text { people }\end{array}$ & 1.48 & 1.34 & 62 & .85 & & \\
\hline $\begin{array}{l}\text { It would be more rewarding to me to help } \\
\text { animals rather than people }\end{array}$ & .41 & 1.47 & .53 & .87 & & \\
\hline $\begin{array}{l}\text { I take great comfort in the relationships I have } \\
\text { with the animals }\end{array}$ & 1.31 & 1.35 & .74 & .82 & & \\
\hline I feel a strong emotional bond with animals & .79 & 1.46 & .77 & .81 & & \\
\hline $\begin{array}{l}\text { I value the sense of companionship I receive } \\
\text { from animals }\end{array}$ & 1.23 & 1.37 & .75 & .81 & & \\
\hline
\end{tabular}

Note. ${ }^{\text {a }}$ Items were coded on 7 -point scales ranging from -3 (strongly disagree) to +3 (strongly agree)

${ }^{\mathrm{b}}$ Item was reverse coded prior to analysis 
We conducted a reliability analysis to check if acceptability of lethal control across species (python, elephant, panther, monkey) is consistent across the three levels of problem severity. Cronbach's alphas were .82 (encounter situations), .83 (economic loss situations) and .86 (human death situations). On the basis of these figures, we computed indices, as the average of the four underlying items, which were used for subsequent analyses.

\section{Predictive validity}

Both the model with wildlife value orientation scales and the model with basic belief scales predicted acceptability of lethal control in all three situations that reflect different humanwildlife problem levels (Table 2.2). The first model, with domination and mutualism as independent variables, predicted 8 to 11 per cent of the variability of acceptability of lethal control. These effect sizes flag a typical relationship (Vaske, 2008) or medium effect size (Cohen, 1988). Mutualism was a better predictor than domination across scenarios.

Table 2.2. Wildlife value orientations predicting acceptability of lethal control.

\begin{tabular}{|c|c|c|c|c|c|c|}
\hline Model & \multicolumn{2}{|c|}{$\begin{array}{l}\text { Encounter } \\
\text { situation }\end{array}$} & \multicolumn{2}{|c|}{$\begin{array}{l}\text { Economic loss } \\
\text { situation }\end{array}$} & \multicolumn{2}{|c|}{$\begin{array}{l}\text { Human death } \\
\text { situation }\end{array}$} \\
\hline Wildlife value orientations & $\beta$ & $\begin{array}{l}\operatorname{Adj} R^{2} \\
.11^{* * *}\end{array}$ & $\beta$ & $\begin{array}{l}\operatorname{Adj} R^{2} \\
.10^{* * * *}\end{array}$ & $\beta$ & $\begin{array}{l}\operatorname{Adj} R^{2} \\
.08^{* * * *}\end{array}$ \\
\hline Domination & $.15^{* *}$ & & $.15^{* *}$ & & $.13^{*}$ & \\
\hline Mutualism & $-.27^{* * *}$ & & $-.26^{* * *}$ & & $-.22^{* * *}$ & \\
\hline Basic beliefs & & $.14^{* * * *}$ & & $.14^{* * *}$ & & $.11^{* * *}$ \\
\hline Appropriate use & $.25^{* * *}$ & & $.27^{* * *}$ & & $.24^{* * *}$ & \\
\hline Hunting & -.06 & & -.09 & & -.10 & \\
\hline Social affiliation & -.11 & & -.11 & & $-.18^{*}$ & \\
\hline Caring & $-.23^{* *}$ & & $-.22^{* *}$ & & -.11 & \\
\hline
\end{tabular}

The second model, with appropriate use, hunting, social affiliation and caring beliefs, predicted 11 to 14 per cent of the variability of lethal control acceptability, indicating typical relationships (or medium effect sizes in Cohen's terminology). Consistently, use beliefs were a superior predictor relative to all other basic beliefs. Caring beliefs were statistically significant in two situations, and hunting beliefs did not predict acceptability in any of the situations.

Across situations, the second model predicted acceptability of lethal control better than the first model. While in the first model mutualism was the best predictor, in the second model appropriate use beliefs (associated with domination) was the best predictor. 


\section{Other religious segments}

Cronbach's alphas for the different religion segments in our sample were comparable (domination: .74 for Muslims, .79 for Buddhists, .70 for Christians, .76 for Hindus; mutualism: .88 for Muslims, .91 for Buddhists, .92 for Christians, .90 for Hindus). Predictive validity of wildlife value orientations for Buddhists were in the same range as for Muslims (i.e. $R^{2}$ of .11 to .13 for Buddhists, and .08 to .11 for Muslims). Predictive validity for Christians was lower than for Muslims (between .05 and .07, not statistically significant). For Hindus, however, the predictive validity was remarkably large (.48 to .54$)$. We want to emphasize again that these figures are based on very small subsamples.

\section{CONCLUSION AND DISCUSSION}

Our findings suggest that the WVO scales are reliable and have predictive validity among Malaysian Muslim students. Reliability figures in the United States (Manfredo et al., 2009), Germany (Hermann et al., 2013), and The Netherlands (Jacobs et al., 2014; Vaske, Jacobs, \& Sijtsma, 2011) for domination were $.83, .85$ and .85 respectively, all exceeding the Cronbach's alphas of .74 in our Muslim sample. On the other hand, reliability for domination in a Danish sample was .68. The reliability of mutualism (.87) was comparable with the figures in the United States (.86), Germany (.88), The Netherlands (.88), and Denmark (.86). The comparison suggests that the reliability of mutualism is relatively invariant across these nations, while the reliability of domination is considerably less in the Malaysian sample compared to three of the four western nation samples. Our findings suggest that the items measuring hunting beliefs reflect two different latent constructs in our Muslim student sample: consequences of hunting for wildlife, and hunting opportunities for humans. Various explanations for lower reliability of the domination scale our study could be contemplated. The domination scale could be less optimal to capture basic beliefs in (a) Muslims, in (b) Malaysians, or in (c) any nonwestern people. We will elaborate on each potential explanation.

The influence of Judeo-Christian religion in western nations has been argued as one of the key factors that has shaped the domination orientation (Manfredo et al., 2009). Within this ideology, man is proclaimed by God as the steward of living beings, thus having mastery over animals. Islam might extend into a different ideology pertaining to wildlife, as holy Islamic text emphasizes that humans are entitled to gain tangible benefits (e.g., meat harvest) from animals (Quran 5:1; Oxford World's Classics edition), yet should not hunt wild animals for sport or pleasure, as taught by the Prophet Muhammad, the second main reference in Islam (Hadith Muslim as cited in Islam \& Islam, 2015). Even in the act of hunting for reasons legitimized by Islam ideology, no injustice or mistreatment of animals is allowed, and suffering must be minimalized (as is also apparent in current Islamic ritual slaughtering) (Quran 5:3; Oxford 
World's Classics edition). To illustrate, in certain circumstances, if the hunted game is only injured and still alive when the hunter reaches the animal, they need to cut the windpipe, the gullet and the two jugular veins at the animal's throat using only a sharp object (Al-Qaradawi, 1985). This slaughtering method is conducted to both domesticated and wild animals to ensure the process is quick and as painless as possible for the animal (Islam \& Islam, 2015), as well as to render their meat halal, a prominence concept among Muslims. Hence, explicit holy Islamic text on hunting reflects both the hunting benefits for humans, as well as the hunting consequences for wildlife. Our findings that hunting beliefs items reflect two dimensions resonates well with this ideology. Maybe, Islam ideology explains the relatively low reliability of the domination scale.

If Islam ideology would be driving the lower reliability of domination, one could expect that reliability figures of domination scales among Malaysians adhering to different religions would be different. Our findings, although illustrative only (due to small sample sizes) suggest this is not the case, but rather suggest it pertains to Malaysians in general. This would not necessarily exclude the influence of Islam ideology. Nations with a specific predominant religion might have national cultures that were historically shaped by that religious tradition (Inglehart \& Baker, 2000). Even people with a different religion within those nations are to some extent socialized within that predominant culture, and might have similar basic beliefs about wildlife.

The interpretation that hunting beliefs are conditional in nature in our sample resonates with findings of a qualitative study among rural Mongolians, a society with Buddhism as predominant religion (Kaczensky, 2007). Long-standing hunting norms were still present among pastoralists. Hunting large predators like wolves was accepted by many but inflicting unnecessary suffering to the animals was deemed to create strong infuriation amongst the public to the hunter and his family. Our finding that the current hunting belief items are not catered to tease out salient beliefs about hunting because the items do not reflect the conditions under which hunting is acceptable, extends to other non-western culture as well. Importantly, Cronbach's alpha for domination in a Danish sample (Gamborg \& Jensen, 2016; Teel et al., 2010) was in the same range as alpha in our study, and hence a lower reliability for domination is not exclusive to non-western societies. These papers do not present additional exploratory factor analyses to reveal whether hunting belief items reflect a two dimensional structure, as figures in our article suggest. The background causes for a lower reliability in Denmark, however, are likely to be very different from those causes in Malaysia. While our figures do not present a decisive answer, we believe that the current domination scale is not optimal to capture hunting beliefs in Malaysian culture, fuelled by Islam being an important ideology that has shaped this culture, including to some extent those adhering to other religions within Malaysia. 
The predictive validity of WVO scales in our models was inferior to the predictive validity in the aforementioned studies in Germany and The Netherlands. The lower predictive validity of domination is probably due to the hunting beliefs scale, which might not match a one-dimensional predominant belief amongst Muslims, as argued above. In the model with the four basic beliefs, the predictive validity of use beliefs (one of the two basic beliefs that comprise domination) was larger than the predictive validity of any other basic beliefs.

In contrast to domination, the similarities on reliability figures between Malaysia and western nations for mutualism suggest that the items are applicable across both predominantly Christian and Islam cultures. The Prophet Muhammad explained that any cruelty or good deed towards animals is equivalent to the ruthless or kind act towards human being, and all living creatures (including human being and animals) are like a family (Hadith Bukhari as cited in Islam \& Islam, 2015). The items of the mutualism scale seem to resonate well with this tradition of Prophet Muhammad. Yet, our interpretation on the basis of holy Islamic sources is speculative in nature, equivalent to the above reasoning about the domination scale. Mutualism scales were found to have larger internal consistency than domination scales in eight European countries (Teel et al., 2010), and mutualism was also identified across cultures in qualitative studies (Teel et al., 2007).

Our article raises issues for further research. Our sample was drawn from a Malaysian student sample with an age range of 19 to 26 . While this age range comprises a larger share of the Malaysian population than any other age range (Department of Statistics Malaysia, 2011), and value orientations of individuals are believed to have stabilized at this age (Schwartz, 2006), we cannot assume that students reflect the whole Malaysia population. Previous research has found that wildlife value orientations might vary across generations (Manfredo et al., 2009). Representative descriptive figures for the whole Malaysian population would require a different, more elaborated, and more expensive sampling approach.

Research in other Islamic nations is needed to be confident that Islamic ideology, and not other specifics of Malaysian culture, is a root cause of the relatively low reliability of domination and predictive potential of WVOs, and to test if our reasoning rings true. To know whether the large predictive potential of WVOs for acceptability of lethal control among Malaysia Hindu's flags a real relationship or is rather an artefact due to the small sample size, it would be interesting to administer a WVO survey amongst a sample of the Indian population.

Although reliability of the WVO scales was sufficient and the predictive validity was statistically significant, we recommend to proceed with caution in applying these scales in future research in Islamic cultures. The notions of minimal animal suffering and the hunting conditions that are emphasized in the Islamic holy text are less apparent in the current hunting scales. We recommend including additional items that emphasize minimal suffering to reflect 
consequences of hunting for wildlife, and conditional norms pertaining to hunting (note that Jafarpour and Mariapan (2014) did not include these kind of items in their WVO study amongst Malaysians). Exploratory qualitative research (i.e. semi-structured interviews) could increase our understanding of whether the existing WVO scales reflect all relevant basic beliefs about wildlife.

Only if problem situations or actions towards wildlife are relevant within a population, is it likely that responses can be predicted well by more basic cognitions (Ajzen, 2001). Perhaps, the relatively low predictive validity of WVOs for acceptability of lethal control might indicate that the problem scenarios do not reflect salient issues amongst the Malaysian student sample. Future research in Malaysia could incorporate measures of different (and preferable salient) wildlife related attitudes and behaviours, such as support for policy conservation or participation in wildlife-recreation activities, to investigate if predictive validity of WVOs indeed increases. Naturally, salient issues might be different across segments of the Malaysian population (e.g., farmers versus urbanites).

The current WVO scales are applicable to Malaysian Muslim students, probably to Malaysians in general, and perhaps to Muslims in general. As such, the current scales might be useful for comparing thought about wildlife across cultures and nations. For future research, it is important to realize that such a comparison is useful for comparing the basic beliefs reflected by the scales across cultures, but does not necessarily adequately capture salient basic beliefs about wildlife as they exist in non-western cultures (both Muslim and non-Muslim cultures). Additional items that capture the conditional nature of hunting beliefs (i.e., for which purposes hunting is allowable) might increase the usefulness of WVO scales for cross-cultural comparisons. In turn, such refined scales might be better suited to gain understanding of the sources of conflicts over wildlife at the global level. 


\section{REFERENCES}

Ajzen, I. (2001). Nature and operation of attitudes. Annual Review of Psychology, 52, 27-58.

Al-Qaradawi, Y. (1985). The Lawful and Prohibited in Islam (Vol. 94). London: Sharouk International.

Azhar, B., Lindenmayer, D., Wood, J., Fischer, J., Manning, A., McElhinny, C., \& Zakaria, M. (2013). Contribution of illegal hunting, culling of pest species, road accidents and feral dogs to biodiversity loss in established oil-palm landscapes. Wildlife Research, 40(1), 19. doi:10.1071/WR12036

Cohen, J. (1988). Statistical Power Analysis for the Behavioral Sciences (2nd ed). Hillsdale: Lawrence Erlbaum.

Dayer, A., Stinchfield, H. M., \& Manfredo, M. J. (2007). Stories about wildlife: Developing an instrument for identifying wildlife value orientations cross-culturally. Human Dimensions of Wildlife, 12(5), 307-315. doi:10.1080/10871200701555410

Department of Statistics Malaysia. (2011). Population distribution and basic demographic characteristics. Putrajaya, Malaysia.

DWNP. (2006). Pelan pengurusan kera (Macaca fascicularis) bermasalah di Semenanjung Malaysia. Kuala Lumpur, Malaysia.

DWNP. (2013). Department of Wildlife and National Parks of Peninsular Malaysia Annual Report 2013. Kuala Lumpur, Malaysia.

Federal Constitution (2006). Laws of Malaysia. Kuala Lumpur, Malaysia: Percetakan Nasional Malaysia Bhd.

Fulton, D. C., Manfredo, M. J., \& Lipscomb, J. (1996). Wildlife value orientations: A conceptual and measurement approach. Human Dimensions of Wildlife, 1(2), 24-47. doi:10.1080/10871209609359060

Gamborg, C., \& Jensen, F. S. (2016). Wildlife value orientations: A quantitative study of the general public in Denmark. Human Dimensions of Wildlife, 21(1), 34-46. doi:10.1080/10871209.2015.1098753

Hermann, N., Voß, C., \& Menzel, S. (2013). Wildlife value orientations as predicting factors in support of reintroducing bison and of wolves migrating to Germany. Journal for Nature Conservation, 21(3), 125-132. doi:10.1016/j.jnc.2012.11.008

Inglehart, R., \& Baker, W. E. (2000). Modernization, cultural change, and the persistence of traditional values. American Sociological Review, 65(1), 19-51.

Islam, M. N., \& Islam, M. S. (2015). Human-animal relationship: Understanding animal rights in the Islamic ecological paradigm. Journal for the Study of Religions and Ideologies, 14(41), 96-126.

Jacobs, M. H. (2007). Wildlife value orientations in The Netherlands. Human Dimensions of 
Wildlife, 12(5), 359-365. doi:10.1080/10871200701555345

Jacobs, M. H., Vaske, J. J., \& Sijtsma, M. T. J. (2014). Predictive potential of wildlife value orientations for acceptability of management interventions. Journal for Nature Conservation, 22(4), 377-383. doi:10.1016/j.jnc.2014.03.005

Jacobs, M. H., Vaske, J. J., Teel, T. L., \& Manfredo, M. J. (2012). Human dimensions of wildlife. In L. Steg, A. E. van den Berg, \& J. I. M. de Groot (Eds.), Environmental psychology: An introduction (pp. 77-86). Chicester: Blackwell.

Jafarpour, M., \& Mariapan, M. (2014). Wildlife value orientations based on age, gender and education in Malaysia. Life Science Journal, 11(6), 194-201.

Kaczensky, P. (2007). Wildlife value orientations of rural Mongolians. Human Dimensions of Wildlife, 12(5), 317-329. doi:10.1080/10871200701555303

Kim, H.-Y. (2013). Statistical notes for clinical researchers: Assessing normal distribution (2) using skewness and kurtosis. Restorative Dentistry \& Endodontics, 38(1), 52-54. doi:10.5395/rde.2013.38.1.52

Manfredo, M. J., \& Dayer, A. (2004). Concepts for exploring the social aspects of humanwildlife conflict in a global context. Human Dimensions of Wildlife, 9(4), 1-20. doi:10.1080/10871200490505765

Manfredo, M. J., Teel, T. L., \& Henry, K. L. (2009). Linking society and environment: A multilevel model of shifting wildlife value orientation in the western United States. Social Science Quartely, 90, 407-427.

Raadik, J., \& Cottrell, S. (2007). Wildlife value orientations: An Estonian case study. Human Dimensions of Wildlife, 12(5), 347-357. doi:10.1080/10871200701555378

Schwartz, S. (2006). A theory of cultural value orientations: Explication and applications. Comparative Sociology, 5(921), 137-182. doi:10.1163/156913306778667357

Sijtsma, M. T. J., Vaske, J. J., \& Jacobs, M. H. (2012). Acceptability of lethal control of wildlife that damage agriculture in the Netherlands. Society \& Natural Resources, 25(12), 13081323. doi: $10.1080 / 08941920.2012 .684850$

Syed Ismail, S. H. (2007). Values and ethics towards quality public delivery system of Malaysia. Journal of Syariah, 15(2), 25-43.

Tanakanjana, N., \& Saranet, S. (2007). Wildlife value orientations in Thailand: Preliminary findings. Human Dimensions of Wildlife, 12(5), 339-345. doi:10.1080/10871200701555519

Teel, T. L., \& Manfredo, M. J. (2009). Understanding the diversity of public interests in wildlife conservation. Conservation Biology: The Journal of the Society for Conservation Biology, 24(1), 128-139. doi:10.1111/j.1523-1739.2009.01374.x

Teel, T. L., Manfredo, M. J., Jensen, F. S., Buijs, A. E., Fischer, A., Riepe, C., ... Jacobs, M. 
H. (2010). Understanding the cognitive basis for human-wildlife relationships as a key to successful protected-area management. International Journal of Sociology, 40(3), 104123. doi:10.2753/IJS0020-7659400306

Teel, T. L., Manfredo, M. J., \& Stinchfield, H. M. (2007). The need and theoretical basis for exploring wildlife value orientations cross-culturally. Human Dimensions of Wildlife, 12, 297-305. doi:10.1080/10871200701555857

Vaske, J. (2008). Survey research and analysis: Applications in parks, recreation and human dimensions. State College, PA: Venture Publishing.

Vaske, J. J., Jacobs, M. H., \& Sijtsma, M. T. J. (2011). Wildlife value orientations and demographics in The Netherlands. European Journal of Wildlife Research, 57(6), 11791187. doi:10.1007/s10344-011-0531-0

Veterinary Services Department declares rabies outbreak in three states. (2015). The Star Online. $\quad$ Retrieved $\quad$ March 11, 2016, from http://www.thestar.com.my/news/nation/2015/09/17/rabies-perak-penang-kedah/

Whittaker, D., Vaske, J. J., \& Manfredo, M. J. (2006). Specificity and the cognitive hierarchy: Value orientations and the acceptability of urban wildlife management actions. Society \& Natural Resources, 19, 515-530. doi:10.1080/08941920600663912

Zinn, H. C., Manfredo, M. J., Vaske, J. J., \& Wittmann, K. (1998). Using normative beliefs to determine the acceptability of wildlife management actions. Society \& Natural Resources, 11(7), 649-662. doi:10.1080/08941929809381109

Zinn, H. C., \& Shen, X. S. (2007). Wildlife value orientations in China. Human Dimensions of Wildlife, 12(5), 331-338. doi:10.1080/10871200701555444 


\section{Chapter 3}

\section{Abstract wildlife is nice, concrete wildlife less so: Salient thought about wildlife in a Malaysian sample}




\begin{abstract}
A certain level of abstraction and positive-negative evaluation are inherent properties of thought about wildlife. This article investigates whether these properties are associated in salient thought among Malaysians. As human-wildlife problems exist on the level of concrete experiences, we expect abstract thought to be positive more frequently than concrete thought. Semi-structured interviews were conducted among 30 inhabitants of Peninsular Malaysia, with different demographic characteristics. Six themes recurred in salient thought: undesired exploitation, concern for wildlife, attraction to wildlife, concern about human-wildlife conflicts, respect, and religious and traditional beliefs. Each discrete statement was coded as abstract (defined as not reporting a specific experience and not about a specific species of wildlife) or concrete, and as positive (defined as positive for or positive about wildlife), neutral or negative. The findings reveal that abstract thought was more often positive than concrete thought $\left(\chi^{2}=\right.$ 28.02, $p<.001$, Cramer's $V=.35$ ). Urbanites more often expressed abstract and positive thought than rural inhabitants. The identified association between the two dimensions is perhaps fundamental to understanding diversity in society.
\end{abstract}

Keywords: attitudes, belief evaluation, memory, salience, specificity 


\section{INTRODUCTION}

$\mathrm{W}$

ildlife management interventions and policy measures are often controversial, as the public is diverse (Jacobs, Vaske, \& Sijtsma, 2014). An important aim of human dimensions of wildlife research is to understand diversity in thought about wildlife (Teel \& Manfredo, 2009). Understanding helps to gauge and predict how people respond to the presence of wildlife, human-wildlife conflicts, management actions and policy measures, thus assisting practitioners in identifying differences in opinion, and finding acceptable solutions and useful communication strategies (Manfredo, 2008). The cognitive hierarchy model is a frequently used model to examine human thought about and responses to wildlife. The model suggests that cognitions exist on different levels of abstraction, and that more abstract cognitions guide more concrete cognitions (Teel \& Manfredo, 2009). Thus, the level of abstraction as a property of thought is a key principle of the model. Wildlife value orientations, as a core concept in the cognitive hierarchy model, are patterns of basic beliefs that guide and give meaning to fundamental values in the context of wildlife (Fulton, Manfredo, \& Lipscomb, 1996). Empirical research indeed suggests that wildlife value orientations predict more concrete cognitions, such as the acceptability of management interventions (Jacobs et al., 2014). Thus, research guided by this theory helps in assessing and explaining diversity in society.

However, the same theoretical model and habitually used survey methodology leaves an important question open: Is the level of abstraction of thought associated with other properties of thought? In this article, we explore this question by focusing on a potential relationship between abstract versus concrete thought on the one hand and positive versus negative thought on the other. The next section explains the theoretical background and rationale for this aim.

\section{Theoretical Framework}

Two concepts that reflect dimensions of thought comprise our theoretical framework. Firstly, each thought has a position on the abstract-concrete continuum. The abstract-concrete continuum refers to the specificity of manifestations of mental images or sensory information (Slovic, Finucane, Peters, \& MacGregor, 2004; Wiemer-Hastings \& Xu, 2005). According to this view, abstract thinking reflects a general, enduring and stable mental representation of information of self, objects, events or environments. Concrete thinking is infused with contextualised features and linked to experiences. Abstract thinking usually encodes reality in terms of symbols and words, while concrete thought encodes reality in terms of images, narratives and metaphors (Slovic et al., 2004).

Secondly, each thought is positive, neutral, or negative to some degree. The positivenegative dimension is fundamental in how people mentally relate to the world. Attitude theory 
suggests that we perpetually and automatically evaluate events or objects along this dimension (Ajzen, 2001). Also, emotion theory advocates that valence (the positive-negative dimension) is the most basic feature of affective states (Russell, 2003).

Building on these theoretical notions, we anticipated a relationship between the abstractconcrete continuum and the positive-negative dimension of thought about wildlife. Typically, human-wildlife problems occur at the level of interactions. Informed by experiences of problematic interactions, concrete thought about wildlife could be negative. Abstract thought is less likely to be steered by specific experiences, and more likely to be driven by fundamental values or ideals (Manfredo, Teel, \& Henry, 2009; Teel \& Manfredo, 2009). For many individuals, these ideals are likely to be positive. On the other hand, concrete thought can also reflect positive experiences such as the fascination someone felt when seeing a certain animal in the wild (Curtin, 2009). Similarly, abstract thought can also be negative. Memory theory posits that a series of episodic memories (memories of specific events) can turn into semantic memories (schematic memories not tied to specific events) on the basis of recurring patterns (Miyashita, 2004). Hence, repetitive negative experiences can constitute negative abstract thought. For instance, if an individual repeatedly experiences problems with wolves, a more general belief of wolves as problematic might come into existence. As an association between the level of abstraction and direction of evaluation is not self-evident, this paper seeks to answer the following question: Is abstract salient thought about wildlife more positive than concrete salient thought?

Answering this question contributes to the existing literature as it offers a new and complementary perspective on sources of diversity in thought about wildlife among individuals. Practically, this study is relevant if different segments in society tend to think about wildlife at different levels of abstraction. Urbanites have fewer concrete interactions with wildlife than rural dwellers, so they are less exposed to wildlife-related problems. Thought by those living in cities, then, is less likely to be fuelled by concrete interactions and problem experiences, and more likely to be influenced by the media. Of course, media messages can reflect problems, but intermediated problems usually have less impact than directly experienced problems. Therefore, this study also addresses the question whether salient thought about wildlife among urbanites is more abstract and positive than salient thought among inhabitants of rural areas.

Studying salient thought also serves another goal. Previous research suggests that the existing wildlife value orientation scales as applied in Western nations are applicable to Malaysian students in terms of having acceptable reliability and predicting specific responses (Zainal Abidin \& Jacobs, 2016). At the same time, the predictive validity and reliability indices were somewhat smaller than the indices in some Western studies. This might suggest that among Malaysians, other beliefs about wildlife are important than the beliefs important to 
Western people, as reflected in the wildlife value orientation scales. Studying beliefs about wildlife in an open way might reveal those beliefs and hence offer suggestions for tailoring the wildlife value orientations scale to the Malaysian population.

\section{METHODS}

\section{Sampling}

We used a purposive sampling approach to select individuals among inhabitants in Peninsular Malaysia to participate in semi-structured interviews. Research has suggested that Malaysians' perceptions of wildlife vary by age, place of residence and sex (Abd Mutalib, Fadzly, \& Foo, 2013; Aziz, Clements, Giam, Forget, \& Campos-Arceiz, 2017; Mohamad Muslim, Hosaka, Numata, \& Yahya, 2018). Therefore, we included individuals of both sexes, different age categories and different places of residence. We employed network sampling, contacting relatives and friends of the researcher, as well as former university students to ask them for introductions to their relatives or friends. The initial contact persons then provided the researcher with the potential interviewees' phone numbers. A total of 34 candidates were contacted and asked to participate. Only four of them did not wish to participate, reporting that they were not interested, felt uncomfortable or did not have time to be interviewed.

The final sample size of 30 was guided by the strategy of data saturation: selection of new interviewees was continued up to the point where subsequent interviews did not provide additional information (Ritchie \& Lewis, 2003). The sample consisted of 18 urbanites and 12 rural dwellers, 21 men and 9 women, their ages varying from 23 to 79 years old. Semi-structured interviews were conducted between December 2015 and February 2016.

\section{Semi-structured interview}

We used semi-structured interviews to collect the data for this study. This method allows the interviewer to ask questions that are neutral with respect to the concepts that guide the study as well as to the kind of beliefs that might be elicited, not anticipating or evoking specific thought (Ritchie \& Lewis, 2003). The interview protocol consisted of three general and neutral questions about how people think about wildlife and human-wildlife relationships: (1) "What comes into your mind when you think about wildlife?", (2) "How do you think humans and wildlife are related?", and (3) "How should humans treat wildlife?". Initially, the interview questions were tested among five adults to ensure understandability and concise translation. During the pre-testing, we noticed that three of the five interviewees also talked about domestic animals. A similar issue was identified in a study to explore wildlife value orientations in China (Zinn \& Shen, 2007). Therefore, the final protocol included an introduction that defined wildlife as wild animals (vertebrates and invertebrates) that are living freely in the natural habitat, city, 
or even in residents' backyard, and are not domesticated or trained to be of use to humans, to differentiate between wildlife and domestic animals. After asking what creatures come to mind when one thinks about wildlife, the definition of wildlife as used in this study was stated for clarification. Additional pre-testing among friends of the first author indicated this strategy made interviewees differentiate between wildlife and domestic animals as desired. Probing techniques (repeating the interviewee's responses, active listening) were used to stimulate interviewees to elaborate and continue talking (Kallio, Pietilä, Johnson, \& Kangasniemi, 2016).

The choice of venue and time were left to the participant. Interviews were conducted in Malay and/or in English. Interviewees were first introduced to the study and its general purpose, assured confidential treatment of responses, and asked for permission to record the interviews. On average, interviews lasted 35 minutes, ranging from 10 to 84 minutes. Responses were recorded on a digital audio recorder and transcribed ad verbatim into a text file that was used for analysis.

\section{Analysis}

Analysis of qualitative data implies assigning codes (representing concepts) to quotes (discrete phrases in the interview) in order to organise raw data and make sense of it on a conceptual level. Across transcripts, 236 discrete statements about wildlife and human-wildlife relationships were identified and targeted for further analysis. Each statement was coded as either abstract or concrete thought about wildlife. Based on previous research (WiemerHastings \& Xu, 2005), a statement was labelled as abstract if neither reflecting a specific species nor a specific experience; other statements were labelled as concrete. In addition, statements were coded as positive, neutral or negative. Statements were labelled as positive if reflecting a thought that was good for wildlife (e.g., the belief that wildlife should be protected) or a positive emotion towards wildlife. Two coders coded a subset of phrases independently to constitute an inter-rater-reliability test. Fleiss' Kappa was 0.80 for the abstract-concrete distinction, and 0.86 for the positive-negative dimension. These figures suggest 'almost perfect agreement' (Landis \& Koch, 1977).

To estimate the relationship between the abstract and positive attributes of thought about wildlife, quantitative analysis was used. Once coded and assigned a numeric level, qualitative data can be analysed statistically. A chi-square $\left(\chi^{2}\right)$ test was used to estimate the relationship, with Cramer's $V$ as the associated effect size index, with $.1, .3$, and .5 suggesting a minimal, typical, and substantial relationship, respectively (Vaske, 2008). Chi-square tests were used to estimate whether frequencies of abstract/concrete and positive/negative statements were different between people living in cities and people living in rural areas. 


\section{RESULTS}

\section{Salient beliefs about wildlife}

Six themes that reflect distinctive salient basic beliefs about wildlife were identified (Table 3.1): undesired exploitation, concern for wildlife, attraction to wildlife, concern about human-wildlife conflicts, respect, and religious and traditional beliefs.

Table 3.1. Salient beliefs about wildlife in a Malaysian sample.

\begin{tabular}{|c|c|}
\hline $\begin{array}{l}\text { Basic beliefs } \\
\text { (Definition) }\end{array}$ & $\begin{array}{l}\text { Example quotes (abstract-concrete/positive- } \\
\text { negative dimensions) }\end{array}$ \\
\hline $\begin{array}{l}\text { Undesired exploitation } \\
\text { (Belief that humans exploit wildlife } \\
\text { and natural habitat excessively } \\
\text { through habitat destruction and } \\
\text { illegal poaching) }\end{array}$ & $\begin{array}{l}\text { "A lot of capitalists. The big companies went there } \\
\text { [to East Malaysia] and cut the forests for oil } \\
\text { palm plantation" (Abstract/Positive) } \\
\text { "I think it is unacceptable to kill wildlife for our } \\
\text { own use. Like the pangolin. Some people } \\
\text { killed them to export their skin." } \\
\text { (Concrete/Positive) }\end{array}$ \\
\hline $\begin{array}{l}\text { Concern for wildlife } \\
\text { (Concern about the protection and } \\
\text { conservation of wildlife species, } \\
\text { management strategy, and wildlife } \\
\text { rights) }\end{array}$ & $\begin{array}{l}\text { "Endangered species nowadays and animals that } \\
\text { are nearly extinct - I think we have to care } \\
\text { about them. There are not enough spaces left } \\
\text { for them as humans exploited their habitat." } \\
\text { (Abstract/Positive) } \\
\text { "We also need wildlife, like worms. Yes, worms } \\
\text { are small creatures. But imagine a world with } \\
\text { no worms, the food chain will be disrupted and } \\
\text { that affects other living beings." } \\
\text { (Concrete/Positive) }\end{array}$ \\
\hline $\begin{array}{l}\text { Attraction to wildlife } \\
\text { (Feeling of appreciating wildlife, the } \\
\text { importance of wildlife for mental } \\
\text { health and ecosystem, and desire to } \\
\text { learn about wildlife) }\end{array}$ & $\begin{array}{l}\text { "... hearing birds chirping, looking at fish } \\
\text { swimming, this already makes me feel } \\
\text { peaceful. For me it is like a therapy." } \\
\text { (Abstract/Positive) } \\
\text { "We have the ability to differentiate between good } \\
\text { and bad. For example, the monkeys at the } \\
\text { Melawati Hills. They only lived there. } \\
\text { Sometimes when I went there, I brought some } \\
\text { bananas or other fruit for the monkeys. I also } \\
\text { brought my grandchildren. The monkeys } \\
\text { looked happy. I am also happy." } \\
\text { (Concrete/Positive) }\end{array}$ \\
\hline
\end{tabular}


Table 3.1. (continued)

Concern about human-wildlife
conflicts

(Concern about various negative interactions with wildlife such as possible injury and economic loss, feeling fear of wildlife)

\section{Respect}

(Indicating that humans and wildlife need each other, humans should not interfere with their lives/habitat, and that wildlife should be treated fairly. Appropriate use was also suggested as part of respect: the 'use' of wildlife for humans must be with respect)

Religious and traditional beliefs (Associations between wildlife and interaction with wildlife and a variety of religious or traditional beliefs)
"If wildlife poses a threat to us, we have to defend ourselves" (Abstract/Negative)

"The big and small ones, both can create problems. But for us [interviewee and family] the big animals are a concern. Because we live close to them." (Abstract/Negative)

"I encountered elephants quite a long time ago, about 2 or 3 of them. When I drove past them, they were very close to the roadside; I had to be very careful. If you accidentally honk your car, the elephants can be startled and might attack." (Concrete/Negative)

"I am not sure about any relationship, because I do not see any. They [wildlife] do not understand anything. Like the plan to develop a tiger tunnel. Is there any guarantee the tiger will use it? They will still cross the road because they do not know what a tunnel is. If it happens again [tiger-vehicle collision], it's not anyone's fault." (Concrete/Negative)

"We should respect wildlife. They should be free from hunger, from pain, and have the freedom to access food, to find a partner."

(Abstract/Positive)

"The term wildlife already sounds like dangerous animals. But, with proper training, they can be submissive to us." (Abstract/Negative)

"I looked at the birds [in a cage], we did not treat them with respect. What I mean is, if they have a certain way of life, do not change it. Because if we want to take care of them, it is still possible, but it is no longer in their natural habitat." (Concrete/Positive)

"It is a general teaching in my religion, that there are certain animals [domesticated] that are allowed to be eaten. It is like a guideline to protect wildlife. If human laws did not mention anything about this [what animals can be eaten], the religion already had guidelines. Eating exotic animals are not permitted." (Abstract/Positive)

"The python sneaked into my kitchen. I was there with my child at that moment. But I could not hurt it. It would be a sin. I was taught by my great-grandmother that King Cobra is like an avatar, the divine being reverenced by my religious tradition." (Concrete/Positive) 
Almost all interviewees expressed both abstract and concrete thought. Overall, abstract thought was more frequently expressed (55 per cent of statements) than concrete thought (45 per cent) (Table 3.2). Abstract thought often reflected undesired exploitation, concern for wildlife protection, and respect for wildlife. Predominant themes expressed by concrete statements included concern for human-wildlife conflicts, attraction to wildlife, and religious or traditional beliefs.

In addition, interviewees expressed positive thought (49 per cent of statements), negative thought (33 per cent) and neutral thought (18 per cent). Positive thought included undesired exploitation, respect for wildlife, concern for wildlife protection, attraction to wildlife, and religious and traditional beliefs. Negative thought particularly pertained to concern for human-wildlife conflicts. There are some statements that have both negative and positive evaluations (e.g., "dangerous" and "wildlife conservation"). The set of discrete statements included each combination of the two categorisations (abstract/concrete and positive/neutral/negative) as illustrated in Table 3.1.

\section{Abstract-concrete and positive-negative dimensions}

The majority of abstract expressions about wildlife were positive (Table 3.2). Concrete thought about wildlife, on the other hand, was predominantly negative. The relationship between the abstract-concrete dimension and positive-negative dimension was statistically significant $\left(\chi^{2}=28.02, p<.001\right)$. The effect size (Cramer's $\left.V=.35\right)$ suggests a relationship between typical and substantial (Vaske, 2008). Statements by urbanites were more frequently abstract than statements by rural inhabitants $\left(\chi^{2}=11.11, p<.001\right.$, Cramer's $\left.V=.22\right)$, and also more frequently positive $\left(\chi^{2}=28.75, p<.001\right.$, Cramer's $\left.V=.25\right)$.

Table 3.2. Relationship between the abstract-concrete dimension and the positive-negative dimension.

\begin{tabular}{lccc}
\hline \multirow{2}{*}{ Evaluation } & \multicolumn{2}{c}{ Number of statements } & \\
\cline { 2 - 3 } & Abstract & Concrete & Total \\
\hline Positive & $79(61 \%)$ & $37(35 \%)$ & $116(49 \%)$ \\
Neutral & $27(21 \%)$ & $15(14 \%)$ & $42(18 \%)$ \\
Negative & $24(19 \%)$ & $54(51 \%)$ & $78(33 \%)$ \\
\hline Total & $130(55 \%)$ & $106(45 \%)$ & \\
\hline
\end{tabular}

\section{CONCLUSION AND DISCUSSION}

The present study examined the association between abstract versus concrete salient thought about wildlife and the positive versus negative evaluation of the same thought. Findings indicated that abstract thought about wildlife is more frequently positive than concrete thought. However, the strength of the association (between typical and substantial) as well as the 
illustrative quotes revealed that a considerable portion of abstract thought is negative and a considerable portion of concrete thought is positive. Salient thought about wildlife among people living in cities is more frequently abstract and positive than salient thought among those living in the countryside.

Two limitations are important to consider when interpreting these findings. Since our data were limited to a sample of Malaysians, research in other nations is needed to examine whether the findings would generalise across nations. The present study offers both a theoretical model and a methodology that can be adopted across nations. Also, discrete statements were the level of analysis in the present study. Consequently, the results should not be interpreted on the level of individual subjects. The present sample size did not allow for meaningful statistical inferences on this level. An interesting question is whether individuals whose salient thought is more abstract also tend to think more positively about wildlife. Future research, using a larger sample, is needed to answer this question.

Our contribution is important to theory in the first place. The abstract versus concrete and positive versus negative continuum are inherent and basic dimensions of thought (Ajzen, 2001; Russell, 2003). Consequentially, the identified association between the two dimensions is perhaps very fundamental to explaining diversity in society. As such, the association could assist further interpretation of existing research outcomes. For instance, the finding that salient thought amongst urbanites is more positive than thought amongst inhabitants of rural areas is line with previous research into relationships between wildlife value orientations and demographics. Urbanites are more mutualism-oriented that rural inhabitants (Vaske, Jacobs, \& Sijtsma, 2011), meaning they are more likely to believe that wildlife is part of an extended family and deserving of rights and care. Future research could examine whether mutualists are also likely to think more abstractly and positively about wildlife than people with a domination orientation. A mixed methods approach, combining the methods presented in this study with existing quantitative scales to assess wildlife value orientations (Teel \& Manfredo, 2009) could provide a feasible approach.

In the second place, our findings are useful for evaluating whether there are important salient beliefs about wildlife that are not reflected in existing wildlife value orientation scales. There is not a one-to-one match between the basic beliefs as represented in the wildlife value orientation scales and the salient beliefs identified in this study. Yet, content-wise, most of the beliefs as presented in Table 3.1 are part of the basic beliefs of the wildlife value orientation scales, with the exception of the traditional and religious beliefs. Yet, it would be hard to amend the quantitative scales to cater for these beliefs, as it is a category that reflects a wide variety of beliefs, rather than a specific belief. Also, hunting and fishing beliefs, as a component of the wildlife value orientations scales, are not among salient beliefs of Malaysians. This is consistent 
with the previous finding that reliability of the hunting and fishing beliefs scales is problematic among Malaysians, and confirms the interpretation that recreational hunting and fishing is not an issue in this population (Zainal Abidin \& Jacobs, 2016).

Professionals dealing with stakeholders could be sensitive to the level of abstraction of statements made by various parties and check whether abstract thinking indeed tends to be more positive. If so, stressing and explaining that problems occur at the level of concrete experiences could be conducive to mutual understanding among stakeholders. These levels of abstraction most likely also differ between the professionals themselves. National level conservation policy-makers are probably more focused on abstract ideals, while "on the ground" wildlife managers are directly confronted with problematic human-wildlife interactions. Differences in professional practices could then also translate into differences in evaluations of wildlife through the association between level of abstraction and direction of evaluation. 


\section{REFERENCES}

Abd Mutalib, A. H., Fadzly, N., \& Foo, R. (2013). Striking a balance between tradition and conservation: General perceptions and awareness level of local citizens regarding turtle conservation efforts based on age factors and gender. Ocean and Coastal Management, 78, 56-63. doi: 10.1016/j.ocecoaman.2013.03.015

Ajzen, I. (2001). Nature and operation of attitudes. Annual Review of Psychology, 52, 27-58.

Aziz, S. A., Clements, G. R., Giam, X., Forget, P.-M., \& Campos-Arceiz, A. (2017). Coexistence and conflict between the island flying fox (Pteropus hypomelanus) and humans on Tioman Island, Peninsular Malaysia. Human Ecology, 45, 377-389. doi: 10.1007/s10745-017-9905-6

Curtin, S. C. (2009). Wildlife tourism: The intangible, psychological benefits of human-wildlife encounters. Current Issues in Tourism, 12, 451-474. doi: 10.1080/13683500903042857

Fulton, D. C., Manfredo, M. J., \& Lipscomb, J. (1996). Wildlife value orientations: A conceptual and measurement approach. Human Dimensions of Wildlife, 1(2), 24-47. doi: $10.1080 / 10871209609359060$

Jacobs, M. H., Vaske, J. J., \& Sijtsma, M. T. J. (2014). Predictive potential of wildlife value orientations for acceptability of management interventions. Journal for Nature Conservation, 22(4), 377-383. doi: 10.1016/j.jnc.2014.03.005

Kallio, H., Pietilä, A. M., Johnson, M., \& Kangasniemi, M. (2016). Systematic methodological review: Developing a framework for a qualitative semi-structured interview guide. Journal of Advanced Nursing, 72(12), 2954-2965. doi: 10.1111/jan.13031

Landis, J. R., \& Koch, G. G. (1977). The measurement of observer agreement for categorical data. Biometrics, 1, 159-174. doi: 10.2307/2529310

Manfredo, M. J. (2008). Who cares about wildlife? Social science concepts for exploring human-wildlife relationships and conservation issues. New York: Springer.

Manfredo, M. J., Teel, T. L., \& Henry, K. L. (2009). Linking society and environment: A multilevel model of shifting wildlife value orientation in the western United States. Social Science Quarterly, 90, 407-427.

Miyashita, Y. (2004). Cognitive memory: Cellular and network machineries and their top-down control. Science, 306, 435-440. doi: 10.1126/science.1101864

Mohamad Muslim, H. F., Hosaka, T., Numata, S., \& Yahya, N. A. (2018). Nature experience promotes preference for and willingness to coexist with wild animals among urban and suburban residents in Malaysia. Ecological Processes, 7(18). doi: 10.1186/s13717-0180127-7

Ritchie, J., \& Lewis, J. (2003). Qualitative research practice: A guide for social science students and researchers (1st ed.). London: SAGE. 
Russell, J. A. (2003). Core affect and the psychological construction of emotion. Psychological Review, 110(1), 145-172. doi: 10.1037/0033-295X.110.1.145

Slovic, P., Finucane, M. L., Peters, E., \& MacGregor, D. G. (2004). Risk as analysis and risk as feelings: Some thoughts about affect, reason, risk, and rationality. Risk Analysis, 24(2). doi: 0272-4332/04/0100-0311\$22.00/1

Teel, T. L., \& Manfredo, M. J. (2009). Understanding the diversity of public interests in wildlife conservation. Conservation Biology, 24(1), 128-139. doi: 10.1111/j.15231739.2009.01374.x

Vaske, J. J. (2008). Survey research and analysis: Applications in parks, recreation and human dimensions. State College, PA: Venture Publishing.

Vaske, J. J., Jacobs, M. H., \& Sijtsma, M. T. J. (2011). Wildlife value orientations and demographics in the Netherlands. European Journal of Wildlife Research, 57(6), 11791187. doi: 10.1007/s 10344-011-0531-0

Wiemer-Hastings, K., \& Xu, X. (2005). Content differences for abstract and concrete concepts. Cognitive Science, 29(5), 719-736. doi: 10.1207/s15516709cog0000_33

Zainal Abidin, Z. A., \& Jacobs, M. H. (2016). The applicability of wildlife value orientations scales to a Muslim student sample in Malaysia. Human Dimensions of Wildlife, 21(6), 555-566. doi: 10.1080/10871209.2016.1199745

Zinn, H. C., \& Shen, X. S. (2007). Wildlife value orientations in China. Human Dimensions of Wildlife, 12(5), 331-338. doi: 10.1080/10871200701555444 
3 | Abstract wildlife is nice, concrete wildlife less so 


\section{Chapter 4}

\section{Relationships between valence towards wildlife and wildlife value orientations}

This chapter has been accepted for publication as:

Zainal Abidin, Z. A., \& Jacobs, M. H. (2019). Relationships between valence towards wildlife and wildlife value orientations. Journal for Nature Conservation, 49, 63-68. doi:

10.1016/j.jnc.2019.02.007 


\begin{abstract}
Research to understand human responses to wildlife and wildlife issues has predominantly focused on cognitions. Yet, as emotions are basic human responses to wildlife, emotions are important too. Integrating cognition and emotion concepts could foster the overall understanding of human-wildlife relationships. This study tested the relationships between valence (the pleasant-unpleasant dimension of emotion) regarding wildlife and wildlife value orientations (patterns of basic cognitions in the context of wildlife). Also, this study estimated the additional predictive potential of emotion next to cognition for the acceptability of lethal control and support for wildlife conservation. Analyses showed that valence was associated with wildlife value orientations. Valence had additional explanatory value next to cognition for conservation support. Valence, however, did not have additional predictive potential for acceptability of lethal control. Based on these findings, we recommend integrating cognition and emotion measurements in future research to understand human responses to wildlife issues. Also, wildlife managers could take the emotion of stakeholders into account in their communication and decision-making processes.
\end{abstract}

Keywords: cognition, emotion, wildlife conservation support, acceptability of lethal control 


\section{INTRODUCTION}

Quccessful wildlife conservation depends on public responses to management and policy actions. The concept of the public denotes a broader set of people than the concept of stakeholders, which usually refers to people with clearly recognised interests. People without direct interests can influence the effectiveness of conservation efforts as well, for instance through voting, donations, petitions, and obeying or disobeying rules. Diversity amongst the public presents a major challenge (Kaltenborn, Bjerke, Nyahongo, \& Williams, 2006). Lethal control of problematic wildlife, for example, could be an efficient way to solve the problem and might therefore be supported by some, especially by those experiencing the problem. Yet, others might perceive the same action as a wrong way to treat of animals and therefore oppose the action (Treves \& Naughton-Treves, 2005; Treves \& Karanth, 2003). Reversely, some people appraise government conservation policies and actions that positively affect species populations, but local inhabitants who have problems with certain animals on a daily basis often have a negative attitude (Aziz, Clements, Giam, Forget, \& Campos-Arceiz, 2017; Bjerke \& Kaltenborn, 1999). Public diversity often leads to societal controversy and conflict. Understanding the views of the public is important to be able to identify the root causes of controversy and to think of potential solutions for wildlife conservation (Manfredo, 2008). Conservation social science aims to understand the human dimensions of wildlife conservation by examining the social complexity of wildlife issues (Bennett et al., 2017; Prokop \& Randler, 2018; Vaske \& Manfredo, 2012).

Psychological conservation research has traditionally focused on cognitions - units of thought - to understand people's reasoning about and responses to wildlife (Jacobs, 2012; Manfredo, 2008). Cognition concepts that have typically guided human dimensions of wildlife research include wildlife value orientations, attitudes, and norms (Jacobs, Vaske, Teel, \& Manfredo, 2018; Vaske \& Manfredo, 2012). Wildlife value orientations are patterns of basic beliefs that give meaning and direction to fundamental values in the context of human-wildlife interactions (Fulton, Manfredo, \& Lipscomb, 1996; Vaske \& Manfredo, 2012). Research suggests that wildlife value orientations explain up to 45 per cent of the variation of more specific cognitions such as attitudes towards wildlife, wildlife issues, and wildlife management actions (Hermann, Voß, \& Menzel, 2013; Jacobs, Vaske, \& Sijtsma, 2014; Sijtsma, Vaske, \& Jacobs, 2012; Teel \& Manfredo, 2009; Whittaker, Vaske, \& Manfredo, 2006). Next to cognitions, social scientists have started to address emotions towards wildlife (Jacobs, 2009; Prokop \& Randler, 2018). This more recent strand of research is equally relevant as emotions lie at the heart of human attraction to, repulsion from, and conflict over wildlife (Manfredo, 2008). Studies indicate that emotions also explain a considerable portion of the variation in 
specific thought, such as acceptability of wildlife management actions (Jacobs, Vaske, Dubois, \& Fehres, 2014).

As both cognitions and emotions have predictive potential for understanding diversity amongst the public, a crucial question is to what extent this predictive potential of cognitions and emotions overlap or complement each other. To the author's knowledge, cognition and emotion approaches have hitherto been separate research tracks, except for two studies. One study examined the influence of anger, sadness, fury, and fear (emotions) in addition to wildlife value orientations (cognitions), on intentions to support the reintroduction of wolves amongst German teenagers (Hermann \& Menzel, 2013). Yet, the studied emotions concerned the situation of wolves being at risk in Germany and hence not wildlife as such. Another study examined the mediation effects of anticipated emotions in a model that used general attitudes towards, and symbolic existence beliefs about coyotes to predict the acceptability of lethal coyote control (Sponarski, Vaske, \& Bath, 2015). As emotion was conceptualised as a mediating variable instead of an exogenous (i.e., independent) variable next to cognition, possible additional predictive potential of emotion next to cognition was not examined. Therefore, a simultaneous study of cognitions and emotions is needed to know if the predictive potential of emotion adds to the predictive potential of cognition. The present paper makes a new contribution to the literature by addressing this knowledge gap. A survey was distributed amongst a sample of Malaysians $(n=1062)$ to examine to what extent wildlife value orientations and emotions towards wildlife predict the acceptability of lethal wildlife control and support for wildlife conservation.

\section{Theoretical framework}

Cognitions encompass a collection of mental dispositions and processes that function as units of thought in perceiving, thinking and understanding. The cognitive hierarchy theory suggests that cognitions are organised in a hierarchical continuum where more specific cognitions are informed by more general cognitions (Fulton et al., 1996; Jacobs et al., 2018). The cognitive hierarchy theory applies this principle to the context of human thought about and responses to wildlife and wildlife management actions. The concept of wildlife value orientations is a core component of the cognitive hierarchy, as the concept is assumed to mediate between fundamental values that transcend any context and attitudes, norms, and behavioural intentions in specific human-wildlife interaction contexts (Manfredo, Teel, \& Henry, 2009).

Conservation social scientists have identified domination and mutualism as the predominant wildlife value orientations in the USA (Manfredo et al., 2009; Teel \& Manfredo, 2009). Domination reflects the ideology of mastery over nature and has been associated with 
the rise of Judeo-Christian religion, the growth of science and technology, Western European colonialism, and the expansion of capitalism (Hand \& Van Liere, 1984; Manfredo et al., 2009; Pattberg, 2007). Domination-oriented people prioritise the well-being of humans over that of wildlife and believe that humans have the right to use wildlife for human purposes (Jacobs et al., 2018). In contrast, mutualism reflects an egalitarian ideology that prioritises equality. People who are oriented towards mutualism believe that individuals should care for the welfare of others. Modernisation processes, associated with higher income and education levels, leads to rise in non-materialist values (Inglehart \& Baker, 2000). People in modernised societies feel a need to belong and to feel social affiliation (Poston, 2009). This need includes bonds with wildlife (Manfredo et al., 2009). Mutualism-oriented people believe wildlife deserves rights and care (Teel \& Manfredo, 2009). Studies in different countries suggest that domination and mutualism exist and can be measured reliably with a standardised scale, also outside of the US (Cerri, Mori, Vivarelli, \& Zaccaroni, 2017; Gamborg \& Jensen, 2016; Vaske, Jacobs, \& Sijtsma, 2011; Zainal Abidin \& Jacobs, 2016).

Mounting evidence suggests that domination and mutualism indeed predict specific cognitions, as anticipated by the cognitive hierarchy theory. In general, individuals who are more domination-oriented have shown to be more likely to accept lethal control, as opposed to people who are more mutualism-oriented (Jacobs, Vaske, Dubois, \& Fehres, 2014). Domination and mutualism have also shown to predict intentions to support the reintroducing of wildlife in Germany (Hermann et al., 2013). Mutualism-oriented people were more likely to support wildlife reintroduction than domination-oriented people.

For the present study, two considerations are important. First, the concept of wildlife value orientations is frequently used in empirical research. Adopting this concept allows us to capitalise on and add to existing research. Second, research suggests that domination and mutualism exist and have predictive potential across different countries, as indicated before. Specifically, a pilot study amongst Malaysian students demonstrated that the concepts and associated measurement scales had adequate reliability and predictive validity (Zainal Abidin $\&$ Jacobs, 2016). The choice to focus on wildlife value orientations produces a requirement for operationalising emotion. Concepts have a particular level of abstraction by necessity. For instance, the concept of attitudes towards snakes pertains to snakes. The concept of care for animals pertains to many different species and is hence more abstract than attitudes towards snakes. Ideally, to simultaneously examine emotions and wildlife value orientations, the level of abstraction of the emotion concept and measurement would be the same as the level of abstraction of wildlife value orientations. Since the latter pertain to wildlife in general, emotion in this study should be emotion towards wildlife in general as well. 
Emotions are momentary conditions constituted by complex processes that include physiological responses, motor expression, action tendency, and subjective feeling (Kleinginna \& Kleinginna, 1981; Winkielman, Knutson, Paulus, \& Trujillo, 2007). Emotions influence people's evaluation (Ajzen, 2005), perception (Dolan, 2002), decision-making (Izard, 2007), and memory (Talarico, LaBar, \& Rubin, 2004). The term "emotion" is used in the literature to denote two different concepts (Jacobs, Vaske, \& Roemer, 2012). First, emotions as states reflect momentary emotional responses and experiences that vary in time. Second, emotions as traits indicate stable dispositions that function as criteria against which the emotional relevance of stimuli is judged (Jacobs, Vaske, \& Roemer, 2012; Lerner \& Keltner, 2000). To illustrate: an individual can fear snakes (emotion as trait) without currently being in fear of a snake (emotion as state), simply because there is no snake present, and hence the disposition is not activated. The present study conceptualises emotion as a trait, since wildlife value orientations are traits as well.

Emotion scholars have employed two different theoretical perspectives to categorise the variety of emotions (Jacobs, Fehres, \& Campbell, 2012). The discrete emotion perspective assumes the existence of a number of qualitatively different basic emotions, such as fear and joy. The basic emotions claim (Ekman, 1992) is an example of the discrete perspective. The dimensional perspective categorises emotions as positions along different dimensions (Jacobs, Fehres, \& Campbell, 2012). Emotion theory and empirical research suggest that valence (pleasure-displeasure continuum) and arousal (activation-deactivation continuum) are the most important dimensions (Feldman Barrett, Mesquita, Ochsner, \& Gross, 2007; Russell, 2003). The present study focuses on valence. Research has demonstrated that of all potential single emotion measures, valence is superior when it comes to understanding the variability in emotional dispositions of states (Bradley \& Lang, 2000). In addition, valence is relevant to any wildlife species. Relevance of specific discrete emotions, on the other hand, varies across species (e.g. fear might be specifically relevant in case of large predators and joy in case of mammals that pose no danger). Focus on valence then, would allow us to construct an overall index for emotion towards wildlife in general thus meeting the requirement that the emotion concept should be on the same level of abstraction as wildlife value orientations.

The concept of acceptability of wildlife management actions refers to normative evaluations in a given context, different from abstract thought like wildlife value orientations (Sijtsma et al., 2012). Previous research has demonstrated that wildlife value orientations predict wildlife management acceptability, particularly the acceptability of lethal control of problematic wildlife, with effect sizes up to 46 per cent (Jacobs, Vaske, \& Sijtsma, 2014; Teel \& Manfredo, 2009; Whittaker et al., 2006). For this reason, the acceptability of lethal control was adopted in the present study as a dependent variable. Another dependent variable was 
included to broaden the scope of the research: conservation support. Wildlife value orientations are found to predict conservation support as well (Hermann et al., 2013). Conservation denotes interventions that are beneficial to wildlife, while lethal control is harmful to wildlife.

While emotion and cognition are to a great extent constituted by different neural systems in the human brain, these systems interact and as a result there is perpetual and mutual influence between emotion and cognition (LeDoux, 1998). It is therefore likely that relationships exist between wildlife value orientations and valence towards wildlife. On the basis of previous arguments, the following hypotheses were tested:

H1: Wildlife value orientations and valence towards wildlife are associated.

H2: Valence towards wildlife predicts acceptability of lethal wildlife control, next to the predictive potential of wildlife value orientations.

H3: Valence towards wildlife predicts support for wildlife conservation policy, next to the predictive potential of wildlife value orientations.

\section{METHODS}

A close-ended questionnaire in English and Malay (on the same form) was distributed in two districts in the state of Johor, Malaysia, between August and November 2016. The questions translated into Malay had previously been tested in a pilot study on wildlife value orientations amongst Malaysian students (Zainal Abidin \& Jacobs, 2016). The questionnaire was pre-tested among inhabitants of Johor - no changes were made upon the pre-test. The questionnaire was also presented to officials of the Department of Wildlife and National Parks of Peninsular Malaysia (DWNP) for contextual relevance.

\section{Sampling and procedures}

People living in 21 residential areas were surveyed. Residential areas were randomly selected, from all areas with frequent wildlife disturbances (DWNP, 2014, 2015, 2016) that are close to green spaces, and are non-gated and non-guarded. Within residential areas, every second street, and within streets, every fourth house was selected. Permanent residents of the selected houses of 18 years or over who had the most recent birthday by the time of the arrival of the researcher were asked to fill out the questionnaire. The alternate selection procedure and age selection criteria increased the probability of random selection of respondents at the residential and household level, and presented less intrusive randomisation processes (Steele et al., 2001).

Questionnaires were distributed to 1943 households using a drop-off/pick-up method (Steele et al., 2001). Respondents who agreed to participate were handed a cover letter explaining the purpose of the research, a questionnaire form, and a consent form. Completed 
questionnaires were collected during the second visit on the next day. The distributor made a new appointment with respondents for a third visit on a date and time that was convenient for respondents if they did not return the completed questionnaire during the second visit. Of the 1943 questionnaires initially handed-out, 1100 surveys were returned (57 per cent response rate), 1062 of which were usable. The main reason to exclude some returned surveys was "straight-lining", meaning that people had selected the same answer for each item in a longer list (Cole, McCormick, \& Gonyea, 2012).

\section{Independent variables}

We used the standard 19-item wildlife value orientations scales as previously applied in various countries (Jacobs, Vaske, \& Sijtsma, 2014; Manfredo et al., 2009; Zainal Abidin \& Jacobs, 2016). The domination wildlife value orientation consisted of appropriate use (6 items) and hunting (4 items) beliefs, whereas the mutualism wildlife value orientation was composed of social affiliation (4 items) and caring ( 5 items) beliefs. All items were coded on 7-point scales ranging from -3 (strongly disagree) to +3 (strongly agree) with 0 as the neutral point. Two items (i.e., "Hunting is cruel and inhumane to the animals" and "Hunting does not respect the lives of animals.") were reverse coded prior to analysis. To assess valence with regard to wildlife, respondents were asked to indicate how pleasant or unpleasant they found 56 animals. Responses were coded on 7-point scales ranging from -3 (unpleasant) to +3 (pleasant) with 0 as the neutral point. The list of animal species was adopted from a previous study on fear of animals (Arrindell, 2000; Davey et al., 1998). Several minor modifications were made to adjust the list according to the local context: slug and gerbil were removed from the original list due to unfamiliarity; snake and wild bird were changed to cobra and owl; deer, wild boar, elephant, python, civet, and monkey were added as these animals are common in Malaysia; and panda was added because of its increasing popularity in Malaysia.

\section{Dependent variables}

To measure the acceptability of lethal wildlife control, we designed six questions that reflect three different ways of interacting with wildlife (encountering an animal, economic loss caused by wildlife, and human death caused by wildlife), and involve two species (monkey and elephant). These species were selected because they present actual problems in the state of Johor, making it likely that the questions tap into salient thought. The three interactions were included to build on previous research that has also used these three interactions (Jacobs, Vaske, Dubois, \& Fehres, 2014). Building on previous research is ideal in order to estimate the additional value of examining emotion. Respondents were asked to indicate how acceptable they found lethal wildlife control. For example, one of the questions asked was: "A troop of 
monkey lives in a large nature area. There's a chance that hikers will encounter them. How unacceptable or acceptable is it if wildlife agencies trap-to-eliminate the animal?" To assess support for wildlife conservation policy, respondents were asked to rate their support for or opposition against the conservation of 12 animals that are a subset from the valence list. A previous pilot study among students (Zainal Abidin \& Jacobs, 2016) indicated that repeating all 56 species would easily lead to mental fatigue. Therefore, we presented a random selection of the longer list. As an index of conservation support across species was used for statistical testing, the full list of species was not necessary. The question was: "In general, do you support or oppose conservation of the animals listed below?" Both dependent variables were coded on 7-point scales.

\section{Data analysis}

Reliability analyses (Cronbach's alpha) were performed to estimate the internal consistency of the items reflecting each concept. Pearson correlations were used to estimate the association between wildlife value orientations and valence. Stepwise regression analyses were used to estimate the predictive potential of both wildlife value orientations and valence for the acceptability of lethal control and conservation support.

\section{RESULTS}

\section{Internal consistency}

On average, inhabitants of Johor were slightly mutualism-oriented towards wildlife (Table 4.1). The relatively negative average appraisal of lethal control stands out. All reliability coefficients suggest acceptable reliability (using the cut-off point of $\geq 0.65$; Vaske, 2008). Initial reliability analysis on domination generated an alpha of 0.62 . Three of ten items were dropped to obtain acceptable reliability. Composite indices were calculated on the basis of the means of the associated items. The indices were used for further analyses.

\section{Relationships between domination, mutualism, and valence}

The more domination-orientated people are, the less pleasant they find wildlife, as valence was negatively associated with domination $(r=-0.11, p<.01)$. Yet, the effect size suggests a minimal relationship. Conversely, the more mutualism-oriented people are, the more pleasant they find wildlife, as a positive association was observed between mutualism and valence $(r=0.32, p<.001)$, the effect size indicating a typical relationship. These results confirm hypothesis 1 . 
Table 4.1. Descriptive and reliability analyses of the independent and dependent variables.

\begin{tabular}{|c|c|c|c|}
\hline Variable & Mean & SD & $\begin{array}{l}\text { Cronbach's } \\
\text { alpha }\end{array}$ \\
\hline Domination $^{\mathrm{a}}$ & .21 & 1.06 & .68 \\
\hline Mutualism $^{\mathrm{b}}$ & .72 & 1.11 & .87 \\
\hline Valence to wildlife $^{c}$ & -1.03 & .84 & .96 \\
\hline Acceptability of lethal wildlife control ${ }^{\mathrm{d}}$ & -1.42 & 1.51 & .89 \\
\hline Support for wildlife conservation policy & .27 & 1.46 & .94 \\
\hline
\end{tabular}

Note. SD = Standard deviation

a Average score of agreement-disagreement scales on seven items. Deleted items were:

"Humans should manage wildlife populations so that humans benefit", "Hunting is cruel and inhumane to the animals" and "Hunting does not respect the lives of animals."

${ }^{\mathrm{b}}$ Average score of agreement-disagreement scales on nine items.

${ }^{\mathrm{c}}$ Average score of pleasant-unpleasant ratings on 56 animal species.

${ }^{d}$ Average score of acceptable-unacceptable scales to lethal monkeys and elephants control in the encounter, economic loss, and human death situations.

${ }^{\mathrm{e}}$ Average score of support-oppose scales to conservation support of 12 wildlife species (i.e., parakeets, squirrels, turtles, deer, spiders, beetles, bats, lizards, tigers, bears, crocodiles, sharks).

\section{Predictive potential of wildlife value orientations and valence}

Wildlife value orientations predicted the acceptability of lethal control as well as support for conservation policy (Table 4.2), explaining about 10 per cent of the variability and indicating typical relationships. Adding valence as a predictor did not increase the portion of predicted variability of acceptability of lethal control. These findings lead to the rejection of the second hypothesis. Valence, however, did have additional predictive potential next to wildlife value orientations for conservation policy support. The explained variance increased from 8 to 17 per cent, and valence was a superior predictor than both domination and mutualism. These figures support hypothesis 3 .

Table 4.2. Multiple regression results of domination, mutualism wildlife value orientations and valence predicting acceptability of lethal wildlife control and support for wildlife conservation policy.

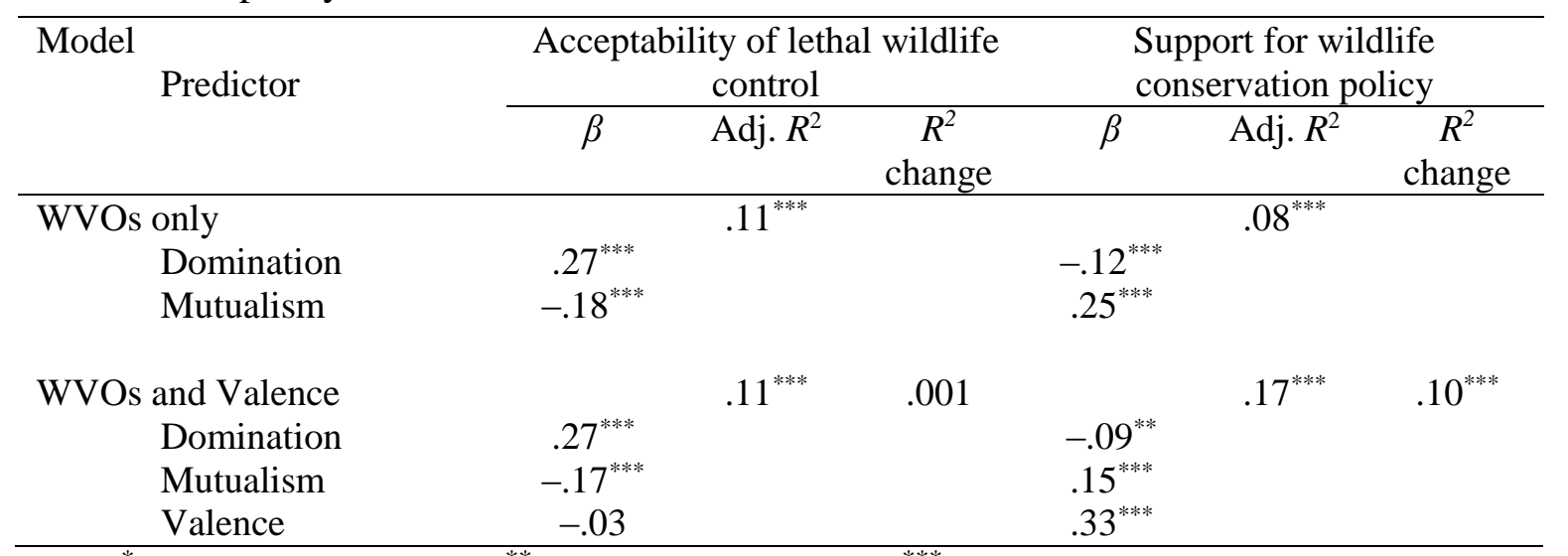

Note. ${ }^{*}$ Significant at $\mathrm{p}<.05,{ }^{* *}$ Significant at $\mathrm{p}<.01,{ }^{* * *}$ Significant at $\mathrm{p}<.001$ 


\section{DISCUSSION}

Our study suggests that both cognition and emotion are important for understanding diversity in the way people think about wildlife. Future research is needed to examine whether this applies across different contexts and countries. Valence towards wildlife, as the most essential measure of emotion (Russell, 2003; Russell \& Feldman Barrett, 1999), predicted conservation support in addition to wildlife value orientations. Thus, emotion has additional explanatory value next to cognitions, as theory would suggest (Jacobs, 2009; Kahneman, 2003; LeDoux, 1998). However, valence towards wildlife did not explain the acceptability of lethal control on top of the explanatory value of wildlife value orientations. Ancillary analyses revealed that valence alone (i.e. a model without wildlife value orientations) predicted the acceptability of lethal control $(r=-0.10, p<.01)$, as well as conservation support $(r=0.38, p$ $<.001)$. As a standalone factor, valence thus explains a portion of the variance in both dependent variables. Theoretically, we recommend integrating emotion and cognition concepts to understand individual responses to wildlife and wildlife issues. Which specific responses and thoughts about wildlife will be predicted to what extent by emotion and cognition is an intriguing empirical question to be further addressed.

The notion of specificity (Whittaker et al., 2006), meaning that cognitions exist on different levels of abstraction, guided the present study. Consequentially, an indicator of emotion towards wildlife in general was used, as only then the emotion measurement would have the same level of abstraction as the cognition measurement (i.e., wildlife value orientations). Yet, human emotions can vary greatly across species (Prokop \& Randler, 2018). As a background explanation, scientists suggest that stimuli are appraised for their emotional relevance in five different dimensions: (i) novelty, (ii) valence, (iii) goals/needs, (iv) agency, and (v) norms (Ellsworth \& Scherer, 2003; Jacobs, Vaske, \& Roemer, 2012). It is very likely, for instance, that facing a lion blocking a road affects one's goals very differently than seeing a bird flying over. Using more species-specific emotion measurements, would therefore very likely increase the predictive potential.

Human dimensions of wildlife research has traditionally focused on cognitions (Jacobs, 2012) such as value orientations, beliefs, norms, or attitudes (Fulton et al., 1996; Manfredo et al., 2009; Teel \& Manfredo, 2009; Vaske \& Manfredo, 2012; Vaske \& Whittaker, 2004), which have been examined to understand public diversity and predict responses. Recently, scholars have claimed that it is important to consider emotions as well (Jacobs, Vaske, \& Roemer, 2012; Manfredo, 2008; Prokop \& Randler, 2018). Empirical research has confirmed this claim. For instance, using emotional messages to increase people's intentions for whale conservation was more effective than using cognitive messages (Jacobs \& Harms, 2014). Also, emotions towards wolves predicted the acceptability of wolf management actions (Jacobs, Vaske, Dubois, \& 
Fehres, 2014). The findings of the present study further support the claim that emotions are important.

Practically, wildlife managers should therefore consider human emotions as well. For instance, in public meetings, room to express and reflect on emotions could contribute to people feeling heard and acknowledged. Managers can perhaps be afraid of giving space to emotion, believing that emotions corrupt rational decisions (Manfredo, 2008). But talking about emotions felt towards wildlife and wildlife issues is not the same as taking decisions. Also, if human stakeholders are deemed important to managers, and for those stakeholders emotions are important, then human emotions are inevitably relevant as well. Neglecting the relevance of emotions would not be very rational when it comes to taking good decisions that will work in practice. Moreover, conservation support is positively associated with valence as regards to animals. Managers and policy-makers could emphasise emotion and foreground emotions towards animals as a means to activate people's willingness to support conservation. Neglecting emotion in this case could be detrimental to their conservation goals.

Psychological research suggests that perception and evaluation of animals are not isolated mental processes and dispositions. For instance, a relationship between animal attitudes and more general environmental attitudes was identified (Binngießer \& Randler, 2015). Furthermore, positive attitudes towards animals are associated with a more general interest in biology, and more exposure to natural environments (Torkar, Kubiatko, \& Bajd, 2012). Future research could examine whether association between human emotions towards animals and human emotions towards the broader natural world are also associated.

Importantly, we do not claim to provide a full understanding of the emotional transactions between wildlife and humans or a full account of the consequences of emotions. Testing hypotheses requires focus. Theorizing in other social science disciplines such as cultural geography opens up different avenues for debate and research. For instance, the concept of an animal's atmosphere "describes affective intensities of a particular place that gives rise to actions, feelings and emotions" (Lorimer, Hodgetts, \& Barua, 2019). Animals infuse a place with an "atmosphere" - denoting a set of geographically distributed affective intensities that influence what people do and feel. These influences are not necessarily expressed or expressible through language and not necessarily consciously processed. At the same time, people influence animals' atmospheres, through deliberate management actions or any other behaviours affecting places. From this perspective, it might be equally important to look at how places inhabited or visited by animals evoke emotions in humans. Also, next to public responses, examining practices could be relevant. Even an apparently simple act such as counting animals for a census can be a skilled, demanding and deeply emotional practice guided by ethical motivations (Lorimer, 2008). Furthermore, geographical theory invites to critically reflect on 
the division into human subject and animals as part of the object world (Lorimer, 2007) and the division between the wild and the domestic (Lorimer \& Driessen, 2013). For instance, if human influence wildlife through management and policy, is wildlife as wild as it is often assumed to be?

\section{CONCLUSION}

This article addressed the relationships between valence towards wildlife and wildlife value orientations, and the additional predictive potential of valence next to wildlife value orientations. The relationships between the domination and mutualism wildlife value orientations with valence suggest that the more people like wildlife the more they tend to be mutualism-oriented. Liking wildlife is hardly associated with domination. Valence did predict conservation support on top of the explanatory value of wildlife value orientations. Wildlife value orientations were the better predictors for the acceptability of lethal wildlife control, whereas valence was the better predictor for wildlife conservation support. 
4 | Relationships between valence towards wildlife and wildlife value orientations

\section{REFERENCES}

Ajzen, I. (2005). Attitudes, personality and behavior (2nd ed.). New York: Open University Press.

Arrindell, W. A. (2000). Phobic dimensions: IV. The structure of animal fears. Behaviour Research and Therapy, 38, 509-530. doi: 10.1016/S0005-7967(99)00097-2

Aziz, S. A., Clements, G. R., Giam, X., Forget, P.-M., \& Campos-Arceiz, A. (2017). Coexistence and conflict between the island flying fox (Pteropus hypomelanus) and humans on Tioman Island, Peninsular Malaysia. Human Ecology, 45, 377-389. doi: 10.1007/s10745-017-9905-6

Bennett, N. J., Roth, R., Klain, S. C., Chan, K., Christie, P., Clark, D. A., .. Wyborn, C. (2017). Conservation social science: Understanding and integrating human dimensions to improve conservation. Biological Conservation, 205, 93-108. doi: 10.1016/j.biocon.2016.10.006

Binngießer, J., \& Randler, C. (2015). Association of the environmental attitudes "preservation" and "utilization" with pro-animal attitudes. International Journal of Environmental and Science Education, 10(3), 477-492. doi: 10.12973/ijese.2015.255a

Bjerke, T., \& Kaltenborn, B. P. (1999). The relationship of ecocentric and anthropocentric motives to attitudes toward large carnivores. Journal of Environmental Psychology, 19, 415-421. doi: 10.1006/jevp.1999.0135

Bradley, M., \& Lang, P. (2000). Measuring emotion: Behavior, feeling, and physiology. In R. D. Lane, L. Nadel, \& G. Ahern (Eds.), Cognitive neuroscience of emotion (pp. 242-276). Oxford: Oxford University Press.

Cerri, J., Mori, E., Vivarelli, M., \& Zaccaroni, M. (2017). Are wildlife value orientations useful tools to explain tolerance and illegal killing of wildlife by farmers in response to crop damage? European Journal of Wildlife Research, 63(4), 70-78. doi: 10.1007/s10344-0171127-0

Cole, J. S., McCormick, A. C., \& Gonyea, R. M. (2012). Respondent use of straight-lining as a response strategy in education survey research: Prevalence and implications. In Annual meeting of the American Educational Research Association (pp. 1-18). Vancouver.

Davey, G. C., Mcdonald, A. S., Hirisave, U., Prabhu, G., Iwawaki, S., Jim, I. C., ... Reimann, B. C. (1998). A cross-cultural study of animal fears. Behaviour Research and Theraphy, $36,735-750$.

Dolan, R. J. (2002). Emotion, cognition, and behavior. Science, 298(5596), 1191-1194.

DWNP. (2014). Rekod aduan gangguan hidupan liar Semenanjung Malaysia 2014. Unpublished data 2014.

DWNP. (2015). Rekod aduan gangguan hidupan liar Semenanjung Malaysia 2015. Unpublished data 2015. 
DWNP. (2016). Rekod aduan gangguan hidupan liar Semenanjung Malaysia 2016. Unpublished data 2016.

Ekman, P. (1992). An argument for basic emotions. Cognition and Emotion, 6(3/4), 169-200. doi: 10.1080/02699939208411068

Ellsworth, P. C., \& Scherer, K. R. (2003). Appraisal processes in emotion. In R. J. Davidson, K. R. Scherer, \& H. H. Goldsmith (Eds.), Handbook of affective sciences (pp. 572-595). Oxford: Oxford University Press.

Feldman Barrett, L., Mesquita, B., Ochsner, K. N., \& Gross, J. J. (2007). The experience of emotion. Emotion, 58, 373-403. doi: 10.1146/annurev.psych.58.110405.085709

Fulton, D. C., Manfredo, M. J., \& Lipscomb, J. (1996). Wildlife value orientations: A conceptual and measurement approach. Human Dimensions of Wildlife, 1(2), 24-47. doi: $10.1080 / 10871209609359060$

Gamborg, C., \& Jensen, F. S. (2016). Wildlife value orientations: A quantitative study of the general public in Denmark. Human Dimensions of Wildlife, 21(1), 34-46. doi: 10.1080/10871209.2015.1098753

Hand, C. M., \& Van Liere, K. D. (1984). Religion, mastery-over-nature, and environmental concern. Social Forces, 63(2), 555-570.

Hermann, N., \& Menzel, S. (2013). Predicting the intention to support the return of wolves: A quantitative study with teenagers. Journal of Environmental Psychology, 36, 153-161. doi: 10.1016/j.jenvp.2013.07.017

Hermann, N., Voß, C., \& Menzel, S. (2013). Wildlife value orientations as predicting factors in support of reintroducing bison and of wolves migrating to Germany. Journal for Nature Conservation, 21(3), 125-132. doi: 10.1016/j.jnc.2012.11.008

Inglehart, R., \& Baker, W. E. (2000). Modernization, cultural change, and the persistence of traditional values. American Sociological Review, 65(1), 19-51.

Izard, C. E. (2007). Basic emotions, natural kinds, emotion schemas, and a new paradigm. Perspectives on Psychological Science, 2(3), 260-280. doi: 10.1111/j.17456916.2007.00044.x

Jacobs, M. H. (2009). Why do we like or dislike animals? Human Dimensions of Wildlife, 14(1), 1-11. doi: 10.1080/10871200802545765

Jacobs, M. H. (2012). Human emotions toward wildlife. Human Dimensions of Wildlife, 17(1), 1-3. doi: 10.1080/10871209.2012.653674

Jacobs, M. H., Fehres, P., \& Campbell, M. (2012). Measuring emotions toward wildlife: A review of generic methods and instruments. Human Dimensions of Wildlife, 17(4), 233247. doi: 10.1080/10871209.2012.680175

Jacobs, M. H., \& Harms, M. (2014). Influence of interpretation on conservation intentions of 
whale tourists. Tourism Management, 42, 123-131. doi: 10.1016/j.tourman.2013.11.009

Jacobs, M. H., Vaske, J. J., Dubois, S., \& Fehres, P. (2014). More than fear: Role of emotions in acceptability of lethal control of wolves. European Journal of Wildlife Research, 60(4), 589-598. doi: 10.1007/s10344-014-0823-2

Jacobs, M. H., Vaske, J. J., \& Roemer, J. M. (2012). Toward a mental systems approach to human relationships with wildlife: The role of emotional dispositions. Human Dimensions of Wildlife, 17(1), 4-15. doi: 10.1080/10871209.2012.645123

Jacobs, M. H., Vaske, J. J., \& Sijtsma, M. T. J. (2014). Predictive potential of wildlife value orientations for acceptability of management interventions. Journal for Nature Conservation, 22(4), 377-383. doi: 10.1016/j.jnc.2014.03.005

Jacobs, M. H., Vaske, J. J., Teel, T. L., \& Manfredo, M. J. (2018). Human dimensions of wildlife. In L. Steg, A. E. van den Berg, \& J. I. M. de Groot (Eds.), Environmental psychology: An introduction (2nd ed.). Chichester: BPS Blackwell.

Kahneman, D. (2003). A perspective on judgment and choice: Mapping bounded rationality. American Psychologist, 58(9), 697-720. doi: 10.1037/0003-066X.58.9.697

Kaltenborn, B. P., Bjerke, T., Nyahongo, J. W., \& Williams, D. R. (2006). Animal preferences and acceptability of wildlife management actions around Serengeti National Park, Tanzania. Biodiversity and Conservation, 15(14), 4633-4649. doi: 10.1007/s10531-0056196-9

Kleinginna, P. R., \& Kleinginna, A. M. (1981). A categorized list of emotion definitions, with suggestions for a consensual definition. Motivation and Emotion, 5(4), 345-379. doi: 10.1007/BF00993889

LeDoux, J. (1998). The emotional brain: The mysterious underpinnings of emotional life. New York: Touchstone.

Lerner, J. S., \& Keltner, D. (2000). Beyond valence: Toward a model of emotion-specific influences on judgement and choice. Cognition \& Emotion, 14(4), 473-493. doi: $10.1080 / 026999300402763$

Lorimer, J. (2007). Nonhuman charisma. Environment and Planning D: Society and Space, 25(5), 911-932. doi: 10.1068/d71j

Lorimer, J. (2008). Counting corncrakes: The affective science of the UK corncrake census. Social Studies of Science, 38(3), 377-405. doi: 10.1177/0306312707084396

Lorimer, J., \& Driessen, C. (2013). Bovine biopolitics and the promise of monsters in the rewilding of Heck cattle. Geoforum, 48, 249-259. doi: 10.1016/j.geoforum.2011.09.002

Lorimer, J., Hodgetts, T., \& Barua, M. (2019). Animals' atmospheres. Progress in Human Geography, 43(1), 26-45. doi: 10.1177/0309132517731254

Manfredo, M. J. (2008). Who cares about wildlife? Social science concepts for exploring 
human-wildlife relationships and conservation issues. New York: Springer.

Manfredo, M. J., Teel, T. L., \& Henry, K. L. (2009). Linking society and environment: A multilevel model of shifting wildlife value orientation in the western United States. Social Science Quarterly, 90, 407-427.

Pattberg, P. (2007). Conquest, domination and control: Europe's mastery of nature in historic perspective. Journal of Political Ecology, 14, 1-9.

Poston, B. (2009). An exercise in personal exploration: Maslow's hierarchy of needs. Surgical Technologists, 41, 347-353.

Prokop, P., \& Randler, C. (2018). Biological predispositions and individual differences in human attitudes toward animals. In R. R. N. Alves \& U. P. Alburquerque (Eds.), Ethnozoology (pp. 447-466). Amsterdam: Elsevier.

Russell, J. A. (2003). Core affect and the psychological construction of emotion. Psychological Review, 110(1), 145-172. doi: 10.1037/0033-295X.110.1.145

Russell, J. A., \& Feldman Barrett, L. (1999). Core affect, prototypical emotional episodes, and other things called emotion: Dissecting the elephant. Journal of Personality and Social Psychology, 76(5), 805-819. doi: 10.1037//0022-3514.76.5.805

Sijtsma, M. T. J., Vaske, J. J., \& Jacobs, M. H. (2012). Acceptability of lethal control of wildlife that damage agriculture in the Netherlands. Society \& Natural Resources, 25(12), 13081323. doi: 10.1080/08941920.2012.684850

Sponarski, C. C., Vaske, J. J., \& Bath, A. J. (2015). The role of cognitions and emotions in human-coyote interactions. Human Dimensions of Wildlife, 20(3), 238-254. doi: 10.1080/10871209.2015.1010756

Steele, J., Bourke, L., Luloff, A. E., Liao, P.-S., Theodori, G. L., \& Krannich, R. S. (2001). The drop-off/pick-up method for household survey research. Journal of the Community Development Society, 32(2), 238-250. doi: 10.1080/15575330109489680

Talarico, J. M., LaBar, K. S., \& Rubin, D. C. (2004). Emotional intensity predicts autobiographical memory experience. Memory \& Cognition, 32(7), 1118-1132. doi: 10.3758/BF03196886

Teel, T. L., \& Manfredo, M. J. (2009). Understanding the diversity of public interests in wildlife conservation. Conservation Biology, 24(1), 128-139. doi: 10.1111/j.15231739.2009.01374.x

Torkar, G., Kubiatko, M., \& Bajd, B. (2012). Assessing pre-service teachers (dis)liking of some animal species. Journal of Baltic Science Education, 11(4), 393-402.

Treves, A., \& Karanth, K. U. (2003). Human-carnivore conflict and perspectives on carnivore management worldwide. Conservation Biology, 17(6), 1491-1499. doi: 10.1111/j.15231739.2003.00059.x 
Treves, A., \& Naughton-Treves, L. (2005). Evaluating lethal control in the management of human-wildlife conflict. In R. Woodroffe, S. Thirgood, \& A. Rabinowitz (Eds.), People and wildlife: Conflict or coexistence? (pp. 86-106). Cambridge, UK: Cambridge University Press.

Vaske, J. J. (2008). Survey research and analysis: Applications in parks, recreation and human dimensions. State College, PA: Venture Publishing.

Vaske, J. J., Jacobs, M. H., \& Sijtsma, M. T. J. (2011). Wildlife value orientations and demographics in the Netherlands. European Journal of Wildlife Research, 57(6), 11791187. doi: 10.1007/s10344-011-0531-0

Vaske, J. J., \& Manfredo, M. J. (2012). Social psychological considerations in wildlife management. In D. J. Decker, S. J. Riley, \& W. F. Siemer (Eds.), Human dimensions of wildlife management. Baltimore, MD: John Hopkins University Press.

Vaske, J. J., \& Whittaker, D. (2004). Normative approaches to natural resources. In M. J. Manfredo, J. J. Vaske, B. L. Bruyere, D. R. Field, \& P. J. Brown (Eds.), Society and natural resources: A summary of knowledge (pp. 283-294). Jefferson, MO: Modern Litho.

Whittaker, D., Vaske, J. J., \& Manfredo, M. J. (2006). Specificity and the cognitive hierarchy: Value orientations and the acceptability of urban wildlife management actions. Society \& Natural Resources, 19, 515-530. doi: 10.1080/08941920600663912

Winkielman, P., Knutson, B., Paulus, M., \& Trujillo, J. L. (2007). Affective influence on judgments and decisions: Moving towards core mechanisms. Review of General Psychology, 11(2), 179-192. doi: 10.1037/1089-2680.11.2.179

Zainal Abidin, Z. A., \& Jacobs, M. H. (2016). The applicability of wildlife value orientations scales to a Muslim student sample in Malaysia. Human Dimensions of Wildlife, 21(6), 555-566. doi: 10.1080/10871209.2016.1199745 


\section{Chapter 5}

\section{Understanding public acceptance of wildlife management interventions in Malaysia}




\begin{abstract}
A wide range of management interventions have been implemented to mitigate human-wildlife conflicts. Some of the management methods are more acceptable to the public than the other. This study examined public acceptability of doing nothing, drive shooting, and lethal control management methods in three situations: an encounter with wildlife, economic loss caused by wildlife, and human death caused by wildlife. Three predominant concepts in human dimensions of wildlife research were examined: wildlife value orientations (WVOs), valence towards wildlife, and wildlife risk perception. Data were obtained with the use of a dropoff/pick-up method $(\mathrm{n}=1062)$ sent to a random inhabitant sample in the state of Johor, Malaysia. Three structural equation models were performed. The results showed that a specific set of predictors can predict public acceptability of different wildlife management interventions. A domination orientation predicted acceptability of management actions in different situations. Both a mutualism WVO and wildlife risk perception predicted acceptability for at least one of the wildlife management interventions, whereas valence only indirectly predicted the acceptability of doing nothing. The significant predictors accounted for 6 to 24 per cent of the variance of acceptability. Overall, the results suggest that the WVO domination is an important concept when explaining public responses towards wildlife among the study sample.
\end{abstract}

Keywords: Human-wildlife conflict, situation specific, structural equation model, Malaysia 


\section{INTRODUCTION}

$\mathrm{T}$ here is a global increase in reported human-wildlife conflicts (HWCs): wildlife-caused incidents, fatalities and economic losses. In urban areas, HWCs often occur in the form of disturbances, wildlife-vehicle collisions, and property damage (Soulsbury \& White, 2015). In rural areas, particularly in developing countries, HWCs frequently occur in the form of crop raiding and property damage with severe consequences for the livelihoods of the local inhabitants (Distefano, 2005). As a response, wildlife authorities have implemented various management interventions. Management interventions can comprise both lethal (e.g., traps, poison, regulated hunting) and non-lethal control measures (e.g., drive shooting, guarding) (Nyhus, 2016). Other management strategies include doing nothing, education and consultation.

Acceptability of HWC management actions can vary among the public. As researchers suggest (Dickman, 2010; Jacobs, Vaske, Dubois, \& Fehres, 2014; Jacobs, Vaske, \& Sijtsma, 2014; Manfredo, 2008; Sijtsma, Vaske, \& Jacobs, 2012), public acceptability is influenced by people's values, deep-rooted antagonism to wildlife, and the level of perceived risk of HWC. People who perceive a certain intervention as unacceptable might oppose it. Unsuccessful management interventions can even create future HWC and human-human conflicts (Dickman, 2010; Teel \& Manfredo, 2009). Therefore, examining social psychological factors is relevant to HWC management. Social psychological research can help wildlife professionals and practitioners to understand public thought about wildlife and the degree of public acceptance of wildlife management interventions (Bennett et al., 2017; Vaske \& Manfredo, 2012).

Social psychological research implies the application of social knowledge to inform solutions and make decisions in order to improve natural resource management (Bennett et al., 2017; Manfredo, 2008), in this case wildlife management interventions. Social psychological research is typically focused on the individual level of analysis by examining people's thoughts regarding wildlife or wildlife management (Vaske \& Manfredo, 2012). Three typical concepts used in social psychological research of human relationships with wildlife are wildlife value orientations, emotions towards wildlife, and wildlife risk perception. Wildlife value orientations are patterns of basic beliefs about wildlife (Fulton, Manfredo, \& Lipscomb, 1996). Emotions are characterised by, but not limited to, physiological responses (e.g., increased heartbeat), experiences (e.g., feeling fear), and behavioural reactions (e.g., avoidance) to any object in question (Kleinginna \& Kleinginna, 1981), in this context wildlife. Risk perception is defined as a subjective judgment that people make about potential dangers of their surroundings (Slovic, 1987) including wildlife, guided by beliefs and emotions (Slovic, Finucane, Peters, \& MacGregor, 2004; Wildavsky \& Dake, 1990).

Scientists have revealed that wildlife value orientations, emotions towards wildlife, and 
risk perceptions about wildlife predict specific attitudes and actions, including acceptability of wildlife management interventions (Hanisch-Kirkbride, Riley, \& Gore, 2013; Jacobs, Vaske, Dubois, \& Fehres, 2014; Jacobs, Vaske, \& Sijtsma, 2014; Sijtsma et al., 2012). Yet, these influences have been studied separately in previous research, and hence leave the question open whether combining the concepts improves understanding and predicting acceptability of management actions. Moreover, assessment of public acceptability based on the three psychological factors would greatly benefit from considering the differences between situations. Situational factors (e.g., level of HWC impact on humans or wildlife) have been shown to influence public acceptability of management methods (Decker, Jacobson, \& Brown, 2006; Zinn, Manfredo, Vaske, \& Wittmann, 1998). Therefore, the current study attempts to examine the Malaysian public's wildlife value orientations (WVOs), emotions towards wildlife, and wildlife risk perception (WRP) to explain acceptability of doing nothing (ACCDN), acceptability of drive shooting (ACCDS), and acceptability of lethal control (ACCKILL) in three different situations with different human-wildlife problem levels.

\section{Theoretical background}

Wildlife value orientations. WVOs are concepts within the cognitive hierarchy theory. In this theory, WVOs are informed by fundamental values and influence wildlife-related attitudes and norms (Fulton et al., 1996). Fundamental values are general, they do not concern specific objects or events, and transcend situations, and hence do not explain much about the variation in individual thought in specific contexts (Jacobs, Vaske, Teel, \& Manfredo, 2018). For example, two persons who highly value freedom can have dissimilar thoughts about wildlife conservation or actions either to protect or neglect wildlife, as one person might attach the value of freedom to all living beings, while the other might attach freedom only to humans (Jacobs et al., 2018). Value orientations follow from fundamental values. In the context of wildlife, wildlife value orientations give meaning to fundamental values and mediates fundamental values to specific thought and actions.

Studies in the North America suggest two predominant WVOs - domination and mutualism (Manfredo, Teel, \& Henry, 2009; Teel \& Manfredo, 2009). The former reflects the view of mastery over nature and is characterised by appropriate use and hunting beliefs, and the latter reflects an egalitarian ideology (view that all living beings are equal) and is characterised by social affiliation and caring beliefs. A person who is more domination oriented believes that the well-being of people is more important than that of wildlife, and hence is more likely to hold a positive attitude towards management methods that could harm wildlife. In contrast, a person who has a more mutualist orientation views wildlife as companions or extended family. Such a person is more likely to have a negative attitude towards management 
options that are harmful to wildlife. Indeed, empirical findings have demonstrated that individuals with a strong domination orientation tended to accept lethal wildlife control (Jacobs, Vaske, \& Sijtsma, 2014; Sijtsma et al., 2012), while individuals who are more mutualist oriented perceived lethal control as unacceptable.

Several studies have been done into the WVOs of Malaysian citizens. Two studies explored salient beliefs about wildlife among Malaysians (King \& Nair, 2013; Zainal Abidin, chapter 3 of this thesis). The identified salient beliefs about wildlife in those studies reflect a domination and mutualism continuum; hence the widely used WVOs scales should be more or less applicable to a sample of the Malaysian public. Recent findings among Malaysian university students showed that for this sample the domination and mutualism scales were reliable and predicted the acceptability of lethal wildlife control (Zainal Abidin \& Jacobs, 2016). Researchers also suggested that items reflecting hunting beliefs are two-dimensional (Wan Mahamad \& Kunasekaran, 2016; Zainal Abidin \& Jacobs, 2016), reflecting consequences of hunting for humans and for animals. Another study found rural people to be more utilitarian than urban dwellers, and men to be more mutualistic than women (Jafarpour \& Mariapan, 2014). Yet none of these studies fully examined the predictive potential of WVOs. Overall, these studies suggest the WVO scales are useful in Malaysia, but additional research is needed to investigate to what extent WVOs help to anticipate how individuals in a general population sample in Malaysia will respond to wildlife management measures, and understand how they think about wildlife and wildlife issues.

Valence towards wildlife. Emotions lie at the heart of attraction to, and conflict over, wildlife (Manfredo, 2008). Researchers have argued that emotions are fundamental to individual life tasks, as emotions can regulate organisms' biological bodily systems (Sander, Grandjean, \& Scherer, 2005; Scherer, 2005) and influence other mental phenomena such as memory and motivation (Dolan, 2002; Talarico, LaBar, \& Rubin, 2004). The importance of emotions applies the context of wildlife as well. From an evolutionary perspective, emotions have been described as being innate, functioning as effective adaptive mechanisms that promote human survival and well-being (Damasio, 2001; Jacobs, Vaske, \& Roemer, 2012; LeDoux, 1998). It is reasonable to agree with this suggestion, as animals were crucial for the survival of our distant ancestors, either as sources of danger or food. In a predator-prey encounter, for example, fear regulates people's physiological and physical body reactions. Bodily freezing reduces the chances of being spotted by carnivores, adrenaline releases prepare humans to focus, and increased heartbeat enhances the bodily condition for fight-or-flight reactions (Jacobs, 2009). These emotional processes are innate; hence explicit knowledge and learning processes are not needed. Responses that require explicit learning processes need more time and will only impede the rapid defence recruitment (Öhman \& Mineka, 2001). 
But emotions are also influenced by cultures and learning experiences (Jacobs, 2009). Most people will have a positive emotional reaction when they see a rabbit in a field, perhaps as a result of a predisposition evolved as rabbits are a potential food source. But farmers may very well have a negative emotional reaction, because their experience has taught them that rabbits eat their crops.

Two theoretical distinctions are important in emotion research. First, the concept of emotions can reflect emotional states or traits (Jacobs et al., 2012; Manfredo, 2008). Emotional states reflect the temporary physiological, expressive, or physical responses to emotional stimuli, while emotional traits are the stable mental dispositions against which the emotional relevance stimuli are judged (Lerner \& Keltner, 2000). Similar to cognitive dispositions, emotional traits or dispositions are appraised in an abstract-contextual continuum, from general guidance of evaluation and action tendency, to more specific adaptive responses or adjustments (Ellsworth \& Scherer, 2003). Second, researchers make a distinction between discrete and dimensional classifications of emotional dispositions. Discrete classification of emotions suggests that various emotions such as fear and joy are qualitatively different (Ekman \& Friesen, 1971). Dimensional classifications characterise emotions by dimensions, most notably arousal and valence. Arousal is the activation-deactivation dimension, whereas valence is the pleasure-displeasure dimension (Feldman Barrett, 1998; Russell, 2003). Scientists have argued that valence is the raw assessment of one's current condition (Russell, 2003) and the most fundamental aspect of emotion (Russell, 2009). Empirical research suggests that the measure of valence explains a large portion of the variability in emotions, larger than any other emotion measure (Bradley \& Lang, 2000). In a study of human emotions towards wildlife, valence was found as the best predictor of thought about wildlife-related issues when it was compared to discrete emotions (Jacobs, Vaske, Dubois, \& Fehres, 2014). Consequently, this study will include valence towards wildlife as an emotional disposition next to WVOs to understand acceptability of wildlife management interventions. The underlying structure of valence towards animals is explored, and its predictive influence on the three management actions will be examined.

Wildlife risk perception. Risk perception is defined as a subjective judgment that people make about potential dangers in their surroundings (Slovic, 1987). In a broader context, the cultural and psychometric approaches have contributed to the current understanding of risk perception. The cultural theory of risk perception suggests that individuals who hold hierarchical, egalitarian, individualistic or fatalistic worldviews will "choose" to be concerned with different types of risks (Douglas \& Wildavsky, 1982; Wildavsky \& Dake, 1990). The psychometric paradigm suggests differences in risk definition between experts and laypersons (Slovic, 1987). Whereas experts have a more objective estimation of risk, laypersons are more 
subjective in the way they perceive the likelihood and seriousness of a risk. Within this paradigm, recent theory suggests that the emotional system, next to the analytical system, guides humans to comprehend risk (Slovic et al., 2004). This theory asserts that perceptions of risk are also informed by rapid mental processing that is based on the pleasure-pain orientation (Slovic et al., 2004). Taken together, these approaches indicate values and emotions as important antecedents of risk perception. Studies based on these approaches have also demonstrated risk perception can predict public responses to various issues such as climate change (van der Linden, 2015), technological hazards (Sjöberg, 2004), and safety and security (Reisinger \& Mavondo, 2005).

The research approaches used to examine risk perception are applicable in the context of wildlife too. As theories assert both ideologies and emotions influence risk perception, it is expected that WVOs and valence will inform risk perception about wildlife. Moreover, previous studies have demonstrated that WRPs predict stakeholder acceptance of wildlife (Riley \& Decker, 2000), tolerance to carnivores (Inskip, Carter, Riley, Roberts, \& MacMillan, 2016), and the acceptability of selective killing methods to control outbreaks of wildlife diseases (Hanisch-Kirkbride et al., 2013). In most cases, individuals with a greater WRP are less accepting of wildlife and more accepting of lethal control.

Risk perceptions are multidimensional (Helgeson, van der Linden, \& Chabay, 2012; Renn, 1992). Often risk perceptions are assessed using indexes of various constructs. Based on the psychological approach, the current study will consider subjective evaluation of likelihood and severity to measure WRP. An additional dimension of dread or worry is included as scholars have argued that it is a relevant dimension of risk perception (Hanisch-Kirkbride et al., 2013; Riley \& Decker, 2000; Sjöberg, 1998; Terpstra, Gutteling, Geldof, \& Kappe, 2006). Taking these dimensions into account, the current study will examine the perceived likelihood, severity, and wariness regarding various possible risks involving wildlife to reflect a general WRP.

Responses to wildlife issues in specific situations. Contextual characteristics influence public reasoning and responses to management actions (Decker et al., 2006; Kleiven, Bjerke, \& Kaltenborn, 2004; Zinn et al., 1998). To have a broad view of the predictive potential of wildlife value orientations, valence, and risk perceptions, this study will examine three different situations with different types of management interventions and different human-wildlife problem levels. The situations reflect realistic scenarios that actually occur or are likely to occur in Malaysia. The first is the possibility of an encounter with wildlife, a situation with the least severity. The second situation concerns economic loss due to agricultural damage caused by wildlife. The third situation is that of human death caused by wildlife, a situation that concerns human safety. 


\section{Conceptual model and hypotheses}

The present study is guided by a conceptual model that integrates WVOs, valence, and WRP (Figure 5.1). The model posits relationships between the WVOs, valence, and WRP with ACCDN, ACCDS, and ACCKILL in three different situations.

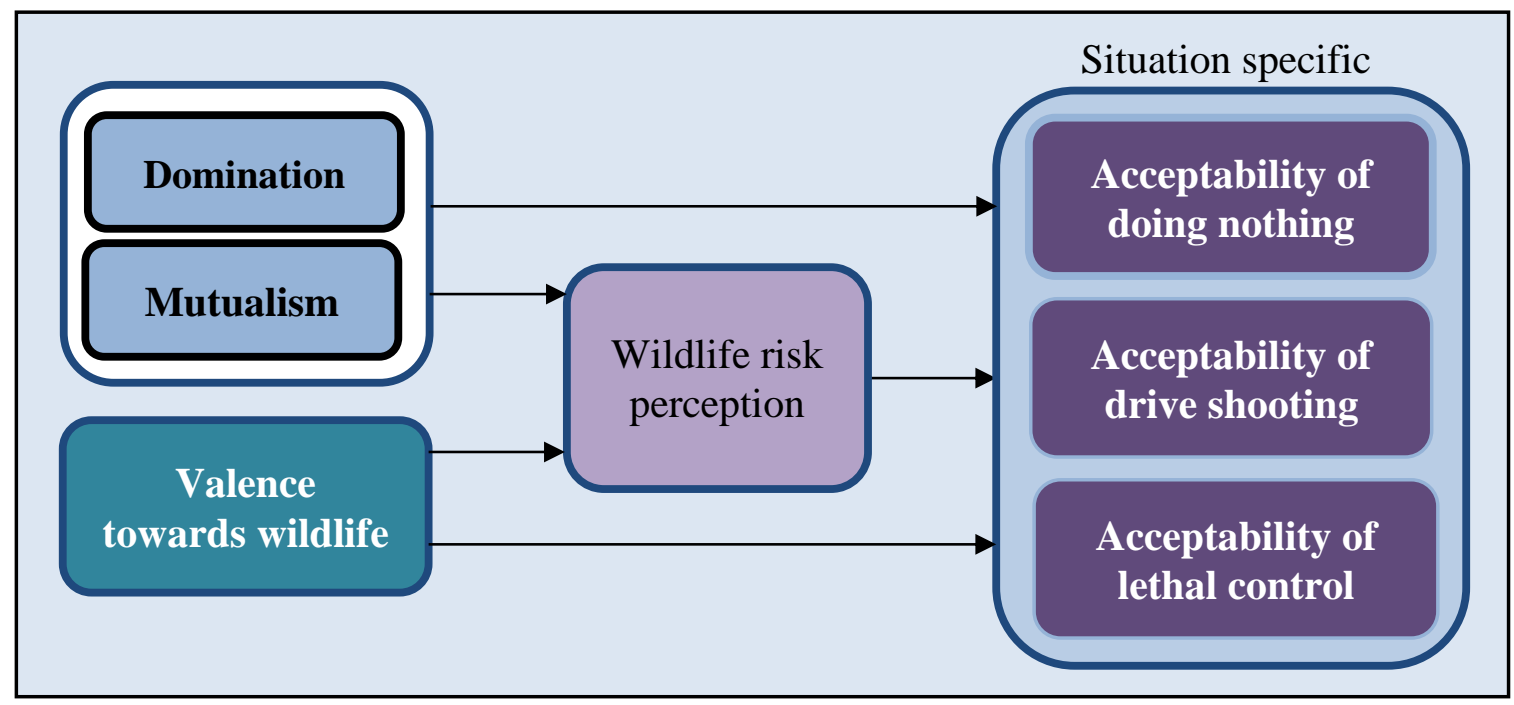

Figure 5.1. Conceptual model to understand acceptability of wildlife management interventions. Arrows represent the expected direct relationships between variables.

The following hypotheses were tested (as there are three dependent variables, the first four main hypotheses are subdivided):

$\mathrm{H}_{1}$ : Domination predicts acceptability of wildlife management actions

$\mathrm{H}_{1 \mathrm{a}}$ : Domination predicts acceptability of doing nothing

$\mathrm{H}_{1 \mathrm{~b}}$ : Domination predicts acceptability of drive shooting

$\mathrm{H}_{1 \mathrm{c}}$ : Domination predicts acceptability of lethal control

$\mathrm{H}_{2}$ : Mutualism predicts acceptability of wildlife management actions

$\mathrm{H}_{2 \mathrm{a}}$ : Mutualism predicts acceptability of doing nothing

$\mathrm{H}_{2 \mathrm{~b}}$ : Mutualism predicts acceptability of drive shooting

$\mathrm{H}_{2 \mathrm{c}}$ : Mutualism predicts acceptability of lethal control

$\mathrm{H}_{3}$ : Valence predicts acceptability of wildlife management actions

$\mathrm{H}_{3 \mathrm{a}}$ : Valence predicts acceptability of doing nothing

$\mathrm{H}_{3 b}$ : Valence predicts acceptability of drive shooting

$\mathrm{H}_{3 \mathrm{c}}$ : Valence predicts acceptability of lethal control

$\mathrm{H}_{4}$ : Wildlife risk perception predicts acceptability of wildlife management actions

$\mathrm{H}_{4 a}$ : Wildlife risk perception predicts acceptability of doing nothing

$\mathrm{H}_{4 \mathrm{~b}}$ : Wildlife risk perception predicts acceptability of drive shooting

$\mathrm{H}_{4 \mathrm{c}}$ : Wildlife risk perception predicts acceptability of lethal control 
$\mathrm{H}_{5}$ : Domination predicts wildlife risk perception

$\mathrm{H}_{6}$ : Mutualism predicts wildlife risk perception

$\mathrm{H}_{7}$ : Valence predicts wildlife risk perception

\section{METHODS}

A survey was conducted between August and November 2016 in two districts in the state of Johor, Malaysia (Figure 5.2). A close-ended questionnaire was prepared in English and Malay (on the same form) based on a pilot study on WVOs amongst Malaysian university students (Zainal Abidin \& Jacobs, 2016). Additional pre-testing conducted among residents of Johor suggested no changes were necessary. The questionnaire was also presented to officials of the Department of Wildlife and National Parks of Peninsular Malaysia (DWNP) for contextual relevance. No major changes were made afterwards.

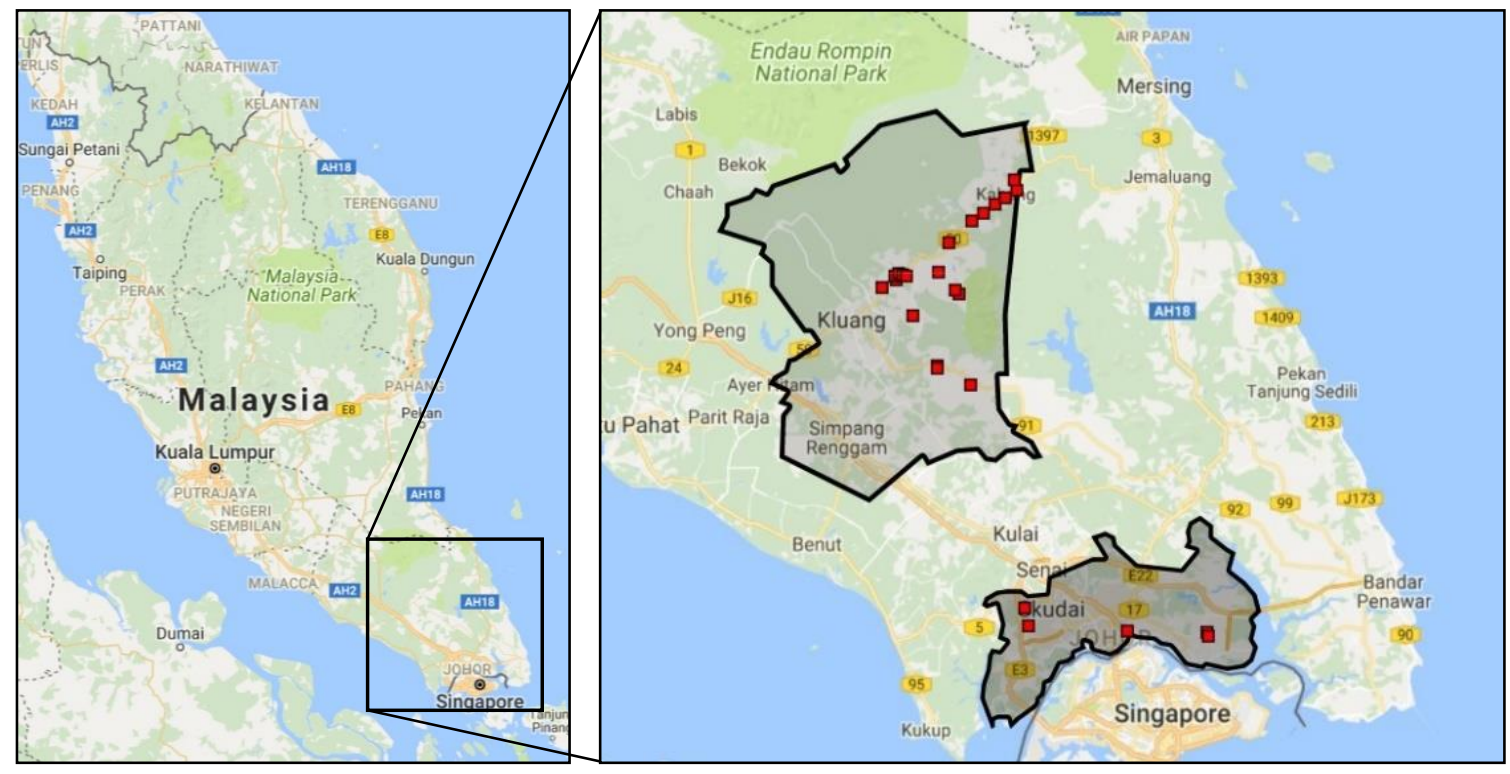

Figure 5.2. Overview of the study areas. The red squares within the shaded areas indicate the 21 surveyed areas within the two study districts in the state of Johor (right-side box). Source: https://www.google.com/maps/d/edit?mid=18LfLAnZgmSlGcfJtBDMzCreoMIw\&ll=2.0686 $55109280346 \% 2 \mathrm{C} 103.34455514880369 \& \mathrm{z}=10$

\section{Sampling and procedures}

Residential areas for the survey were randomly selected from all areas with frequent wildlife disturbances (DWNP, 2014, 2015b, 2016), which are close to green spaces, and are non-gated and non-guarded. Within residential areas, every second street, and within streets, every fourth house was selected. At household level, only permanent residents of 18 years or over who had the most recent birthday by the time of the arrival of the researcher were asked to fill out the questionnaire. Considering the complex addressing system in the majority of the 
residential areas, the alternate selection procedure and age selection criteria increased the probability of approaching random selection of respondents at the residential and household level, and presented less intrusive survey processes than more formal randomisation procedures (Steele et al., 2001).

Questionnaires were distributed to 1943 households using a drop-off and pick-up method (Steele et al., 2001). Inhabitants who agreed to participate in the study were handed a cover letter explaining the purpose of the research, a questionnaire form, and a consent form. Completed questionnaires were collected during the second visit on the next day. The researcher made a new appointment with respondents for a third visit on a date and time that was convenient for the respondents if they did not return the completed questionnaire during the second visit. Of the 1943 questionnaires that were handed out, 1100 were returned (57 per cent response rate) and 1062 were usable. Overall, over half of the sample (57 per cent) was female. Also 57 per cent of respondents were younger adults (age < 39). The sample was dominated by respondents with a Malay background (87.2\% Malay, 3.9\% Chinese, 6.4\% Indian, $2.5 \%$ other cultural backgrounds).

To maintain privacy, respondents' identities were not recorded and logbooks with their addresses were disposed of at the end of the survey. The survey questions and procedures conform to the general research ethics criteria of Wageningen University and Research, and the survey study was granted permission by the Economic Planning Unit of Malaysia (EPU) with a recommendation from the DWNP.

\section{Questionnaire}

The questionnaire was designed to measure wildlife value orientations (WVOs), valence towards wildlife, wildlife risk perception (WRP), acceptability of doing nothing (ACCDN), acceptability of drive shooting (ACCDS), and acceptability of lethal control (ACCKILL):

1) WVOs - domination and mutualism questions were adopted from the original standardised scale of WVOs (Manfredo et al., 2009). The domination WVO was indicated through corresponding beliefs of appropriate use (6 items) and hunting (4 items). The mutualism WVO was also indicated through two corresponding beliefs: social affiliation (4 items) and caring ( 5 items). Responses were coded on a 7-point scale ranging from -3 (strongly disagree) to +3 (strongly agree) with 0 as the neutral point. Two questions on hunting beliefs (i.e., "Hunting is cruel and inhumane to the animals" and "Hunting does not respect the lives of animals") were reverse coded prior to analysis.

2) Valence with regard to animals - respondents rated how pleasant or unpleasant they found a list of 56 animals. The list was adopted from a previous study on fear for animals 
(Davey et al., 1998) with several changes made to conform the local contexts: slugs and gerbils were not listed due to unfamiliarity; snakes and wild birds were changed to cobras and owls, respectively; deer, wild boars, elephants, pythons, and monkeys were added as these animals are common in Malaysia; panda was added because of its increasing popularity in Malaysia; civets was added to the list on the request of DWNP. The question was: "Please indicate for each animal in the list below how pleasant or unpleasant you find it". Responses were coded on a 7-point scale ranging from -3 (unpleasant) to +3 (pleasant) with 0 as the neutral point.

3) WRP - a total of 15 questions that measure the perceived likelihood, severity, and wariness of five possible risks with wildlife (i.e., invasion, financial losses, vehiclecollision, attack, disease transfer) were asked. Responses were coded on a 4-point scale ranging from 0 (not worried/unlikely to happen/not severe) to +3 (very worried/very likely to happen/very severe).

4) Acceptability of management interventions - There were 18 questions designed to measure ACCDN, ACCDS, and ACCKILL with regard to monkeys and elephants. Conflicts between humans and monkeys or elephants commonly occur in the study areas (Ahmad Zafir \& Magintan, 2016; DWNP, 2015a). Respondents were asked to rate how acceptable they found each management action in every situation. As an example, this was one of the questions asked: "A troop of monkey lives in a large nature area. There's a chance that hikers encounter them. How unacceptable or acceptable is it if wildlife agencies trap-to-eliminate the animal?" Responses were coded on a 7-point scale.

\section{Data analysis}

For data analysis, a three-step analysis procedure was performed. The first two steps concern the measurement model. The first step involves identifying the underlying factor (i.e., first-order factors) of WVOs and valence. Exploratory factor analyses - principal component analysis [PCA] with Varimax rotation - were performed on the 19 items that measured WVOs and on the 56 items that measured valence. PCA is a useful analysis to identify underlying factors from a set of variables to understand the structure of latent variables (Field, 2013).

The PCA identified five first-order factors of WVOs and three first-order factors of valence (Table 5.1). Following PCA, three confirmatory factor analyses (CFA) were conducted to validate the first-order factors of WVOs and valence identified in the previous PCA, and three factors of WRP (i.e., worried, severity, likelihood). CFA is a well-established method to ascertain how well the items represent an exact factor indicated by theory (Lattin, Carroll, \& Green, 2003). The overall fit of the models was assessed using a combination of absolute and incremental indices. As indicated in CFA, only items with a significant factor loading, factor 
loading scores $>.50$, and with modification indices $(\mathrm{MI})$ values $<10$ were retained (Table 5.1). Three items of WVOs with a factor loading of less than .50 were retained because of relevance and content relative to their associated items in the same first-order factor (see Appendix A1 for more details regarding the measurement models).

Table 5.1. Reliability, correlation, means, standard deviations, and factor loadings for the items reflect first-order factors (CFA).

\begin{tabular}{|c|c|c|c|}
\hline $\begin{array}{l}\text { First-order factors } \\
\text { Items }\end{array}$ & $M$ & SD & $\begin{array}{c}\text { Factor } \\
\text { loading }\end{array}$ \\
\hline Appropriate use $^{\mathrm{a}}(\alpha=.64)$ & .39 & 1.37 & \\
\hline $\begin{array}{l}\text { It is acceptable for people to kill wildlife if they think it poses a } \\
\text { threat to their life }\end{array}$ & .93 & 1.86 & .698 \\
\hline $\begin{array}{l}\text { It is acceptable for people to kill wildlife if they think it poses a } \\
\text { threat to their property }\end{array}$ & .33 & 1.83 & .845 \\
\hline $\begin{array}{l}\text { It is acceptable to use wildlife and fish in research even if it } \\
\text { may harm or kill some animals }\end{array}$ & -.09 & 1.70 & .349 \\
\hline Human benefit ${ }^{\mathrm{a}}(\alpha=.60)$ & .07 & 1.23 & \\
\hline $\begin{array}{l}\text { The needs of humans should take priority over wildlife and } \\
\text { fish protection }\end{array}$ & .23 & 1.88 & .407 \\
\hline Wildlife and fish are on earth primarily for people to use & .33 & 1.79 & .668 \\
\hline $\begin{array}{l}\text { We should strive for a world where there's an abundance of } \\
\text { wildlife and fish for hunting and fishing }\end{array}$ & .16 & 1.82 & .650 \\
\hline $\begin{array}{l}\text { People who want to hunt should be provided the opportunity to } \\
\text { do so }\end{array}$ & -.45 & 1.75 & .416 \\
\hline Social-affiliation $^{\mathrm{a}}(\alpha=.69)$ & .90 & 1.33 & \\
\hline $\begin{array}{l}\text { We should strive for a world where humans and wildlife and } \\
\text { fish can live side by side without fear }\end{array}$ & 1.12 & 1.69 & .509 \\
\hline Animals should have rights similar to the rights of humans & .83 & 1.76 & .605 \\
\hline Wildlife are like my family and I want to protect them & 76 & 1.62 & .784 \\
\hline $\operatorname{Caring}^{\mathrm{a}}(\alpha=.84)$ & .59 & 1.34 & \\
\hline I take great comfort in the relationships I have with the animals & .71 & 1.51 & .795 \\
\hline I feel a strong emotional bond with animals & .29 & 1.61 & .767 \\
\hline I value the sense of companionship I receive from animals & .78 & 1.52 & .820 \\
\hline Hunting consequences $^{\mathrm{a}}(r=.72)$ & 1.10 & 1.68 & \\
\hline Hunting is cruel and inhumane to the animals ${ }^{\mathrm{d}}$ & 1.20 & 1.83 & .768 \\
\hline Hunting does not respect the lives of animals ${ }^{\mathrm{d}}$ & 1.14 & 1.79 & .935 \\
\hline Valence to harmless animals ${ }^{\mathrm{a}}(\alpha=.85)$ & .36 & 1.30 & \\
\hline Cow & .34 & 1.52 & .815 \\
\hline Sheep & .29 & 1.52 & .830 \\
\hline Goat & .31 & 1.58 & .775 \\
\hline Horse & .52 & 1.64 & .638 \\
\hline Valence to contamination animals ${ }^{\mathrm{a}}(\alpha=.82)$ & -1.82 & 1.00 & \\
\hline Spider & -1.66 & 1.29 & .676 \\
\hline Leech & -1.93 & 1.24 & .768 \\
\hline Bat & -1.98 & 1.21 & .787 \\
\hline Lizard & -1.70 & 1.26 & .670 \\
\hline
\end{tabular}


Table 5.1. (continued)

\begin{tabular}{|c|c|c|c|}
\hline Valence to dangerous animals $\mathrm{s}^{\mathrm{a}}(\alpha=.84)$ & -2.10 & 1.11 & \\
\hline Crocodile & -2.11 & 1.40 & .730 \\
\hline Tiger & -2.03 & 1.44 & .819 \\
\hline Hippopotamus & -1.80 & 1.48 & .760 \\
\hline Cobra & -2.45 & 1.03 & .755 \\
\hline Worried $^{\mathrm{b}}(\alpha=.88)$ & 2.92 & .98 & \\
\hline Worried over road accidents with wildlife & 2.77 & 1.05 & .778 \\
\hline Worried over wildlife attack & 2.95 & 1.10 & .917 \\
\hline Worried over infected with a zoonotic disease & 3.05 & 1.12 & .831 \\
\hline $\operatorname{Severity}^{\mathrm{b}}(\alpha=.85)$ & 2.88 & .94 & \\
\hline The seriousness of wildlife invasion into living space & 2.91 & 1.06 & .844 \\
\hline The seriousness of financial loss caused by wildlife & 2.63 & 1.09 & .785 \\
\hline The seriousness of wildlife attack & 3.09 & 1.06 & .800 \\
\hline Likelihood $^{\mathrm{b}}(\alpha=.83)$ & 2.90 & .71 & \\
\hline The possibility of wildlife invasion into living space & 2.84 & .87 & .687 \\
\hline The possibility of road accident with wildlife & 2.93 & .78 & .774 \\
\hline The possibility of wildlife attack & 2.92 & .80 & .923 \\
\hline $\begin{array}{l}\text { Acceptability of doing nothing ... } \\
. . \text { in encounter situation with monkey and elephant }(r=.521) \\
. . \text { in economic loss situation with monkey and elephant }(r=.555) \\
. . \text { in human death situation with monkey and elephant }(r=.470)\end{array}$ & $\begin{array}{r}-.91 \\
-1.82 \\
-1.90\end{array}$ & $\begin{array}{l}1.76 \\
1.41 \\
1.36\end{array}$ & \\
\hline $\begin{array}{l}\text { Acceptability of drive shooting ... } \\
. . \text { in encounter situation with monkey and elephant }(r=.479) \\
. . \text { in economic loss situation with monkey and elephant }(r=.580) \\
. . \text { in human death situation with monkey and elephant }(r=.598)\end{array}$ & $\begin{array}{r}-.04 \\
.41 \\
.55\end{array}$ & $\begin{array}{l}1.78 \\
1.84 \\
1.88\end{array}$ & \\
\hline $\begin{array}{l}\text { Acceptability of lethal control ... } \\
. . \text { in encounter situation with monkey and elephant }(r=.523) \\
\text {.. in economic loss situation with monkey and elephant }(r=.542) \\
. . \text { in human death situation with monkey and elephant }(r=.611)\end{array}$ & $\begin{array}{l}-1.67 \\
-1.51 \\
-1.09\end{array}$ & $\begin{array}{l}1.51 \\
1.59 \\
1.85\end{array}$ & \\
\hline
\end{tabular}

Note. Only items after model modification in CFA were presented.

$\alpha=$ Cronbach's alpha coefficient, $M=$ Mean, SD = Standard deviation

${ }^{\text {a }}$ Items were measured on 7-point semantic differential scales. For example, $-3=$ strongly

disagree $; 0=$ neutral $; 3=$ strongly agree .

${ }^{\mathrm{b}}$ Items were measured on 4-point semantic differential scales. For example, $1=$ never

worried $; 2$ = rarely worried $; 3=$ frequently worried $; 4=$ always worried .

${ }^{\mathrm{c}}$ Completely standardized factor loadings in CFA and significant at $p<.001$.

${ }^{\mathrm{d}}$ Items were reverse coded prior to CFA to avoid misunderstanding in interpretation.

Internal consistency of the first-order factors and the nine acceptability measures was inspected by conducting reliability analyses and bivariate correlations. Of the 20 verified firstorder factors, 18 have sufficient internal consistency, as these factors had Cronbach's alpha coefficient $\geq .65$, while factors with two items had significant Pearson's $r$ above .40 (Vaske, 2008). 
Finally, three separate structural equation models (SEM) were used to test the predictive validity of the model, as well as to assess the mediation role of WRP. SEM is a powerful statistical method that combines the purpose of confirmatory techniques in its measurement part - in this present study the interrelationships between first-order factors - and examining the direct structural relationships between multiple exogenous (i.e., independent/predictor) and endogenous (i.e., dependent/outcome) variables that are not directly observable (i.e., first- and second-order factors) (Lattin et al., 2003; Schreiber et al., 2006). SEM can also include a mediator variable in its structural model to assess the indirect effect of a predictor variable(s) on an outcome variable(s). The context of SEM implies that predictor variables influence other variables under study and are not influenced by other factors in the model, while outcome variable(s) are influenced either by predictor and/or mediator variables. For the SEMs, a 'lavaan' package (ver. 0.6-1) in R software (R Core Team, 2017) was used.

Initially, six fit measures that comprised of the absolute and incremental indices were inspected - namely the normed chi-square $\left(\chi^{2} / \mathrm{df}\right.$; an acceptable fit $\left.<5\right)$, comparative fit index (CFI; an acceptable CFI value > .90), goodness-of-fit index (GFI; an acceptable GFI value >.90), adjusted goodness-of-fit index (AGFI; an acceptable AGFI value > .90), root mean square error of approximation (RMSEA; an acceptable RMSEA < .06), and standardised root mean square residual (SRMR; an acceptable SRMR value < .08) (Hooper, Coughlan, \& Mullen, 2008; Hu \& Bentler, 1998; Lattin et al., 2003; Wheaton, Muthén, Alwin, \& Summers, 1977). Multiple indices were inspected as this strategy accounts for different aspects of model fit (Hooper et al., 2008; Hu \& Bentler, 1998). Mean responses and standard deviation for each second-order factor were calculated to reveal the degree of domination, mutualism, valence and WRP. As in the CFA, the completely standardised factor loadings for each underlying factor of WVOs, valence and WRP were also inspected to determine the need for model modification. The relationships between variables were inspected by examining the completely standardised regression weight. The indirect and total effects were inspected whenever mediation occurred. Finally, $R^{2}$ was used to determine the amount of variance in each outcome variable explained by the predictor and mediating variables. 


\section{RESULTS}

Values of the indices $\chi^{2} / \mathrm{df}, \mathrm{CFI}, \mathrm{GFI}, \mathrm{AGFI}, \mathrm{RMSEA}$ and SRMR were all in the acceptable range recommended in the literature (Table 5.2). This means that the SEMs demonstrated the data provided an acceptable fit to the model.

Table 5.2. Goodness-of-fit indices of the structural equation model for the encounter, economic loss, and human death situation.

\begin{tabular}{lcccccc}
\hline & $\begin{array}{c}\chi^{2} / \mathrm{df} \\
<5\end{array}$ & $\begin{array}{c}\text { CFI } \\
>.90\end{array}$ & $\begin{array}{c}\text { GFI } \\
>.90\end{array}$ & $\begin{array}{c}\text { AGFI } \\
>.90\end{array}$ & $\begin{array}{c}\text { RMSEA } \\
<.06\end{array}$ & $\begin{array}{c}\text { SRMR } \\
\leq .08\end{array}$ \\
\hline Encounter & 3.09 & .933 & .967 & .948 & .045 & .036 \\
Economic loss & 2.79 & .947 & .969 & .952 & .042 & .037 \\
Human death & 2.71 & .950 & .970 & .953 & .041 & .033 \\
\hline
\end{tabular}

On average, respondents were neither domination $(M=-0.23, \mathrm{SD}=0.91)$ nor mutualism $(M=0.11, \mathrm{SD}=0.89)$ oriented. They found animals a bit unpleasant $(M=-1.18, \mathrm{SD}=0.88)$ and perceived wildlife as risky $(M=2.90, \mathrm{SD}=0.68)$. Across the three models, the factor loadings for each first-order factor were significant and the majority exceeded or was equal to the threshold of .50. However, the factor loadings for hunting consequences in all situations were very low $(\lambda=.16)$. The result indicates hunting consequences as a less important indicator for mutualism. However, since the factor produces significant factor loadings and did not affect the overall fit indices, the factor was retained in the model.

People with more positive feelings tend to find wildlife less risky (Figure 3). WVOs did not predict wildlife risk perceptions. In all situations, direct effects were observed between WVOs and WRP and the acceptability of the actions (Figure 3). There were direct positive effects between domination and the acceptability of all actions in all situations. Only ACCDN in human death situation was not associated with domination. Stronger direct effects were observed between domination and ACCDS, and weaker effects between domination and ACCDN. Individuals who are more domination oriented were more likely to accept all management actions in all situations, particularly ACCDS. Comparing the regression scores of domination with the other explanatory variables, domination had the highest scores for acceptability of each wildlife management action, and across situations. Mutualism had direct negative effects on ACCKILL in all situations and a direct positive effect on ACCDN in the encounter situation. The strength of association between mutualism and ACCKILL varies a little across situations but stays within the same order of magnitude. More mutualist oriented persons tended to be less accepting of lethal control regardless of the situation, and were more likely to accept doing nothing in the wildlife encounter situation. People who perceived wildlife as risky (WRP) tended to find doing nothing less acceptable (ACCDN). 

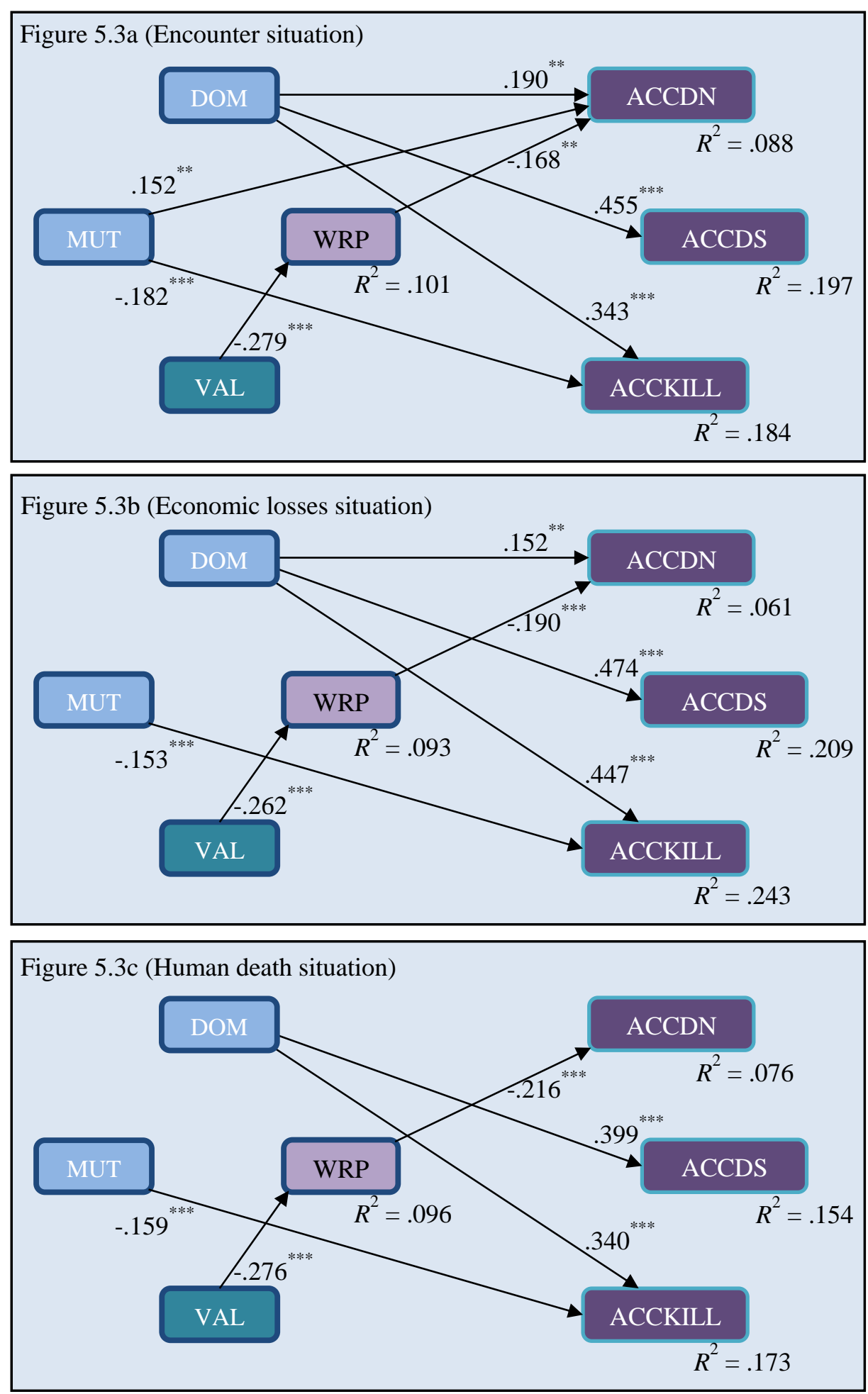

Figure 5.3. Models for understanding acceptability of three wildlife management interventions in three situations. To simplify, only statistically significant coefficients are presented $\left({ }^{* *} \mathrm{p}<0.01,{ }^{* * *} \mathrm{p}<0.001\right)$.

Valence had no direct effects on the acceptability of management actions, but indirect positive effects on ACCDN via WRP were observed in all situations (Table 5.3). The total effect (i.e., the sum of a direct effect and indirect effect between the independent, mediation, and dependent variables) increased with the increasing severity of the HWC scenario. 
Table 5.3. The completely standardized path coefficients for direct, indirect, and total effects from valence to ACCDN via WRP in each situation.

\begin{tabular}{lccc}
\hline Situation & Direct & Indirect & Total \\
\hline Encounter & n.s. & $.047^{* * *}$ & $.126^{* * *}$ \\
Economic loss & n.s. & $.050^{* *}$ & $.136^{* * *}$ \\
Human death & n.s. & $.060^{* * *}$ & $.164^{* * *}$ \\
\hline
\end{tabular}

Note. ${ }^{* *} p<.001,{ }^{* * *} p<.001$, n.s. $=$ Not significant.

As indicated by $R^{2}$, WVOs, valence, and WRP explained 6 to 24 per cent of variances of the acceptability of wildlife management actions. The levels of explained variance were smallest in predicting ACCDN $\left(R^{2}=.06\right.$ to .09$)$. The highest explained variance was observed in ACCKILL, particularly in economic loss situations $\left(R^{2}=.243\right)$. The differences between $R^{2}$ scores for ACCDS and ACCKILL across the three situations were nearly identical.

\section{DISCUSSION}

This study examined the influence of WVOs, valence, and WRP on three wildlife management interventions, namely ACCDN, ACCDS, and ACCKILL. The findings suggest that:

1. Domination predicted the acceptability of wildlife management actions $\left(\mathrm{H}_{1}, \mathrm{H}_{1 \mathrm{a}}\right.$, $\mathrm{H}_{1 \mathrm{~b}}$, and $\mathrm{H}_{1 \mathrm{c}}$ were supported). Domination had positive relationships with the acceptability of wildlife management interventions across the three different situations and was a better predictor of acceptability of wildlife management interventions than the other independent variables.

2. Mutualism predicted the acceptability of lethal control $\left(\mathrm{H}_{2 \mathrm{c}}\right.$ was supported). Mutualism, however, did not predict the acceptability of other management actions $\left(\mathrm{H}_{2}, \mathrm{H}_{2 \mathrm{a}}\right.$, and $\mathrm{H}_{2 \mathrm{~b}}$ were rejected), with the exception of the acceptability of doing nothing in the encounter situation.

3. Valence had no predictive potential for the acceptability of wildlife management actions $\left(\mathrm{H}_{3}, \mathrm{H}_{3 \mathrm{a}}, \mathrm{H}_{3 \mathrm{~b}}\right.$, and $\mathrm{H}_{3 \mathrm{c}}$ were rejected). Valence only indirectly predicted the acceptability of doing nothing via WRP.

4. WRP predicted the acceptability of doing nothing $\left(\mathrm{H}_{4 \mathrm{a}}\right.$ was supported). Across the three situations, wildlife risk perception was negatively associated with the acceptability of doing nothing. However, the acceptability of the other actions was not predicted by WRP $\left(\mathrm{H}_{4 \mathrm{~b}}\right.$ and $\mathrm{H}_{4 \mathrm{c}}$ were rejected).

5. Valence predicted wildlife risk perception $\left(\mathrm{H}_{7}\right.$ was supported). Domination and mutualism did not $\left(\mathrm{H}_{5}\right.$ and $\mathrm{H}_{6}$ were rejected $)$. 
A finding that stands out is that domination was the best predictor both in terms of strength (largest effect sizes) and breadth (predicting the acceptability of different actions for different types of human-wildlife interactions). Some previous research also found that domination predicted the acceptability of management actions better than mutualism (Jacobs, Vaske, \& Sijtsma, 2014; Sijtsma et al., 2012). Yet, the way domination was measured is different in this study. Exploratory and confirmatory factor analyses suggested a different way of constructing a composite index that reflects domination than the way theory and previous research (Teel \& Manfredo, 2009) would suggest. So, interestingly, while domination is ultimately measured differently, it performs well in terms of predicting. Consistent with the literature from various contexts (Cerri, Mori, Vivarelli, \& Zaccaroni, 2017; Jacobs, Vaske, \& Sijtsma, 2014; Sijtsma et al., 2012; Teel \& Manfredo, 2009; Whittaker, Vaske, \& Manfredo, 2006), individuals who are more domination oriented prioritise human well-being over wildlife welfare, and then find drive shooting and lethal control more acceptable. The question of why domination is a better predictor than the other concepts included in this study can of course not be answered on the basis of the data - a brief speculation will follow after the discussion of the other concepts.

The finding that mutualism predicts ACCKILL, but not the acceptability of other management actions (except for doing nothing in the encounter scenario) is in line with previous theorising. Lethal control is likely to cause internal value conflicts (trade-off between solving problems for people and killing animals). As WVOs prioritise values, they can be seen as templates for choosing (Jacobs, Vaske, \& Sijtsma, 2014). Wildlife risk perceptions, on the other hand, predicted ACCDN but not of the other actions. Lethal control and drive shooting are actions that are likely to remove wildlife from places where human-wildlife interactions occur. If wildlife is not present anymore, the level of risk one associates with wildlife becomes irrelevant. The findings reflect this. People's risk perceptions only matter if wildlife remains present in the area (as in the no management option) and the more risky an individual perceives wildlife to be, the less acceptable the management option of doing nothing will be to this person.

The finding that valence did not predict the acceptability of any management action in any situation is in contrast with theoretical assertions and findings from previous studies. Emotions are theorised to be important in the overall functioning of the human mind and behaviour (Damasio, 1996; LeDoux, 1998). And so they would also be important in humanwildlife relationships (Jacobs, 2012; Manfredo, 2008). Research has indeed indicated that emotions towards wildlife influence other mental dispositions related to wildlife. Most notably, these relationships were examined for wolves and amongst western populations. Emotions towards wolves predicted people's willingness to pay for large carnivore policy (Johansson, Sjöström, Karlsson, \& Brännlund, 2012), beliefs about wolf recovery (Slagle, Bruskotter, \& 
Wilson, 2012) and the acceptability of wolf management actions (Jacobs, Vaske, Dubois, \& Fehres, 2014). Two differences between this set of studies and the current research might explain the divergence of findings. First, previous studies have assessed emotion towards a specific species (i.e., wolves), while the present study has used a composite index that reflects valence towards wildlife in general in the analyses. It is likely that a more general and abstract emotional disposition has less influence on specific thought than a mental disposition at the same level of specificity in terms of species. Second, the present study concerns a Malaysian population while the previously mentioned studies examined Swedish, American, Canadian and Dutch populations. These societies are known as rather individualistic cultures, whereas Malaysians represent a collectivistic society (Hofstede, 1984). Possibly, people in collectivistic society are less willing to allow their emotions (if seen as a private matter) to influence their evaluation of management actions, whereas Western people are much more willing to do so.

Yet, the finding that valence indirectly predicted the acceptability of doing nothing via WRP resonates with claims of Slovic et al. (2004), who propose that affect serves as a cue for judgments, including probability judgment. This process, termed as the affect heuristic, explains that if individuals' affects toward an object or event are unfavourable, they tend to associate it with a high risk; if their affects toward a stimulus are favourable, they tend to come to an opposite judgement - low risk. In other words, people base their judgment on how they feel about it, and not necessarily on what they think about an object or event. The respondents in this study who judge animals a bit unpleasant are more likely to perceive wildlife as risky. Consequently, they are more likely to less accept the management option of doing nothing as a wildlife management option.

The pattern of findings is similar across situations, both in terms of significant relationships and in terms of effect sizes, differences only show in details. This implies that the situation (wildlife is present, wildlife causes damage, wildlife kills a human being) hardly matters for the way inhabitants of Johor evaluate management actions. As a striking feature of the overall pattern, domination is an important concept to understand thought about wildlife amongst the residents of Johor. Yet the structure and measurement of domination is different than in previous studies in Western nations.

Future research could include emotion measurements on the same level of specificity as the dependent measurements. It would also be interesting if samples of other collectivistic populations were to be studied. That research could check the merits of the potential explanations of why valence did not directly predict the dependent measurements. Also, the sample of this study is skewed towards the Malay ethnic segment. While the majority of the Malaysian population consists of Malay (Department of Statistics Malaysia, 2011) future studies that incorporate other ethnic segments including the indigenous peoples are needed to 
determine whether the findings could be generalised to the whole Malaysian population.

The current study only measured personal risk perception about wildlife (risk for individuals). In addition to personal risk, social risks (e.g., risks for family members, neighbours or the environment) can be important to risk perception (van der Linden, 2015). Future studies including measures of societal risks could investigate the distinction between personal and societal risk perception, and whether societal risk perceptions are more important drivers of thought than personal risk perceptions. Future research could also include different types of management interventions. Next to the ones investigated here, there are other ways to manage wildlife, such as translocation, introducing new predator species, or installing electric fences (Nyhus, 2016). Including different types of management interventions could expand the findings of the current research.

\section{CONCLUSION}

This chapter concerns a psychological model to understand public acceptability of wildlife management actions in Malaysia. Based on three previously used concepts in human dimensions of wildlife research, an integrated model was tested on a sample of the Malaysian public. Domination was the best predictor, followed by mutualism and WRP to predict public acceptability. Valence influenced WRP but did not directly predict acceptability. The model explains a portion of the variability of public acceptability that ranges from 6 to 24 per cent. 


\section{REFERENCES}

Ahmad Zafir, A. W., \& Magintan, D. (2016). Historical review of human-elephant conflict in Peninsular Malaysia. Journal of Wildlife and National Parks, 31, 1-19.

Bennett, N. J., Roth, R., Klain, S. C., Chan, K., Christie, P., Clark, D. A., ... Wyborn, C. (2017). Conservation social science: Understanding and integrating human dimensions to improve conservation. Biological Conservation, 205, 93-108. doi: 10.1016/j.biocon.2016.10.006

Bradley, M., \& Lang, P. (2000). Measuring emotion: Behavior, feeling, and physiology. In R. D. Lane, L. Nadel, \& G. Ahern (Eds.), Cognitive neuroscience of emotion (pp. 242-276). Oxford: Oxford University Press.

Cerri, J., Mori, E., Vivarelli, M., \& Zaccaroni, M. (2017). Are wildlife value orientations useful tools to explain tolerance and illegal killing of wildlife by farmers in response to crop damage? European Journal of Wildlife Research, 63(4), 70-78. doi: 10.1007/s10344-017$1127-0$

Damasio, A. (2001). Fundamental feelings. Nature, 413(6858), 781. doi: 10.1038/35101669

Damasio, A. R. (1996). The somatic marker hypothesis and the possible functions of the prefrontal cortex. Philosophical Transactions of the Royal Society of London: Series B, $351,1413-1420$.

Davey, G. C., Mcdonald, A. S., Hirisave, U., Prabhu, G., Iwawaki, S., Jim, I. C., ... Reimann, B. C. (1998). A cross-cultural study of animal fears. Behaviour Research and Theraphy, $36,735-750$.

Decker, D. J., Jacobson, C. A., \& Brown, T. L. (2006). Situation-specific "impact dependency" as a determinant of management acceptability: Insights from wolf and grizzly bear management in Alaska. Wildlife Society Bulletin, 34(2), 426-432.

Department of Statistics Malaysia. (2011). Population distribution and basic demographic characteristics. Putrajaya, Malaysia.

Dickman, A. J. (2010). Complexities of conflict: The importance of considering social factors for effectively resolving human-wildlife conflict. Animal Conservation, 13(5), 458-466. doi: 10.1111/j.1469-1795.2010.00368.x

Distefano, E. (2005). Human-wildlife conflict worldwide: Collection of case studies, analysis of management strategies and good practices. SARD Initiative Report, Rome, Italy.

Dolan, R. J. (2002). Emotion, cognition, and behavior. Science, 298(5596), 1191-1194.

Douglas, M., \& Wildavsky, A. (1982). How can we know the risks we face? Why risk selection is a social process. Risk Analysis, 2(2), 49-58. doi: 10.1111/j.1539-6924.1982.tb01365.x

DWNP. (2014). Rekod aduan gangguan hidupan liar Semenanjung Malaysia 2014. Unpublished data 2014.

DWNP. (2015a). Department of Wildlife and National Parks of Peninsular Malaysia Annual 
Report 2015. Kuala Lumpur, Malaysia.

DWNP. (2015b). Rekod aduan gangguan hidupan liar Semenanjung Malaysia 2015. Unpublished data 2015.

DWNP. (2016). Rekod aduan gangguan hidupan liar Semenanjung Malaysia 2016. Unpublished data 2016.

Ekman, P., \& Friesen, W. V. (1971). Constants across cultures in the face and emotion. Journal of Personality and Social Psychology, 17(2), 124-129. doi: 10.1037/h0030377

Ellsworth, P. C., \& Scherer, K. R. (2003). Appraisal processes in emotion. In R. J. Davidson, K. R. Scherer, \& H. H. Goldsmith (Eds.), Handbook of affective sciences (pp. 572-595). Oxford: Oxford University Press.

Feldman Barrett, L. (1998). Discrete emotions or dimensions? The role of valence focus and arousal focus. Cognition and Emotion, 12(4), 579-599. doi: 10.1080/026999398379574

Field, A. (2013). Discovering statistics using IBM SPSS statistics (3rd ed.). London: Sage.

Fulton, D. C., Manfredo, M. J., \& Lipscomb, J. (1996). Wildlife value orientations: A conceptual and measurement approach. Human Dimensions of Wildlife, 1(2), 24-47. doi: $10.1080 / 10871209609359060$

Gallagher, D., Ting, L., \& Palmer, A. (2008). A journey into the unknown; taking the fear out of structural equation modeling with AMOS for the first-time user. The Marketing Review, 8(3), 255-275. doi: 10.1362/146934708X337672

Hanisch-Kirkbride, S. L., Riley, S. J., \& Gore, M. L. (2013). Wildlife disease and risk perception. J Wild Dis, 49(4), 841-849. doi: 10.7589/2013-02-031

Helgeson, J., van der Linden, S., \& Chabay, I. (2012). The role of knowledge, learning and mental models in public perceptions of climate change related risks. In A. E.J. Wals \& P. B. Corcoran (Eds.), Learning for sustainability in times of accelerating change (pp. 329346). Wageningen Academic Publishers.

Hofstede, G. (1984). The cultural relativity of the quality of life concept. Academy of Management Review, 9(3), 389-398. doi: 10.5465/AMR.1984.4279653

Hooper, D., Coughlan, J., \& Mullen, M. (2008). Structural equation modelling: Guidelines for determining model fit. Electronic Journal of Business Research Methods, 6(1), 53-60. doi: 10.1037/1082-989X.12.1.58

Hu, L., \& Bentler, P. M. (1998). Fit indices in covariance structure modeling: Sensitivity to underparameterized model misspecification. Psychological Methods, 3(4), 424-453. doi: 10.1037/1082-989X.3.4.424

Inskip, C., Carter, N., Riley, S., Roberts, T., \& MacMillan, D. (2016). Toward human-carnivore coexistence: Understanding tolerance for tigers in Bangladesh. PLoS ONE, 11(1), 1-20. doi: 10.1371/journal.pone.0145913 
Jacobs, M. H. (2009). Why do we like or dislike animals? Human Dimensions of Wildlife, 14(1), 1-11. doi: 10.1080/10871200802545765

Jacobs, M. H. (2012). Human emotions toward wildlife. Human Dimensions of Wildlife, 17(1), 1-3. doi: 10.1080/10871209.2012.653674

Jacobs, M. H., Vaske, J. J., Dubois, S., \& Fehres, P. (2014). More than fear: Role of emotions in acceptability of lethal control of wolves. European Journal of Wildlife Research, 60(4), 589-598. doi: 10.1007/s10344-014-0823-2

Jacobs, M. H., Vaske, J. J., \& Roemer, J. M. (2012). Toward a mental systems approach to human relationships with wildlife: The role of emotional dispositions. Human Dimensions of Wildlife, 17(1), 4-15. doi: 10.1080/10871209.2012.645123

Jacobs, M. H., Vaske, J. J., \& Sijtsma, M. T. J. (2014). Predictive potential of wildlife value orientations for acceptability of management interventions. Journal for Nature Conservation, 22(4), 377-383. doi: 10.1016/j.jnc.2014.03.005

Jacobs, M. H., Vaske, J. J., Teel, T. L., \& Manfredo, M. J. (2018). Human dimensions of wildlife. In L. Steg, A. E. van den Berg, \& J. I. M. de Groot (Eds.), Environmental psychology: An introduction (2nd ed.). Chichester: BPS Blackwell.

Jafarpour, M., \& Mariapan, M. (2014). Wildlife value orientations based on age, gender and education in Malaysia. Life Science Journal, 11(6), 194-201.

Johansson, M., Sjöström, M., Karlsson, J., \& Brännlund, R. (2012). Is human fear affecting public willingness to pay for the management and conservation of large carnivores? Society \& Natural Resources, 25(6), 610-620. doi: 10.1080/08941920.2011.622734

King, N., \& Nair, V. (2013). Determining the wildlife value orientation (WVO): A case study of lower Kinabatangan, Sabah. Worldwide Hospitality and Tourism Themes, 5(4), 377387. doi: 10.1108/WHATT-03-2013-0014

Kleinginna, P. R., \& Kleinginna, A. M. (1981). A categorized list of emotion definitions, with suggestions for a consensual definition. Motivation and Emotion, 5(4), 345-379. doi: 10.1007/BF00993889

Kleiven, J., Bjerke, T., \& Kaltenborn, B. P. (2004). Factors influencing the social acceptability of large carnivore behaviours. Biodiversity and Conservation, 13(9), 1647-1658. doi: 10.1023/B:BIOC.0000029328.81255.38

Lattin, J., Carroll, J., \& Green, P. (2003). Analyzing multivariate data. Pacific Grove CA: Brooks/Cole.

LeDoux, J. (1998). The emotional brain: The mysterious underpinnings of emotional life. New York: Touchstone.

Lerner, J. S., \& Keltner, D. (2000). Beyond valence: Toward a model of emotion-specific influences on judgement and choice. Cognition \& Emotion, 14(4), 473-493. doi: 


\section{$10.1080 / 026999300402763$}

Manfredo, M. J. (2008). Who cares about wildlife? Social science concepts for exploring human-wildlife relationships and conservation issues. New York: Springer.

Manfredo, M. J., Teel, T. L., \& Henry, K. L. (2009). Linking society and environment: A multilevel model of shifting wildlife value orientation in the western United States. Social Science Quarterly, 90, 407-427.

Nyhus, P. J. (2016). Human-wildlife conflict and coexistence. Annual Review of Environment and Resources, 41(1), 143-171. doi: 10.1146/annurev-environ-110615-085634

Öhman, A., \& Mineka, S. (2001). Fears, phobias, and preparedness: Toward an evolved module of fear and fear learning. Psychological Review, 108(3), 483-522. doi: 10.1037//0033295X.108.3.483

R Core Team. (2017). R: A language and environment for statistical computing. Vienna, Austria. Retrieved from https://www.r-project.org/

Reisinger, Y., \& Mavondo, F. (2005). Travel anxiety and intentions to travel internationally: Implications of travel risk perception. Journal of Travel Research, 43(3), 212-225. doi: $10.1177 / 0047287504272017$

Renn, O. (1992). Concepts of risk: A classification. In S. Krimsky \& D. Golding (Eds.), Social Theories of Risk (pp. 53-79). New York: Praeger.

Riley, S. J., \& Decker, D. J. (2000). Risk perception as a factor in wildlife stakeholder acceptance capacity for cougars in Montana. Human Dimensions of Wildlife, 5(3), 50-62. doi: 10.1080/10871200009359187

Russell, J. A. (2003). Core affect and the psychological construction of emotion. Psychological Review, 110(1), 145-172. doi: 10.1037/0033-295X.110.1.145

Russell, J. A. (2009). Emotion, core affect, and psychological construction. Cognition \& Emotion, 23(7), 1259-1283. doi: 10.1080/02699930902809375

Sander, D., Grandjean, D., \& Scherer, K. R. (2005). A systems approach to appraisal mechanisms in emotion. Neural Networks, 18(4), 317-352. doi: 10.1016/j.neunet.2005.03.001

Scherer, K. R. (2005). What are emotions? And how can they be measured? Social Science Information, 44(4), 695-729. doi: 10.1177/0539018405058216

Schreiber, J. B., Nora, A., Stage, F. K., Barlow, E. A., King, J., Nora, A., \& Barlow, E. A. (2006). Reporting structural equation modeling and confirmatory factor analysis results:

A review. The Journal of Educational Research, 99(6), 232-338. doi: 10.3200/JOER.99.6.323-338

Sijtsma, M. T. J., Vaske, J. J., \& Jacobs, M. H. (2012). Acceptability of lethal control of wildlife that damage agriculture in the Netherlands. Society \& Natural Resources, 25(12), 1308- 
1323. doi: $10.1080 / 08941920.2012 .684850$

Sjöberg, L. (1998). Worry and risk perception. Risk Analysis, 18(1), 85-93.

Sjöberg, L. (2004). Explaining individual risk perception: The case of nuclear waste. Risk Management, 6(1), 51-64.

Slagle, K. M., Bruskotter, J. T., \& Wilson, R. S. (2012). The role of affect in public support and opposition to wolf management. Human Dimensions of Wildlife, 17(1), 44-57. doi: $10.1080 / 10871209.2012 .633237$

Slovic, P. (1987). Perception of risk. Science, 236(4799), 280-285.

Slovic, P., Finucane, M. L., Peters, E., \& MacGregor, D. G. (2004). Risk as analysis and risk as feelings: Some thoughts about affect, reason, risk, and rationality. Risk Analysis, 24(2). doi: 0272-4332/04/0100-0311\$22.00/1

Soulsbury, C. D., \& White, P. C. L. (2015). Human-wildlife interactions in urban areas: A review of conflicts, benefits and opportunities. Wildlife Research, 42(7), 541-553. doi: 10.1071/WR14229

Steele, J., Bourke, L., Luloff, A. E., Liao, P.-S., Theodori, G. L., \& Krannich, R. S. (2001). The drop-off/pick-up method for household survey research. Journal of the Community Development Society, 32(2), 238-250. doi: 10.1080/15575330109489680

Talarico, J. M., LaBar, K. S., \& Rubin, D. C. (2004). Emotional intensity predicts autobiographical memory experience. Memory \& Cognition, 32(7), 1118-1132. doi: 10.3758/BF03196886

Teel, T. L., \& Manfredo, M. J. (2009). Understanding the diversity of public interests in wildlife conservation. Conservation Biology, 24(1), 128-139. doi: 10.1111/j.15231739.2009.01374.x

Terpstra, T., Gutteling, J. M., Geldof, G. D., \& Kappe, L. J. (2006). The perception of flood risk and water nuisance. Water Science and Technology, 54(6), 431-439.

van der Linden, S. (2015). The social-psychological determinants of climate change risk perceptions: Towards a comprehensive model. Journal of Environmental Psychology, 41, 112-124. doi: 10.1016/j.jenvp.2014.11.012

Vaske, J. J. (2008). Survey research and analysis: Applications in parks, recreation and human dimensions. State College, PA: Venture Publishing.

Vaske, J. J., \& Manfredo, M. J. (2012). Social psychological considerations in wildlife management. In D. J. Decker, S. J. Riley, \& W. F. Siemer (Eds.), Human dimensions of wildlife management. Baltimore, MD: John Hopkins University Press.

Wan Mahamad, W. A. B., \& Kunasekaran, P. (2016). Wildlife value orientations towards Giant Panda Conservation Centre (GPCC) at Zoo Negara, Malaysia. Asia-Pacific Journal of Innovation in Hospitality and Tourism, 5(3), 123-134. 
Wheaton, B., Muthén, B., Alwin, D. F., \& Summers, G. F. (1977). Assessing reliability and stability in panel models. Sociological Methodology, 8, 84-136.

Whittaker, D., Vaske, J. J., \& Manfredo, M. J. (2006). Specificity and the cognitive hierarchy: Value orientations and the acceptability of urban wildlife management actions. Society \& Natural Resources, 19, 515-530. doi: 10.1080/08941920600663912

Wildavsky, A., \& Dake, K. (1990). Theories of risk perception: Who fears what and why? Daedalus, 119(4), 41-60.

Zainal Abidin, Z. A., \& Jacobs, M. H. (2016). The applicability of wildlife value orientations scales to a Muslim student sample in Malaysia. Human Dimensions of Wildlife, 21(6), 555-566. doi: 10.1080/10871209.2016.1199745

Zainal Abidin, Z. A., \& Jacobs, M. H. (2018). Abstract wildlife is nice, concrete wildlife less so: Salient thought about wildlife in a Malaysian sample. Unpublished manuscript.

Zinn, H. C., Manfredo, M. J., Vaske, J. J., \& Wittmann, K. (1998). Using normative beliefs to determine the acceptability of wildlife management actions. Society \& Natural Resources, 11(7), 649-662. doi: 10.1080/08941929809381109 
Appendix

Two separate exploratory factor analyses (i.e., principal component analysis [PCA] with Varimax rotation and Kaiser-Meyer-Olkin [KMO] measure) were performed on the 19 items that measured WVOs and on the 56 items that measured valence. Initially, the Kaiser-MeyerOlkin (KMO) measure was inspected to verify the sampling adequacy. A decision on the relevant number of underlying factors was based on how many components with Eigen values $>1$ emerged from the data and how many points before curve inflection were indicated by the Scree plot.

The PCA for WVOs produced KMO = .822 (great value according to Field [2013]). verified the sampling adequacy. The Bartlett's test of sphericity was significant $\left(\chi^{2}=6153.45\right.$, $p<.001, \mathrm{df}=171)$, indicating that correlations between items were sufficient for PCA. Five components had Eigen values $>1$ and together explained $59.34 \%$ of the variance (Table A1). The Scree plot was slightly ambiguous and showed inflections that would justify retaining either 3 or 5 components (Figure A1). Mean scores and the correlation matrix of the underlying items were further inspected. The mean scores for the reverse coded items of "Hunting is cruel and inhumane to the animals" (i.e., -1.20) and "Hunting does not respect the lives of the animals" (i.e., -1.14) suggested respondents agreed with these statements, in contrast to the other items of the hunting scale. The correlation matrix indicated the two items were highly correlated with each other $(r=.72)$, significantly correlated with mutualism items, but not significantly correlated with the domination items. Given the correlation matrix results and the convergence of the Scree plot at the fifth component, this is the number of components that were retained for the following analysis.

Table A1. Factor analysis and descriptive results for WVOs questions ${ }^{\mathrm{a}}$.

\begin{tabular}{|c|c|c|c|c|c|c|}
\hline Items & $\begin{array}{l}\text { Factor } 1 \\
(16.7 \%)^{b}\end{array}$ & $\begin{array}{l}\text { Factor 2 } \\
(13.4 \%)^{\mathrm{b}}\end{array}$ & $\begin{array}{l}\text { Factor 3 } \\
(9.9 \%)^{\mathrm{b}}\end{array}$ & $\begin{array}{l}\text { Factor } 4 \\
(9.9 \%)^{\mathrm{b}}\end{array}$ & $\begin{array}{l}\text { Factor 5 } \\
(9.4 \%)^{\mathrm{b}}\end{array}$ & $\begin{array}{c}M \\
(\mathrm{SD})\end{array}$ \\
\hline $\begin{array}{l}\text { I feel a strong emotional bond } \\
\text { with animals }\end{array}$ & .803 & & & & & $\begin{array}{c}.29 \\
(1.61)\end{array}$ \\
\hline $\begin{array}{l}\text { I take great comfort in the } \\
\text { relationships I have with the } \\
\text { animals }\end{array}$ & .756 & & & & & $\begin{array}{c}.71 \\
(1.51)\end{array}$ \\
\hline $\begin{array}{l}\text { I value the sense of } \\
\text { companionship I receive from } \\
\text { animals }\end{array}$ & .744 & & & & & $\begin{array}{c}.78 \\
(1.52)\end{array}$ \\
\hline $\begin{array}{l}\text { It would be more rewarding to } \\
\text { me to help animals rather than } \\
\text { people }\end{array}$ & .707 & & & & & $\begin{array}{c}-.42 \\
(1.69)\end{array}$ \\
\hline $\begin{array}{l}\text { I care about animals as much } \\
\text { as I do other people }\end{array}$ & .548 & & & & & $\begin{array}{c}1.19 \\
(1.44)\end{array}$ \\
\hline
\end{tabular}


Table A1. (continued)

\begin{tabular}{|c|c|c|c|c|c|c|}
\hline $\begin{array}{l}\text { I view all living things as part } \\
\text { of one big family }\end{array}$ & & .744 & & & & $\begin{array}{c}1.17 \\
(1.54)\end{array}$ \\
\hline $\begin{array}{l}\text { We should strive for a world } \\
\text { where humans and wildlife } \\
\text { and fish can live side by side } \\
\text { without fear }\end{array}$ & & .713 & & & & $\begin{array}{c}1.12 \\
(1.69)\end{array}$ \\
\hline $\begin{array}{l}\text { Animals should have rights } \\
\text { similar to the rights of } \\
\text { humans }\end{array}$ & .400 & .556 & & & & $\begin{array}{c}.83 \\
(1.76)\end{array}$ \\
\hline $\begin{array}{l}\text { Wildlife are like my family } \\
\text { and I want to protect them }\end{array}$ & .507 & .552 & & & & $\begin{array}{l}.76 \\
(1.62)\end{array}$ \\
\hline $\begin{array}{l}\text { Humans should manage } \\
\text { wildlife and fish populations } \\
\text { so that human benefit }\end{array}$ & & .528 & & & & $\begin{array}{c}1.72 \\
(1.48)\end{array}$ \\
\hline $\begin{array}{l}\text { It is acceptable for people to } \\
\text { kill wildlife if they think it } \\
\text { poses a threat to their life }\end{array}$ & & & .836 & & & $\begin{array}{c}.93 \\
(1.86)\end{array}$ \\
\hline $\begin{array}{l}\text { It is acceptable for people to } \\
\text { kill wildlife if they think it } \\
\text { poses a threat to their property }\end{array}$ & & & .823 & & & $\begin{array}{c}.33 \\
(1.83)\end{array}$ \\
\hline $\begin{array}{l}\text { It is acceptable to use wildlife } \\
\text { and fish in research even if it } \\
\text { may harm or kill some } \\
\text { animals }\end{array}$ & & & .492 & & & $\begin{array}{c}-.09 \\
(1.70)\end{array}$ \\
\hline $\begin{array}{l}\text { Wildlife and fish are on earth } \\
\text { primarily for people to use }\end{array}$ & & & & .782 & & $\begin{array}{c}.33 \\
(1.79)\end{array}$ \\
\hline $\begin{array}{l}\text { We should strive for a world } \\
\text { where there's an abundance of } \\
\text { wildlife and fish for hunting } \\
\text { and fishing }\end{array}$ & & & & .747 & & $\begin{array}{c}.16 \\
(1.82)\end{array}$ \\
\hline $\begin{array}{l}\text { People who want to hunt } \\
\text { should be provided the } \\
\text { opportunity to do so }\end{array}$ & & & & .587 & & $\begin{array}{c}-.45 \\
(1.75)\end{array}$ \\
\hline $\begin{array}{l}\text { The needs of humans should } \\
\text { take priority over wildlife and } \\
\text { fish protection }\end{array}$ & & & & .471 & & $\begin{array}{c}.23 \\
(1.88)\end{array}$ \\
\hline $\begin{array}{l}\text { Hunting is cruel and } \\
\text { inhumane to the animals }\end{array}$ & & & & & .907 & $\begin{array}{l}-1.20 \\
(1.83)\end{array}$ \\
\hline $\begin{array}{l}\text { Hunting does not respect the } \\
\text { lives of animals }\end{array}$ & & & & & .898 & $\begin{array}{l}-1.14 \\
(1.79)\end{array}$ \\
\hline
\end{tabular}

Note. Item-total correlations $<.40$ are not printed; $\mathrm{M}=$ Mean, $\mathrm{SD}=$ Standard deviation

${ }^{\text {a }}$ Responses were coded on 7-point scale from -3 (strongly disagree) to +3 (strongly agree)

${ }^{\mathrm{b}}$ Explained variance after Varimax rotation (cumulative: $59.3 \%$ ). 


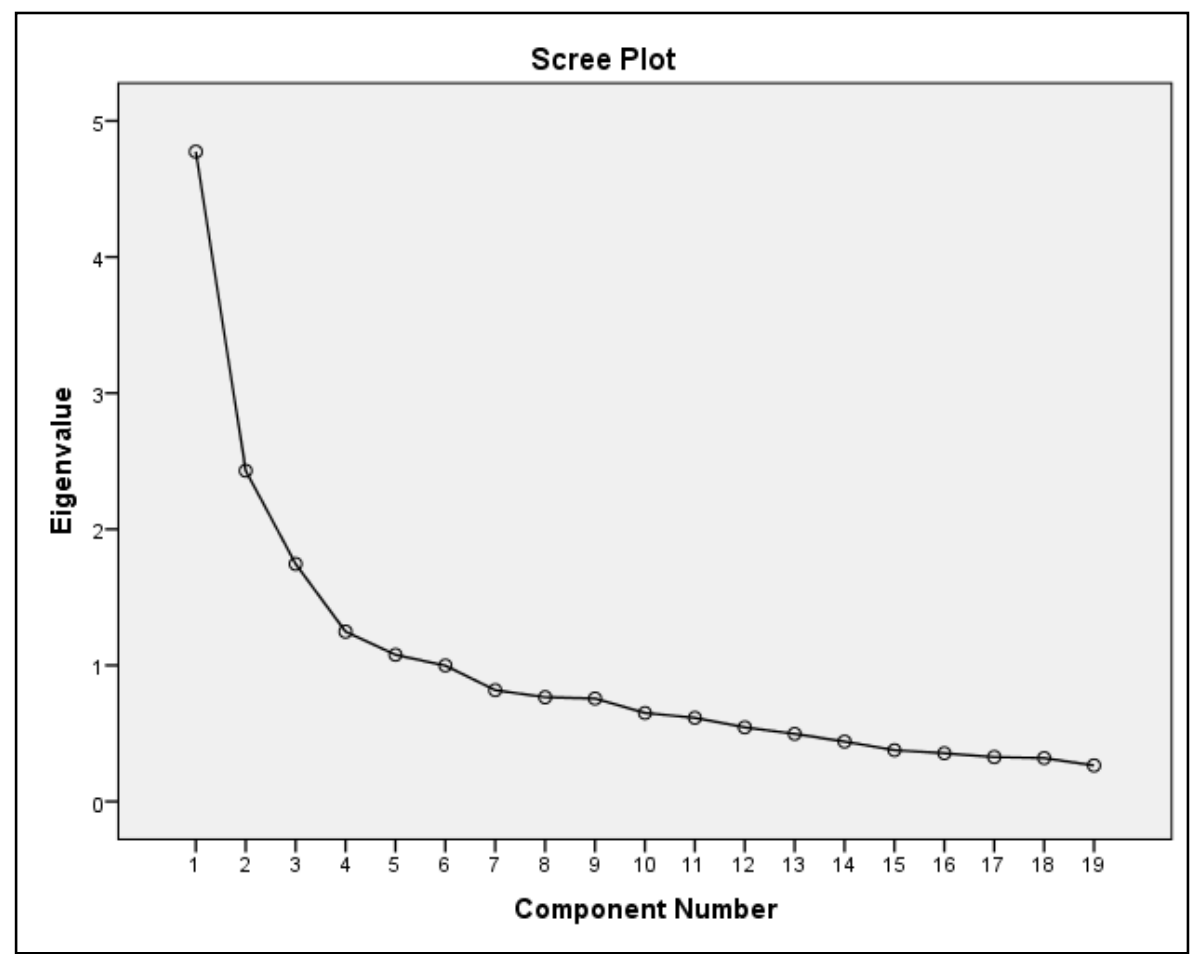

Figure A1. Scree plot of initial factor solutions for WVOs questions.

Thus, five basic wildlife belief dimensions were identified from the WVOs items. Four factors were labelled as caring, social affiliation, appropriate use, and human benefit. The fifth belief dimension was similar to the findings among Malaysia Muslim university students and composed of two items. As a result, the factor was labelled as hunting consequences, similar to the suggestion by Zainal Abidin and Jacobs (2016).

The PCA for valence produced $\mathrm{KMO}=.949(\chi 2=31290.92, \mathrm{p}<.001, \mathrm{df}=1485)$, verifying the sampling adequacy, and correlations were feasible for PCA. Initial factor analysis suggested nine components with Eigen values $>1$. Examination of the Scree plot suggested a three-factor solution would be optimal, as the inflection point was clearly observable at the fourth component (Figure A2). No correlation issues were identified in the correlation matrix. Following the convergence of the Scree plot at the third component, this is the number of components that were retained for the following analysis. Cumulatively, these factors explained 47.5 per cent of the variance.

All items had factor loading over .40 with at least one factor (Table A2). The following species had factor loadings over .40 on two factors: owl, panda, and jellyfish. A decision was made based on the highest factor loading to allocate a species to a factor. The majority of animals in each factor are distinct in the following characteristics. The animals in factor one were predominantly large and dangerous animals, such as tigers, sharks, and lions. The second factor consists of animals that are not dangerous to humans, such as rabbits, horses, and cows. The third factor includes animals associated with contamination, disease, and poison, such as 
lizards, cockroaches, and wasps. Consequently, the three components in valence were labelled as valence to dangerous animals, harmless animals, and contamination animals.

Table A2. Factor analysis and descriptive results of valence ratings for 56 animal species ${ }^{\mathrm{a}}$.

\begin{tabular}{|c|c|c|c|c|}
\hline Species & Factor $1(18.4 \%)^{b}$ & Factor $2(14.6 \%)^{b}$ & Factor $3(14.5 \%)^{b}$ & $M(\mathrm{SD})$ \\
\hline Wolf & .811 & & & $-2.17(1.31)$ \\
\hline Crocodile & .802 & & & $-2.11(1.40)$ \\
\hline Tiger & .799 & & & $-2.03(1.44)$ \\
\hline Lion & .765 & & & $-1.62(1.72)$ \\
\hline Shark & .761 & & & $-2.15(1.39)$ \\
\hline Bear & .749 & & & $-1.64(1.68)$ \\
\hline Civet & .669 & & & $-1.77(1.49)$ \\
\hline Cobra & .650 & & & $-2.45(1.03)$ \\
\hline Hippopotamus & .637 & & & $-1.80(1.48)$ \\
\hline Python & .594 & & & $-2.29(1.22)$ \\
\hline Wild boar & .579 & & & $-2.49(1.14)$ \\
\hline Eagle & .577 & & & $-1.25(1.62)$ \\
\hline Dog & .566 & & & $-2.49(1.22)$ \\
\hline Elephant & .565 & & & $-1.29(1.77)$ \\
\hline Monkey & .549 & & & $-1.50(1.58)$ \\
\hline Alligator & .504 & & & $-1.59(2.04)$ \\
\hline Seal & .493 & & & $-1.03(1.82)$ \\
\hline Owl & .479 & .438 & & $-.79(1.66)$ \\
\hline Guinea pig & .472 & & & $-1.54(1.87)$ \\
\hline Octopus & .465 & & & $-1.62(1.65)$ \\
\hline Pig & .458 & & & $-1.89(1.61)$ \\
\hline Panda & .441 & .415 & & $-.50(2.01)$ \\
\hline Frog & .422 & & & $-1.33(1.54)$ \\
\hline Sheep & & .731 & & $.29(1.52)$ \\
\hline Horse & & .717 & & $.52(1.64)$ \\
\hline Cow & & .710 & & $.34(1.52)$ \\
\hline Goat & & .692 & & $.31(1.58)$ \\
\hline Duck & & .677 & & $.67(1.50)$ \\
\hline Rabbit & & .664 & & $1.44(1.47)$ \\
\hline Chicken & & .662 & & $1.02(1.44)$ \\
\hline Turtle & & .661 & & $.32(1.70)$ \\
\hline Parakeet & & .617 & & $.68(1.70)$ \\
\hline Camel & & .616 & & -.07 (1.67) \\
\hline Goose & & .600 & & $-.21(1.67)$ \\
\hline Cat & & .569 & & $1.69(1.48)$ \\
\hline Deer & & .562 & & $.10(1.76)$ \\
\hline Goldfish & & .551 & & $1.53(1.46)$ \\
\hline
\end{tabular}


Table A2. (continued)

\begin{tabular}{lccc}
\hline Squirrel & $\mathbf{. 5 2 2}$ & $.12(1.68)$ \\
Hamster & $\mathbf{. 4 6 6}$ & & $.26(1.83)$ \\
Eel & $\mathbf{. 4 5 1}$ & & $-.67(1.70)$ \\
Moth & $\mathbf{. 4 0 4}$ & $.38(1.78)$ \\
Lizard & & & $-1.70(1.26)$ \\
Leech & & $\mathbf{7 2 5}$ & $-1.93(1.24)$ \\
Mouse & & $\mathbf{. 7 1 4}$ & $-2.3(1.02)$ \\
Spider & & $\mathbf{. 7 0 0}$ & $-1.66(1.29)$ \\
Cockroach & & $\mathbf{. 6 9 8}$ & $-2.07(1.15)$ \\
Worm & & $\mathbf{. 6 9 5}$ & $-1.54(1.39)$ \\
Rat & & $\mathbf{. 6 7 4}$ & $-2.01(1.44)$ \\
Beetle & & $\mathbf{. 6 6 1}$ & $-1.39(1.42)$ \\
Bat & & $\mathbf{. 6 4 9}$ & $-1.98(1.21)$ \\
Fly & & $\mathbf{. 6 3 0}$ & $-1.97(1.22)$ \\
Maggot & & $\mathbf{. 6 2 5}$ & $-1.71(1.61)$ \\
Wasp & & $\mathbf{. 6 2 1}$ & $-2.15(1.30)$ \\
Bee & & $\mathbf{. 5 8 9}$ & $-1.82(1.36)$ \\
Snail & & $\mathbf{. 5 8 2}$ & $-1.32(1.52)$ \\
Jellyfish & & $\mathbf{. 5 4 0}$ & $-1.83(1.41)$ \\
\hline Note. Item-tota
\end{tabular}

Note. Item-total correlations $<.40$ are not printed; $\mathrm{M}=$ Mean, $\mathrm{SD}=$ Standard deviation ${ }^{\text {a }}$ Responses were coded on 7-point scale from -3 (very unpleasant) to +3 (very pleasant)

${ }^{\mathrm{b}}$ Explained variance after Varimax rotation (cumulative: $47.5 \%$ ).

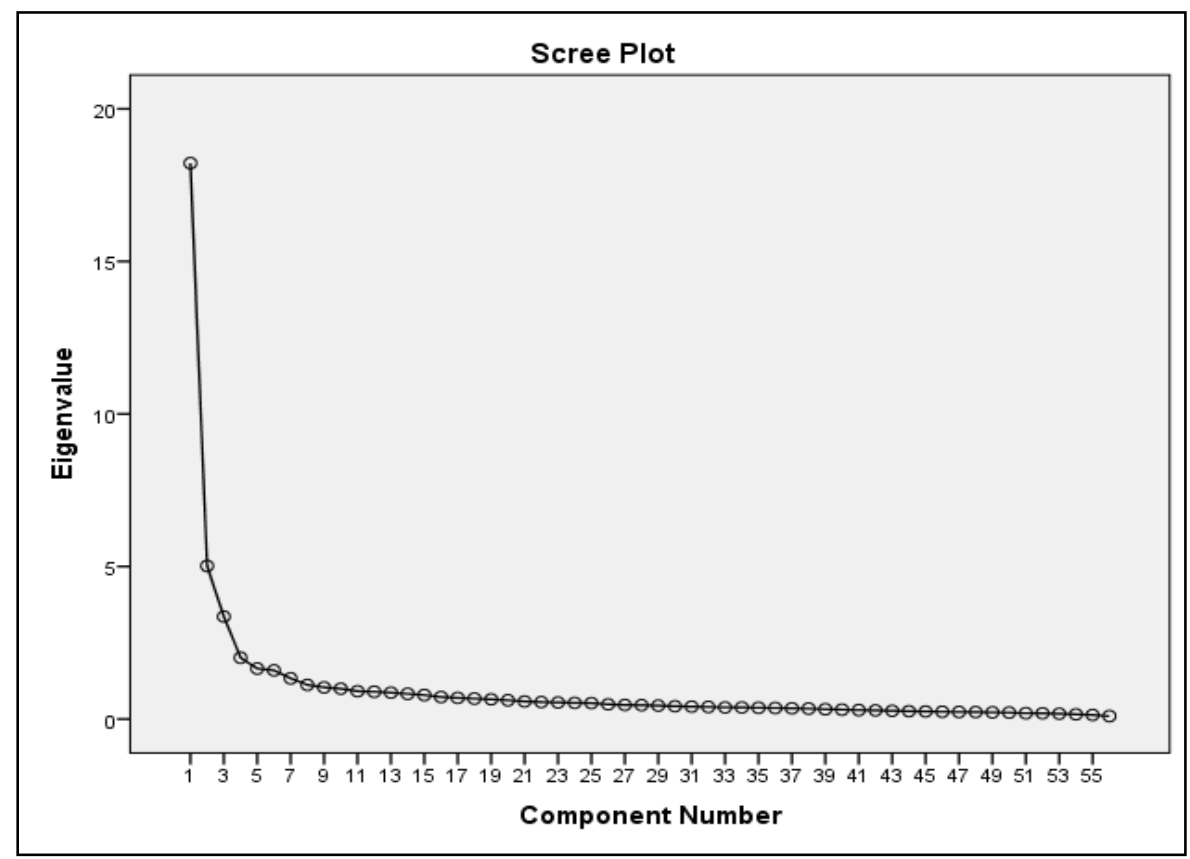

Figure A2. Scree plot of initial factor solutions of valence ratings of 56 species. 
Three separate CFA based on the maximum likelihood estimation were performed on items reflecting WVOs, valence, and WRP using 'lavaan' package (ver. 0.6-1) in R software (R Core Team, 2017). The overall fit of the models was determined by six fit measures, namely the normed chi-square ( $\chi 2 / \mathrm{df})$, comparative fit index (CFI), goodness-of-fit index (GFI), adjusted goodness-of-fit index (AGFI), root mean square error of approximation (RMSEA), and standardized root mean square residual (SRMR). For a model to considered to have an acceptable fit, these indexes was determined based on the following criteria: $\chi 2 / \mathrm{df}<5$ (Wheaton et al., 1977), CFI $\geq .90$ (Hu \& Bentler, 1998; Schreiber et al., 2006), GFI > .90, AGFI > .90, RMSEA $<.06$, and SRMR $\leq .08$ (Hooper et al., 2008; Lattin et al., 2003). Items with insignificant factor loading, factor loading scores $<.50$, and with modification indices values over 10 were suggested for deletion (Gallagher, Ting, \& Palmer, 2008; Lattin et al., 2003). Moreover, items deletion or modification must also consider the conceptual implications (Hooper et al., 2008).

Before conducting CFA on WVOs' model, the items that reflect hunting consequences were reverse coded again to avoid misunderstanding in interpretation. The initial CFA model tested five items each on caring and social affiliation factor and three, four, and two items each on factors of appropriate use, human benefit, and hunting consequences, respectively, yet produced unacceptable goodness of fit. A second CFA for WVOs was performed after deleting four items that match the criteria for item deletion (i.e., "Humans should manage wildlife and fish populations so that human benefit", "I view all living things as part of one big family", "I care about animals as much as I do other people", and "It would be more rewarding to me to help animals rather than people"). This modification improved the goodness of fit with the indices of $\chi^{2} / \mathrm{df}$, CFI, GFI, AGFI, RMSEA, and SRMR were all in the acceptable range (Table A3). Every item significantly loaded on the respective factors. The data provided an acceptable fit for the model.

Table A3. Goodness of fit indices of the confirmatory factor analysis for modified models of WVOs, valence, and WRP.

\begin{tabular}{lcccccc}
\hline & $\begin{array}{c}\chi^{2} / \mathrm{df} \\
<5\end{array}$ & CFI & GFI & AGFI & RMSEA & SRMR \\
& 3.90 & $>.90$ & $>.90$ & $<.06$ & $\leq .08$ \\
\hline WVOs model (15 items) & 3.54 & 0.953 & 0.965 & 0.947 & 0.05 & 0.046 \\
Valence model (12 items) & 3.98 & 0.972 & 0.968 & 0.952 & 0.054 & 0.037 \\
WRP model (9 items) & 5.34 & 0.979 & 0.974 & 0.951 & 0.065 & 0.024 \\
\hline
\end{tabular}

The covariance results suggest that appropriate use and human benefit belong to domination, while social affiliation, caring, and hunting consequences were factors of mutualism. Appropriate use was positively correlated with human benefit $(r=.38)$, negatively correlated with social affiliation $(\mathrm{r}=-.26)$ and caring $(\mathrm{r}=-.19)$, and not correlated with hunting 
consequences. Human benefit hardly had any correlation with social affiliation, caring, and hunting consequences. Social affiliation, caring, and hunting consequences were positively correlated with each other, and the correlation coefficient was especially larger between social affiliation and caring $(\mathrm{r}=.78)$. All covariances are significant at $\mathrm{p}<.001$.

The following CFA model verified the factor of valence to dangerous, harmless, and contamination animals with 22, 18, and 15 species, respectively. As in CFA for WVOs, the first overall fit for valence's model did not have acceptable values. All items, however, were significant with factor loadings $>.70$. Further inspection revealed the majority of items had modification indices (MI) values $>10$, indicating redundancy between respective items. Hence, model modifications were made by deleting recurring items with $\mathrm{MI}>.10$ and strive only for four items with the highest factor loadings in each factor. After deletion of items, the modified CFA model for valence exemplified a goof fit with the data (Table A3). The covariances indicate positive correlations between the three factors. The results suggest the three factors based on 12 animal species were appropriate to reflect valence.

The CFA for WRP model tested five questions in each factor. The six fit measures for the initial WRP's model was also not acceptable. Similar in the valence's CFA model, there were no problems of item significance or low factor loading. Hence, only MI was inspected. There were six items yielding MI > 10 (i.e., worried over invasions and financial losses caused by wildlife, severity in wildlife-vehicle collisions and zoonotic disease transfer, and the likelihood of financial losses caused by wildlife and zoonotic disease transfer), indicating redundancy between these items. These items were deleted for model modification and a second CFA was performed. The modification deletion improved the goodness of fit with CFI, GFI, AGFI, and SRMR exceeding the recommended overall fit scores. The normed chi-square and RMSEA were slightly falling short of the suggested acceptable overall fit. Additional fit indexes of the modified model were inspected. Hooper et al. (2008) and Schreiber et al. (2006) suggested that Akaike (AIC) and Bayes Information Criteria (BIC) are good indexes for model comparison. Smaller value suggests a good fitting. Smaller AIC (21449.65 versus 33913.21) and BIC (21533.56 versus 34076.27) in the modified model than in the initial model were observed. Factor loadings were significant. The results verified three factors of WRP based on the modified CFA model. Overall, the CFA results verified five first-order factors of WVOs, three first-order factors of valence, and three first-order factors of WRP. 
5 | Understanding public acceptance of wildlife management interventions in Malaysia 
Chapter 6

\section{Discussion and conclusions}




\section{UNDERSTANDING HUMAN RESPONSES TO WILDLIFE IN MALAYSIA: REVIEW OF THESIS OBJECTIVE AND RESEARCH QUESTIONS}

This thesis aimed to understand how the Malaysian public thinks about wildlife and wildlife
issues in Malaysia, by examining the role of wildlife value orientations, valence toward wildlife and wildlife risk perception on wildlife-related evaluations. Four research questions have guided the research:

1) Are the wildlife value orientations scales applicable in Malaysia?

2) What are the predominant beliefs about wildlife amongst Malaysians?

3) Does valence have an additional predictive potential next to wildlife value orientations to explain wildlife-related evaluations?

4) To what extent do wildlife value orientations, valence towards wildlife, and wildlife risk perception explain the acceptability of wildlife management interventions in Malaysia?

This chapter presents the conclusions and discusses the findings. In this section, I will answer the four research questions. The following section discusses the theoretical implications of this study, particularly from a cultural perspective, as well as the limitations of this study. Finally, a discussion on how this study can inform wildlife management in Malaysia is presented.

\section{The applicability of wildlife value orientations scales in Malaysia}

In the first empirical chapter (chapter 2), the applicability of wildlife value orientations scales was examined. The findings from the pilot study among Malaysian university students showed that overall, the wildlife value orientations scales were applicable to the study sample, and perhaps to Malaysians in general, in terms of acceptable reliability and predictive validity.

The scales were indeed adequately reliable and did have predictive validity within the study sample. However, there was one clear difference between the results of this pilot study and previous research using the same scales in Western countries. Hunting beliefs were multidimensional - comprised of two latent constructs instead of one as indicated by factor analysis results. Reliability for hunting belief was acceptable as suggested by Cronbach's alpha but slightly lower than the majority of the reliability figures in studies conducted in Western countries. The wildlife value orientations scales had predictive potential for the acceptability of specific management actions. Yet none of the acceptability measurements were predicted by hunting beliefs. The results suggested hunting beliefs might not be salient beliefs about wildlife within the study sample. 


\section{The predominant basic beliefs about wildlife amongst Malaysians}

In chapter 3, I examined the relationship between the abstract-concrete continuum of thought about wildlife on the one hand and positive-negative evaluation of wildlife on the other hand, and explored salient beliefs about wildlife amongst the Malaysians public. Interview data collected from 30 Malaysians with different demographic backgrounds suggested that abstract thought about wildlife was more often positive and concrete thought was more likely to be negative. Six different salient beliefs about wildlife were identified: undesired exploitation, concern for wildlife protection, attraction to wildlife, concern about human-wildlife conflicts, respect for wildlife, and religious or traditional beliefs. Each of the identified beliefs reflects how individuals perceive relationships with wildlife or how they think people should treat wildlife. The identified beliefs within the Malaysian sample to some extent reflected the domination and mutualism orientations, and statements expressed by interviewees were often even very similar to items of the wildlife value orientations measurement tool.

\section{The additional predictive potential of valence next to wildlife value orientations}

One of the main considerations of the study reported in chapter 4 was to address cognitions and emotions - two different but interrelated mental capacities - to improve the overall understanding of human-wildlife relationships. Analyses revealed that valence (the pleasure-displeasure dimension of emotion) has additional explanatory value next to wildlife value orientations to predict support for wildlife conservation policy. Moreover, valence was a better predictor than wildlife value orientations. Valence has no additional explanatory value next to wildlife value orientations to predict the acceptability of lethal wildlife control, but independently would predict the acceptability of this management action. The study also revealed that valence had a stronger correlation with mutualism than with domination, suggesting the more people like wildlife the more they tend to be oriented towards mutualism. In sum, a research model comprised of emotions (e.g., valence towards wildlife) and cognitions (e.g., wildlife value orientations) can predict human responses to wildlife-related issues better than models that focus on either emotion or cognition.

\section{Predicting the acceptability of wildlife management interventions on the basis of wildlife value orientations, valence towards wildlife, and wildlife risk perception}

This study, reported in chapter 5, examined the acceptability for Malaysians of three types of wildlife management interventions, namely doing nothing, drive shooting, and lethal control. Wildlife value orientations, valence towards wildlife, and wildlife risk perception were the predictors. To get a broad view of the influence of the psychological factors, public acceptability of management intervention was examined in three different situations. The first 
was the possibility of an encounter with wildlife, the least severe situation we presented to the respondents. The second situation implied economic losses caused by wildlife, and the third situation was human death caused by wildlife, the most severe situation. The descriptive results revealed that a non-lethal method was more acceptable as a solution to human-wildlife conflicts than hands-off approaches or lethal control methods.

Results from structural equation modelling indicated that factors that influenced public evaluation of wildlife management interventions, both in terms of significant relationships and effect sizes, were by and large the same across the encounter, economic loss, and human death situations. Only minor differences were observed between situations. Domination was the best predictor for the acceptability of management actions, followed by mutualism, wildlife risk perception, and finally valence towards wildlife. Domination predicted public acceptability for all types of management methods and in every situation (except for doing nothing in the human death situation). Mutualism predicted public acceptability of lethal control in every situation and acceptability of doing nothing in the encounter situation. Across situations, wildlife risk perception predicted the acceptability of doing nothing. Valence has indirect effects on acceptability of doing nothing via wildlife risk perception in all situations.

In sum, a very brief answer to the 4 research questions is:

1) Are the wildlife value orientations scales applicable in Malaysia? Yes - the scales have acceptable reliability and predictive potential and could therefore be applied in Malaysia.

2) What are the predominant beliefs about wildlife amongst Malaysians? Predominant beliefs about wildlife reflect undesired exploitation, care for wildlife protection, attraction to wildlife, concern about human-wildlife conflicts, respect for wildlife, and religious or traditional beliefs.

3) Does valence have an additional predictive potential next to wildlife value orientations to explain wildlife-related evaluations? Valence has additional predictive potential for conservation support, but not for the acceptability of lethal control.

4) To what extent do wildlife value orientations, valence towards wildlife, and wildlife risk perception explain the acceptability of wildlife management interventions in Malaysia? Domination is the strongest and most widespread predictor, followed by mutualism and risk perception. Valence did not directly predict the acceptability of actions, but did so indirectly via risk perception. 


\section{REFLECTIONS ON FINDINGS: ADVANCING HUMAN DIMENSIONS OF WILDLIFE RESEARCH IN MALAYSIA AND ELSEWHERE}

Discussing whether the findings of a study can be generalized beyond the specific context (i.e., the province of Johor, Malaysia) is important. Such an exercise guides the reader in thinking about the ramifications of the findings for similar scientific research elsewhere, and, simultaneously addresses the importance of contextual factors. Naturally, discussing the question whether findings would be similar in other populations would not be very fruitful on the level of individual empirical figures, such as the exact effect size found between two concepts in this study. After all, it is very likely that the effect size would be a little different elsewhere. Only empirical research can provide an answer.

On the level of theory, however, a discussion is much more fruitful. The findings obtained in this study have theoretical implications and those implications could be important for studies in other contexts and among other populations. This discussion therefore focuses on the theoretical implications of three major findings. First, the pattern of findings in relation to findings in equivalent studies in Western populations. Second, the finding that domination is the best predictor across the various theoretical models that were tested in this thesis. And third, the finding that emotion predicts conservation support on top of wildlife value orientations, but not the acceptability of lethal control. An important source of explanation across these three discussion topics is the observation that Malaysia is a collectivist society. The next section addresses this trait of Malaysian society.

\section{Malaysia: a collectivist society}

Understanding human-wildlife relationships is fostered by examination at micro and macro levels (Manfredo \& Dayer, 2004). At the micro level, mental factors (e.g., beliefs, emotions) affect the way people behave. At the macro level, societal factors (e.g., social rules, ideologies) shape mental dispositions of individuals. Naturally, these societal factors are relevant because different societies vary in this respect. A frequently mentioned dimension along which societies vary is the individualism versus collectivism continuum. This reflects the relationship between a person and a group. Individualism emphasizes the achievements of individuals whereas collectivism reflects the importance of group cohesiveness (Kagitcibasi, 1997; Triandis, Bontempo, Villareal, Asai, \& Lucca, 1988). The individualism-collectivism continuum is also known as the idiocentrism-allocentrism continuum (Triandis et al., 1988). Important characteristics of collectivist societies are a strong acceptance of in-group norms, a high level of group dependence, a hesitancy to question authority, strong feelings of obligation, and reliance on structures defining status and political hierarchy (Triandis et al., 1988). The dimension of individualism versus collectivism has been suggested as a factor that influences 
behaviours in many domains, including purchasing behaviour (Chan, 2001), education and learning (Cheng, 1998; Merriam \& Mohamad, 2000), and even recycling behaviour (McCarty \& Shrum, 2001).

Malaysian society typically qualifies as a collectivist culture (Merriam \& Mohamad, 2000; Schwartz, 2006; Trommsdorff, Friedlmeier, \& Mayer, 2007). In the context of wildlife and natural resources, the influence of collectivism can for example be seen in the implementation of Environmental Impact Assessments (EIAs). A study suggested that the hierarchical nature of the Malaysian society and public deference to politicians and business leaders with higher status fostered the efficiency of the EIA in the case studied (Boyle, 1998). Public criticism of elite authority over environmental issues was nearly non-existent, probably because it would be considered as causing conflict and disharmony. Moreover, public participation in the EIA was limited due to the authorities' top-down approach (Marzuki, 2009). The public was only informed and not allowed to be actively involved as community empowerment principle are too foreign for the government to accommodate (Hezri \& Hasan, 2006). While the case of the EIA is an illustration, it does suggest that dealing with wildlife issues in the collectivist Malaysian culture can be very different than it would be in individualist, Western societies. Probably, then, thinking about wildlife also works a bit differently. Perhaps the collectivist trait of Malaysian society influences how people respond to questionnaire items, thus affecting the validity of measures and by extension the effect sizes that are estimated on the basis of the measures.

\section{Pattern of findings}

Overall, wildlife value orientations predicted conservation support and the acceptability of management actions. These findings are in line with previous research (Hermann, Voß, \& Menzel, 2013; Jacobs, Vaske, \& Sijtsma, 2014; Whittaker, Vaske, \& Manfredo, 2006). Also, the results support the cognitive hierarchy theory that suggests these relationships. Across situations, 17 to 24 per cent of the variation in the acceptability of lethal control is explained by domination and mutualism. Yet, these effect sizes are lower than the effect sizes as identified in the previous studies among Western populations.

One explanation could be that the questionnaire addresses issues that are not very salient among the population of Johor. In other words, people might not have given these issues much thought before. Saliency of items is known to influence measurement error (Stern, Smyth, \& Mendez, 2012). If an item does not reflect salient thought, it might measure the thoughts respondents construct at that very moment and not their stable mental dispositions (e.g. how people tend to think about wildlife) that are targeted for measurement. If the issues are not salient, those stable mental dispositions might not exist in the first place. This would not imply 
the study is useless. It is useful for managers to know how the population thinks about lethal control of problem wildlife. Also, it is scientifically meaningful to know that the theoretically asserted relationships also exist in a predominantly Islamic non-Western sample. While qualitative research was conducted to investigate whether the basic beliefs reflected by wildlife value orientations also exist among Malaysians (they did except for hunting beliefs), saliency of thought about lethal control was not explored. Additional qualitative research could shed light on this issue.

In addition, the collectivist trait of Malaysian society could explain why effect sizes are a little lower than in previous studies in Western countries. Individuals in collectivist cultures tend to focus on norms, obligations and authority (Hui, 1988). This general tendency is unlikely to be absent or switched off when filling out a questionnaire. If the respondents are asked about conservation policy or management interventions, they might not give too much consideration to their personal opinion. Being from a collectivist culture, they might rather find those actions acceptable they think the authorities would take. Then, the questionnaire's outcome shows what the respondents think they should respond in the light of the authorities' likely actions. And not whether they would personally like the action or not, or find the action good or bad. And hence, more fundamental mental dispositions such as wildlife value orientations and valence guide the acceptability of management actions less than these dispositions would in individualist societies.

This does not imply that all respondents would fill out the same answer in response to the questions about the acceptability of management actions. The variation found in this study might reflect that people have different ideas about what the authorities would do and hence what they should answer. Future research could simultaneously measure, for different wildlife management actions, the perceived likelihood that the action is performed by authorities, and the acceptability of each action. In collectivist societies, the relationship should be stronger if the reasoning rings true. If so, we should consider how useful it is to measure acceptability in the sense of reflecting a personal opinion, as measurement validity could be seriously compromised.

The next sections deal with the finding that domination is the best predictor across the various models, and the importance of emotion as a driver of specific thought about humanwildlife interactions. Here, the findings pertaining to risk perception will be briefly discussed. Risk perceptions predict the acceptability of not managing wildlife in all three contexts (wildlife is present, wildlife causes damage, wildlife kills a person). They do so in the way expected according to theory: the riskier a person perceived wildlife to be, the less this person tended to accept hands-off management. The effect sizes are between small and medium, and risk perceptions did not explain the acceptability of other management actions. So, the effects of 
risk perception are not strong and limited to the acceptability of one action. One explanation could be that wildlife value orientations explain a larger portion of the acceptability of drive shooting and lethal control than they do of doing nothing. So for the acceptability of the latter option, there is simply more left to explain. Another explanation could be that risk perception was operationalized in this study as personal risk perception. Perhaps, this is typically not how members of collectivist societies would consider risk in the first place. Maybe, measuring perceived risk of wildlife for entire families, communities, or larger societies would better reflect actual thinking about risks. And hence, social instead of personal risk perception would have more predictive validity.

\section{The dominance of domination}

Across all models that predict the acceptability of different management actions in different situations, domination is clearly the best predictor (see Chapter 5, Figure 5.3). Hence, more than any other concept addressed in this study (i.e. mutualism, risk perception, valence), the extent to which a person believes wildlife is on earth for people to use drives this person's responses to management actions. Importantly, the dominance of domination pertains to thought about management actions. Conservation support, on the other hand, is much better predicted by valence, and better predicted by mutualism than by dominance (see Chapter 4 , Table 4.2).

Theory about value change suggests that processes of modernization triggers change of value priorities in societies (Inglehart \& Baker, 2000), with income level, education level and degree of urbanization as indicators. In the context of wildlife, this would imply a shift from domination to mutualism (Manfredo, Teel, \& Henry, 2009). Indeed, research in the USA found higher levels of mutualism as average income, education level, and urbanization increase (Manfredo et al., 2009). The findings of the present study do not sit nicely with this picture. Malaysia is known as one of the countries in Southeast Asia with a positive economic outlook, with growth domestic product (GDP) increasing consistently despite the global economic turmoil (IMF, 2018). Despite the rapid economic growth, the purchasing power of Malaysians is not comparable with those of people living in Western countries. Malaysia's GDP per capita was only one-sixth of that of United States, while the GDP per capita in European countries such as the Netherlands, Germany and Denmark is also well ahead of Malaysia ("Country economy," 2018).

Yet, the findings suggest that Malaysia is not highly domination-oriented, relative to Western countries, as modernization theory would predict. Perhaps because of the influence of Islam, people are fairly mutualism-oriented. This finding calls for a questioning of the universal applicability of the modernization hypothesis to the context of thought about wildlife. Perhaps 
that theory is applicable within the setting of Western countries, but not to all countries, or perhaps the application does not work for Islam-oriented countries. While mutualism levels are not low, mutualism is hardly of influence. This finding might suggest that, regardless of the levels of mutualism, domination has a stronger influence on specific thought when countries have lower income, urbanization and education levels. So, regardless of whether levels of mutualism are low or high, due to for instance specific religious ideologies, the modernization phase a society is in would be what determines whether mutualism plays a role in specific thought. Cross-cultural research is needed to examine the merits of this reasoning. If it does ring true, domination would predominantly guide the way people think about wildlife management in pre-modernization or early modernization phases.

\section{The importance of emotion}

In general, theorists emphasize the importance of emotion in the overall working of the human mind (Damasio, 2001; LeDoux, 1998). Influences include almost all mental processes such as perception (Dolan, 2002), memory (Talarico, LaBar, \& Rubin, 2004) and motivation (Izard, 2009). It is therefore reasonable to expect that emotions towards wildlife also guide specific responses (Jacobs, Vaske, \& Roemer, 2012; Johansson, Sjöström, Karlsson, \& Brännlund, 2012; Manfredo, 2008). The results from this study are somewhat mixed in this respect. Valence did not predict the acceptability of lethal control (Chapter 4, Table 4.2) and did not directly predict responses to other management interventions (Chapter 5, Figure 5.3). However, valence did predict conservation support (Chapter 4, Table 4.2). Here, the predictive potential of valence was superior to the predictive potential of wildlife value orientations.

What do these findings say about the importance of emotions towards wildlife for further thought about wildlife? First, the findings at least partly underline the aforementioned theoretical claim, with valence being a better predictor than wildlife value orientations for conservation support. At first glance, the finding that, next to wildlife value orientations emotions do not predict the acceptability of management actions, seems to contradict the claim of the importance of emotions. Also, it might reflect a sample-specific trait, as in a previous study, valence towards wolves was predictive of the acceptability of management actions (Jacobs, Vaske, Dubois, \& Fehres, 2014). Yet, two important differences between the wolf study and the present study need to be considered. First, in the wolf study, valence related to one specific wildlife species was measured, while in this study, valence towards wildlife in general was used as a predictor. It is likely that species-specific emotion is a better predictor for accepting management actions pertaining to that species than emotion towards wildlife in general, as the hierarchy principle (Whittaker et al., 2006) would suggest. Also, in the wolf study, emotion was tested as a standalone predictor, while in this study it was tested next to 
wildlife value orientations. Ancillary analyses showed that as a standalone factor emotion did predict the acceptability of management interventions. It is just that this predictive potential overlaps with the predictive potential of wildlife value orientations. This does not necessarily mean that emotions are not important next to wildlife value orientations. Another way to look at it, is that wildlife value orientations partly originate from emotions - particularly mutualism, as the association between valence and mutualism was considerable. From this perspective, the findings underline rather than undermine the claim of the importance of emotion.

Still, the difference in predictive potential of emotion in the context of responses to conservation and responses to management is remarkable. Perhaps, the influence of emotion towards wildlife is larger for actions or events that are beneficial for wildlife than for actions and events that are harmful towards wildlife. If this is indeed the case, research with other dependent measures that reflect beneficial and harmful actions, as well as research in other countries, should show the same results.

Having said this, and apart from the potential mechanisms or effects explained above, the collectivist tendency in Malaysian society is also relevant here. In collectivists societies, lack of personal control over issues and reliance on authorities can result in passive ways of emotionally reacting to events (Mesquita \& Haire, 2004). Moreover, it is quite possible that the opinions of people in collectivist societies are less likely to be influenced by their personal emotions. If this is indeed the case, one would expect stronger relationships between emotion and other dispositions towards wildlife in individualist societies than in collectivist societies. Future cross-cultural research could address this issue.

\section{Sample limitations}

The composition of the population, the degree of urbanization, the percentages of forested land, as well as the diversity of wildlife species differ between Malaysian states (Department of Statistics Malaysia, 2011; Forestry Department of Peninsular Malaysia, 2016; Ministry of Natural Resources and Environment, 2016). The findings of the current study, on the basis of a sample of inhabitants of the state of Johor, can therefore not be generalized to the whole country's population. For this reason, the focus of this thesis' presentation of findings is not on descriptive statistics, but predominantly on relationships between concepts as anticipated by theory. Since the sample included that similar relationships exist among populations of other states in Malaysia, although empirical research is needed to verify this assertion.

Another concern is the representation of non-Malay or non-Muslim participants in the samples. In chapter 2, the study sample was dominated by Malay students because there are more ethnic Malays in public university than non-Malay students. In chapters 4 and 5, the measurement tools and the researcher's background (Malay) played a role in the low 
representation of non-Malay in the survey. The questionnaire was in English and in Malay. For Malaysians of non-Malay ethnic groups (e.g., Chinese, Indians, native inhabitants), however, English and Malay might not have been sufficient to fully understand the questions or to get people to participate. While Malay is the national language, this does not mean that everybody is proficient in this language. I did not anticipate this, but ran into this problem during the fieldwork. Consequently, the findings in this study should be interpreted as pertaining to Malay Malaysian of Johor, and it is quite conceivable that descriptive figures are different in other ethnic groups. It is therefore recommendable for future survey research in Malaysia to prepare a set of questionnaires with Chinese and Indian translations as well.

\section{RECOMMENDATIONS FOR WILDLIFE POLICY AND MANAGEMENT}

The way the public thinks about wildlife was considered in policy development for wildlife conservation in Malaysia (e.g., DWNP, 2008). However, this has, so far, predominantly been based on assumptions and impressions. The same holds true for wildlife management in Malaysia. Typically, wildlife managers and rangers rely on their own subjective experiences and judgment to estimate how the public will respond to wildlife and wildlife issues.

This research demonstrates that emotion towards wildlife and wildlife value orientations offer a way to gauge responses to conservation and management of specific species. This implies that policy-makers and managers do not necessarily have to do surveys for each case and species again. Knowing how people think about human-wildlife relationships in general, as reflected by wildlife value orientations, predicts how people will respond to specific management actions in specific situations. And knowing how people feel about wildlife in general, as reflected by valence, predicts how people will respond to conservation. Naturally, these predictions will not be one hundred per cent accurate. The human mind is complex, and many other factors are likely to influence how individuals respond to management actions and conservation policy. Yet, the predictions are practically relevant. Therefore, if public opinion is to be taken into account, it would be good to conduct research that is representative for the whole Malaysian population, to include more individuals with a non-Malay background as well as people from other states of Malaysia. The theoretical and methodological approach as developed in this thesis offers a model that is likely to work. After all, measurement reliability merits using the scales and the predictive potential of the concepts is considerable. Specifically, the novel scientific contribution of this research - the integration of cognitive and emotional approaches - is also practically relevant. Cognition is more relevant in one domain of thought (management actions) and emotions are more relevant in another domain of thought (conservation). 
In the context of conservation, human emotions are often neglected, perhaps because considering emotions would be seen as a threat to taking rational decisions (Manfredo, 2008). Yet, ultimately, emotion is a driver of conservation action and support. Addressing emotional relationships with wildlife, rather than neglecting them, would therefore be conducive for communicating with and understanding the public. And, eventually, and in line with previous research (Jacobs \& Harms, 2014), evoking emotion is likely to be effective for stimulating conservation support.

The findings on public acceptability of wildlife management interventions (Chapter 5) could encourage wildlife managers to strive for non-lethal approaches to manage humanwildlife conflicts. In addition to drive shooting, there are many non-lethal options that can be applied to different conflicts, wildlife species, and situations (Boonman-Berson, Turnhout, \& Carolan, 2016; Nyhus, 2016; Treves \& Karanth, 2003).

Yet, perhaps the most important message is that the public is diverse. The findings related to each concept that was used to guide this study - wildlife value orientations, valence, risk perceptions, conservation support, acceptability of management actions - show that the public is varied. Policy-makers and managers frequently make assumptions about the public by necessity, as empirical data often do not exist. The assumptions usually express how the public thinks or feels. However, there is no such as thing as "the public". Dealing with diversity is the major challenge for policy-makers and managers who wish to take psychological and social dimensions of wildlife policy and management into account. 


\section{REFERENCES}

Boonman-Berson, S., Turnhout, E., \& Carolan, M. (2016). Common sensing: Human-black bear cohabitation practices in Colorado. Geoforum, 74, 192-201. doi: 10.1016/j.geoforum.2016.06.010

Boyle, J. (1998). Cultural influences on implementing environmental impact assessment: Insights from Thailand, Indonesia, and Malaysia. Environmental Impact Assessment Review, 18(97), 95-116. doi: 10.1016/S0195-9255(97)00082-6

Chan, R. Y. K. (2001). Determinants of Chinese consumers' green purchase behavior. Psychology \& Marketing, 18(4), 389-413. doi: 10.1002/mar.1013

Cheng, K. (1998). Can education values be borrowed? Looking into cultural differences. Peabody Journal of Education, 73(2), 11-30.

Country economy. (2018). Retrieved November 28, 2018, from https://countryeconomy.com/ Damasio, A. (2001). Fundamental feelings. Nature, 413(6858), 781. doi: 10.1038/35101669

Department of Statistics Malaysia. (2011). Population distribution and basic demographic characteristics. Putrajaya, Malaysia.

Dolan, R. J. (2002). Emotion, cognition, and behavior. Science, 298(5596), 1191-1194.

DWNP. (2008). National Tiger Conservation Action Plan for Malaysia. Kuala Lumpur, Malaysia.

Forestry Department of Peninsular Malaysia. (2016). Forestry Department of Peninsular Malaysia Annual Report 2016. Kuala Lumpur, Malaysia.

Hermann, N., Voß, C., \& Menzel, S. (2013). Wildlife value orientations as predicting factors in support of reintroducing bison and of wolves migrating to Germany. Journal for Nature Conservation, 21(3), 125-132. doi: 10.1016/j.jnc.2012.11.008

Hezri, A. A., \& Hasan, M. N. (2006). Towards sustainable development? The evolution of environmental policy in Malaysia. Natural Resources Forum, 30(1), 37-50. doi: 10.1111/j.1477-8947.2006.00156.x

Hui, C. H. (1988). Measurement of individualism-collectivism. Journal of Research in Personality, 22(1), 17-36. doi: 10.1016/0092-6566(88)90022-0

IMF. (2018). World economic outlook database. Retrieved October 27, 2018, from https://www.imf.org/external/pubs/ft/weo/2018/01/weodata/index.aspx

Inglehart, R., \& Baker, W. E. (2000). Modernization, cultural change, and the persistence of traditional values. American Sociological Review, 65(1), 19-51.

Izard, C. E. (2009). Emotion theory and research: Highlights, unanswered questions, and emerging issues. Annual Review of Psychology, 60(1), 1-25. doi: 10.1146/annurev.psych.60.110707.163539

Jacobs, M. H., \& Harms, M. (2014). Influence of interpretation on conservation intentions of 
whale tourists. Tourism Management, 42, 123-131. doi: 10.1016/j.tourman.2013.11.009

Jacobs, M. H., Vaske, J. J., Dubois, S., \& Fehres, P. (2014). More than fear: Role of emotions in acceptability of lethal control of wolves. European Journal of Wildlife Research, 60(4), 589-598. doi: 10.1007/s10344-014-0823-2

Jacobs, M. H., Vaske, J. J., \& Roemer, J. M. (2012). Toward a mental systems approach to human relationships with wildlife: The role of emotional dispositions. Human Dimensions of Wildlife, 17(1), 4-15. doi: 10.1080/10871209.2012.645123

Jacobs, M. H., Vaske, J. J., \& Sijtsma, M. T. J. (2014). Predictive potential of wildlife value orientations for acceptability of management interventions. Journal for Nature Conservation, 22(4), 377-383. doi: 10.1016/j.jnc.2014.03.005

Johansson, M., Sjöström, M., Karlsson, J., \& Brännlund, R. (2012). Is human fear affecting public willingness to pay for the management and conservation of large carnivores? Society \& Natural Resources, 25(6), 610-620. doi: 10.1080/08941920.2011.622734

Kagitcibasi, C. (1997). Individualism and collectivism. In J. W. Berry, M. H. Segall, \& C. Kagitcibasi (Eds.), Handbook of cross-cultural psychology: Social behavior and applications (2nd ed.). Boston: Allyn and Bacon.

LeDoux, J. (1998). The emotional brain: The mysterious underpinnings of emotional life. New York: Touchstone.

Manfredo, M. J. (2008). Who cares about wildlife? Social science concepts for exploring human-wildlife relationships and conservation issues. New York: Springer.

Manfredo, M. J., \& Dayer, A. (2004). Concepts for exploring the social aspects of humanwildlife conflict in a global context. Human Dimensions of Wildlife, 9(4), 1-20. doi: 10.1080/10871200490505765

Manfredo, M. J., Teel, T. L., \& Henry, K. L. (2009). Linking society and environment: A multilevel model of shifting wildlife value orientation in the western United States. Social Science Quarterly, 90, 407-427.

Marzuki, A. (2009). A review on public participation in Environmental Impact Assessment in Malaysia. Theoretical and Empirical Researches in Urban Environment, 4(3), 126-136.

McCarty, J. A., \& Shrum, L. J. (2001). The influence of individualism, collectivism, and locus of control on environmental beliefs and behavior. Journal of Public Policy \& Marketing, 20(1), 93-104. doi: 10.1509/jppm.20.1.93.17291

Merriam, S., \& Mohamad, M. (2000). How cultural values shape learning in older adulthood: The case of Malaysia. Adult Education Quarterly, 51(1), 45-63.

Mesquita, B., \& Haire, A. (2004). Emotion and culture. Encyclopedia of Applied Psychology. doi: 10.1016/B0-12-657410-3/00393-7

Ministry of Natural Resources and Environment. (2016). National Policy on Biological 
Diversity 2016-2025. Putrajaya, Malaysia.

Nyhus, P. J. (2016). Human-wildlife conflict and coexistence. Annual Review of Environment and Resources, 41(1), 143-171. doi: 10.1146/annurev-environ-110615-085634

Schwartz, S. (2006). A theory of cultural value orientations: Explication and applications. Comparative Sociology, 5(921), 137-182. doi: 10.1163/156913306778667357

Stern, M. J., Smyth, J. D., \& Mendez, J. (2012). The effects of item saliency and question design on measurement error in a self-administered survey. Field Methods, 24(1), 3-27. doi: $10.1177 / 1525822 X 11419478$

Talarico, J. M., LaBar, K. S., \& Rubin, D. C. (2004). Emotional intensity predicts autobiographical memory experience. Memory \& Cognition, 32(7), 1118-1132. doi: 10.3758/BF03196886

Treves, A., \& Karanth, K. U. (2003). Human-carnivore conflict and perspectives on carnivore management worldwide. Conservation Biology, 17(6), 1491-1499. doi: 10.1111/j.15231739.2003.00059.x

Triandis, H. C., Bontempo, R., Villareal, M. J., Asai, M., \& Lucca, N. (1988). Individualism and collectivism: Cross-cultural perspectives on self-ingroup relationships. Journal of Personality and Social Psychology, 54(2), 323-338. doi: 10.1037/0022-3514.54.2.323

Trommsdorff, G., Friedlmeier, W., \& Mayer, B. (2007). Sympathy, distress, and prosocial behavior of preschool children in four cultures. International Journal of Behavioral Development, 31(3), 284-293.

Whittaker, D., Vaske, J. J., \& Manfredo, M. J. (2006). Specificity and the cognitive hierarchy: Value orientations and the acceptability of urban wildlife management actions. Society \& Natural Resources, 19, 515-530. doi: 10.1080/08941920600663912 


\section{Summary}

Wildlife is important to people for a variety of reasons: as a source of fascination, as a threat to goods and health, as an economic asset, or as an important part of the ecosystem. In Malaysia, wildlife is economically important, as it attracts tourists, but wildlife also causes safety and nuisance concerns. Wildlife conservation policy and management actions are traditionally informed by biological and ecological knowledge. Yet, social science knowledge could be equally important. People are diverse in their opinions and hence ecologically optimal solutions might not work in real societies. This thesis aims to understand how Malaysians respond to wildlife and to wildlife policy and management. Existing research traditions in Western countries have used the concepts of wildlife value orientations (patterns of beliefs that give meaning and direction to values in the context of human-wildlife relationships, with domination and mutualism as the predominant orientations), risk perceptions, and emotions (most notably, valence towards wildlife, meaning the positive-negative dimension of emotion) to guide empirical studies. This thesis makes a new contribution to human dimensions of wildlife research by combining these concepts in an overarching theory, and by applying the concepts and associated measurement instruments to a non-Western society (Figure 1).

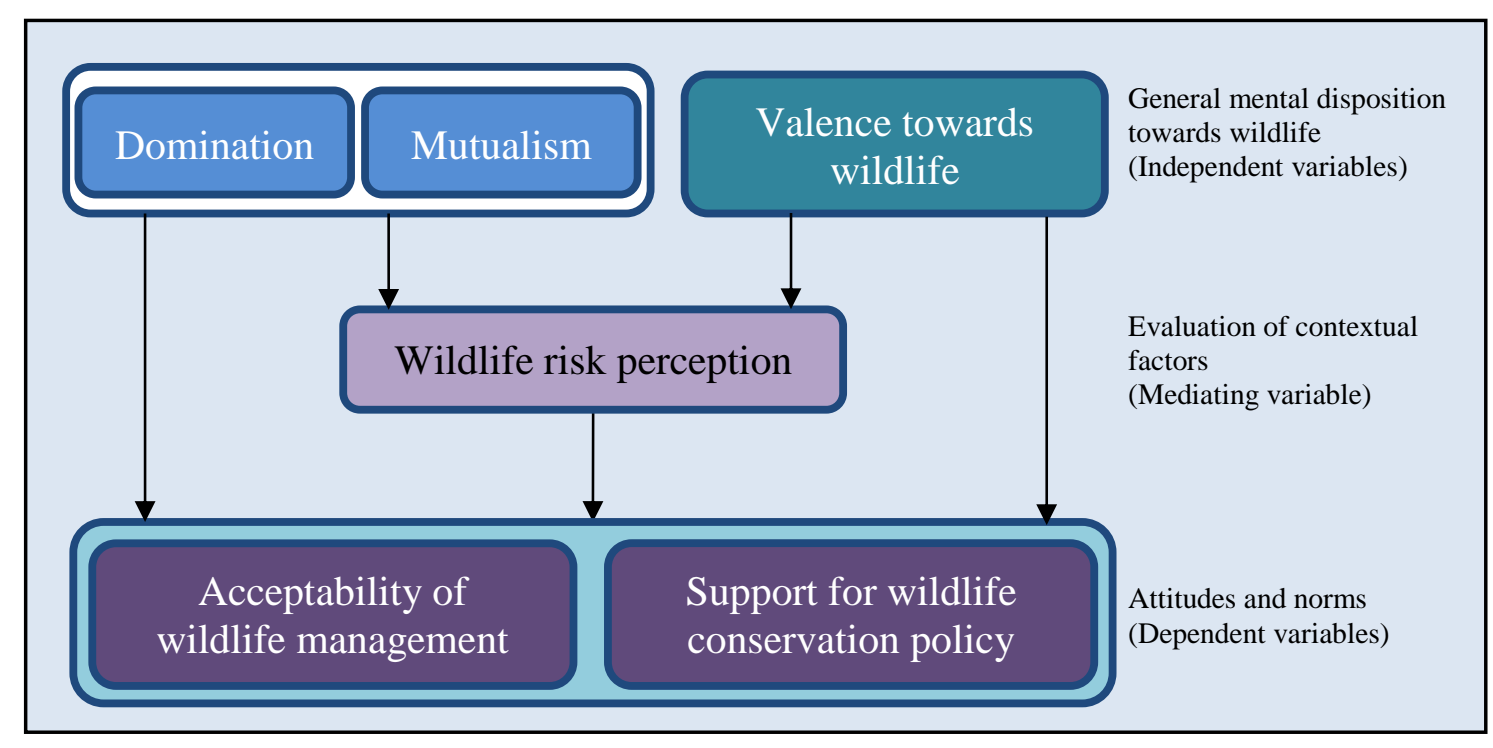

Figure 6. The conceptual model guiding this $\mathrm{PhD}$ research 
The following four research questions have guided the investigations:

1. Are the wildlife value orientations scales applicable in Malaysia?

2. What are the predominant beliefs about wildlife among Malaysians?

3. Does valence have an additional predictive potential next to wildlife value orientations to explain wildlife-related evaluations?

4. To what extent do wildlife value orientations, valence towards wildlife, and wildlife risk perception explain acceptability of wildlife management interventions in Malaysia?

To test the applicability of wildlife value orientation scales that have previously been used in Western societies, a survey $(\mathrm{n}=391)$ was administered among Malaysian University students (Chapter 2). As Malaysian culture is deeply influenced by Islam ideology, this study presents a case for addressing the cross-cultural applicability of the scales. The existing wildlife value orientation scales aim to measure domination and mutualism, the predominant orientations as identified by previous research. Individuals who are more domination oriented prioritize human well-being over wildlife and are more likely to accept lethal wildlife control as part of management interventions. In contrast, individuals who are more mutualism oriented are not likely to accept lethal wildlife control as they view wildlife as companions, deserving of rights and care. Domination is composed of appropriate use (6 items) and hunting (4 items) beliefs, and mutualism is composed of social affiliation ( 4 items) and caring ( 5 items) beliefs. To assess the acceptability of lethal control, responses to lethal control of four different species for three different scenarios that reflected different levels of problem contexts were elicited, using 12 questions. The current wildlife value orientation scales were reliable in the Malaysian student sample - all Cronbach's alphas $\geq .65$ - and had predictive validity -8 to 14 per cent of the variance of the acceptability of lethal control was explained. Yet, both reliability and predictive validity were of a lesser magnitude than figures in previous Western studies. Especially the hunting beliefs scale did not reflect basic thinking about wildlife in our sample, and our data suggest two different hunting dimensions - consequences of hunting for wildlife and human opportunities for hunting. For future cross-cultural comparisons of wildlife value orientations, research to inform potential amendments to the scales to better reflect salient beliefs in nonWestern nations is recommended.

Level of abstraction and positive-negative evaluation are inherent properties of thought about wildlife. Chapter 3 investigated whether the level of abstraction and the direction of evaluation are associated in salient thought among Malaysians, and identified predominant salient beliefs 
of Malaysians. As human-wildlife problems exist on the level of concrete experiences, we expected abstract thought to be positive more frequently than concrete thought. Semi-structured interviews were conducted among 30 inhabitants of Peninsular Malaysia, with different demographic characteristics. Predominant salient beliefs included undesired exploitation, concern for wildlife protection, attraction to wildlife, concern about human-wildlife conflicts, respect for wildlife, and religious or traditional beliefs. Each discrete statement was coded as abstract (defined as not reporting a specific experience and not about a specific species of wildlife) or concrete, and as positive (defined as positive for or positive about wildlife), neutral or negative. The findings indeed revealed that abstract thought was more often positive than concrete thought $\left(\chi^{2}=28.02, p<.001\right.$, Cramer's $\left.V=.35\right)$. Urbanites more often expressed abstract and positive thought than rural inhabitants. The identified association between the two dimensions is perhaps fundamental to understanding diversity in society. To a great extent, the basic beliefs matched with the existing value orientation scales and hence this study did not reveal clear suggestions for amending the current wildlife value orientation scales to tailor them to the Malaysian population.

For the studies reported in chapters 4 and 5, data were obtained with the use of a drop-off/pickup method $(\mathrm{n}=1062)$ sent to a random resident sample in the state of Johor, Malaysia. The survey included measures of wildlife value orientations, wildlife risk perceptions, valence toward wildlife, acceptability of different wildlife actions, and support for wildlife conservation.

Research to understand human responses to wildlife and wildlife issues has predominantly focused on cognitions. Yet, as emotions are basic human responses to wildlife, emotions are also important to consider in research. Integrating cognition and emotion concepts could foster the overall understanding of human-wildlife relationships. Chapter 4 tested the relationships between valence (the pleasant-unpleasant dimension of emotion) towards wildlife and wildlife value orientations (patterns of basic cognitions in the context of wildlife). Also, this study estimated the additional predictive potential of emotion next to cognition for the acceptability of lethal control and support for wildlife conservation. Analyses showed that valence was associated with wildlife value orientations: domination-orientated people find wildlife less pleasant and mutualists find wildlife more pleasant. Valence had additional explanatory value next to cognition for conservation support. Valence, however, did not have additional predictive potential for acceptability of lethal control. Based on these findings, we recommend integrating 
cognition and emotion measurements in future research to understand human responses to wildlife issues. Also, wildlife managers could take the emotion of stakeholders into account in their communication and decision-making processes.

A wide range of management interventions have been implemented to mitigate human-wildlife conflicts. Some of the management methods are more acceptable to the public than others. Chapter 5 examined public acceptability of doing nothing, drive shooting, and lethal control management methods in three situations: an encounter with wildlife, economic loss caused by wildlife, and human death caused by wildlife. Three concepts in human dimensions of wildlife research were examined: wildlife value orientations, valence towards wildlife, and wildlife risk perception. Three structural equation models were applied. The results showed that a specific set of predictors is associated with public acceptability of different wildlife management interventions. A domination orientation predicted the acceptability of management actions in different situations. Both a mutualism orientation and wildlife risk perception predicted the acceptability of at least one of the wildlife management interventions, whereas valence only indirectly predicted the acceptability of doing nothing. The significant predictors accounted for 6 to 24 per cent of the variance of acceptability of wildlife management actions. Overall, the results suggest that the domination orientation is an important concept when explaining public responses to wildlife management interventions among the study sample, explaining a larger portion of variance than the other concepts do.

To conclude, data suggest the following answers to the research questions (chapter 6):

1) Are the wildlife value orientations scales applicable in Malaysia? Yes - the scales have acceptable reliability and predictive potential and could therefore be applied in Malaysia.

2) What are the predominant beliefs about wildlife among Malaysians? Predominant beliefs about wildlife reflect undesired exploitation, care for wildlife protection, attraction to wildlife, concern about human-wildlife conflicts, respect for wildlife, and religious or traditional beliefs. In addition, abstract thought about wildlife tends to be more positive than concrete thought.

3) Does valence have an additional predictive potential next to wildlife value orientations to explain wildlife-related evaluations? Valence has additional predictive potential for wildlife conservation support, but not for the acceptability of lethal wildlife control. 
4) To what extent do wildlife value orientations, valence regarding wildlife, and wildlife risk perception explain the acceptability of wildlife management interventions in Malaysia? Domination is the strongest and most widespread predictor, followed by mutualism and risk perception. Valence did not directly predict the acceptability of actions, but did so indirectly via risk perception.

By and large, findings are in line with theoretical findings and with previous findings from Western studies. The major novel contribution of this thesis is the finding that cognitions are good predictors of responses to action that is harmful to wildlife (lethal control) while emotions are good predictors of action that is good for wildlife (conservation). Future research is needed to examine whether this finding is culture-specific. Ultimately, up to 24 per cent of the acceptability of wildlife management actions was explained by the predictory concepts. The effect sizes were a bit lower than those identified in previous studies using Western samples. Two reasons could be that in Malaysia wildlife issues are less salient than they are in Western countries, and that the collectivist trait of Malaysia culture is reflected in how people fill out questionnaires: perhaps a bit more guided by thinking about what the authorities would do and less guided by personal opinions. Despite these speculative methodological reservations, this study showed that the public is diverse, even in a relatively collectivist society as Malaysia. Dealing with this diversity is a major challenge for managers and policy-makers. 


\section{Samenvatting}

Wilde dieren zijn op verschillende manieren van belang voor mensen: een bron van fascinatie, een bedreiging voor goederen en gezondheid, als economische goed, of als sleutelrol in gezonde ecosystemen. In Maleisië zijn wilde dieren belangrijk voor toerisme maar veroorzaken ze ook zorgen over veiligheid en overlast. Beleid en beheer voor wilde dieren zijn van oudsher gestoeld op biologische en ecologische kennis. Sociaal-wetenschappelijke kennis is echter evengoed belangrijk. Verschillende mensen hebben verschillende opvattingen over wilde dieren. Beleidsoplossingen die ecologisch optimaal zijn kunnen daarom suboptimaal zijn, of zelfs helemaal niet werken, in de complexe maatschappij.

Het doel van dit proefschrift is te begrijpen hoe inwoners van Maleisië denken over wilde dieren en over beleid voor en beheer van wilde dieren. Bestaande onderzoekstradities in Westerse landen hebben verschillende concepten gehanteerd om dit te bestuderen: waardeoriëntaties ten opzichte van wilde dieren (dit zijn overtuigingen over dieren die richting en betekenis geven aan fundamentele waarden in de context van mens-dier interacties, waarbij dominantie en mutualisme de belangrijkste oriëntaties zijn), risicopercepties van wilde dieren, en emoties ten opzichte van wilde dieren (en hierbij met name de positief-negatieve dimensie van emoties, ook wel valentie genoemd). Dit proefschrift presenteert een nieuwe bijdrage aan de kennis door deze concepten te combineren in een nieuwe overkoepelende theorie, en door deze theorie toe te passen in een niet-Westerse samenleving.

Om te onderzoeken of de bestaande waardeoriëntatie-meetschalen ook geschikt zijn om relaties tussen mensen en wilde dieren onder inwoners van Maleisië te meten, is een vragenlijst afgenomen onder studenten van de universiteit van Kuala Lumpur. Zowel de betrouwbaarheid (geschat als de interne consistentie van items die hetzelfde concept meten) als de validiteit (geschat als de mate waarin waardeoriëntaties de acceptatie van het doden van wilde dieren als beheersmaatregel voorspellen) waren voldoende om het meetinstrument te kunnen inzetten onder de bevolking van Maleisië. Daarbij waren de betrouwbaarheid en validiteit wel iets minder goed dan in veel Westerse studies.

Daarom zijn semi-gestructureerde interviews gehouden onder verschillende inwoners van Maleisië, in eerste instantie om te onderzoeken of er belangrijke overtuigingen over wilde dieren bestaan die nog niet weerspiegeld zijn in de bestaande meetschalen. De belangrijkste 
overtuigingen waren: ongewenste exploitatie van wilde dieren, zorgen over bescherming van wild, de aantrekkingskracht van wilde dieren, zorgen over conflicten tussen mens en dier, respect voor wilde dieren, en religieuze of traditionele overtuigingen. Deze overtuigingen zijn, hoewel soms in andere bewoordingen, reeds weerspiegeld in de bestaande meetschalen. Daarnaast bleken abstracte gedachten (niet toegespitst op specifieke soorten of contexten) over wilde dieren vaker positief te zijn dan concrete gedachten (over specifieke soorten in specifieke contexten).

Vervolgens is een grootschalig survey afgenomen onder inwoners van Johor, de provincie in Maleisië waarin de overheid de meeste klachten over overlast van wilde dieren heeft ontvangen. Hierin zijn waardeoriëntaties ten opzichte van wilde dieren, valentie ten opzichte van wilde dieren, en risicoperceptie gemeten als onafhankelijke variabelen, en acceptatie van verschillende beheersmaatregelen alsmede steun aan beschermingsbeleid als afhankelijke variabelen. Deze data zijn gebruikt om te analyseren of valentie (de positief-negatief dimensie van emotie) voorspellende waarde heeft naast de veelgebruikte waardeoriëntaties. Waardeoriëntaties bleken de beste voorspellers voor acceptatie van beheersmaatregelen. Valentie bleek daarentegen de beste voorspeller voor steun aan beschermingsbeleid.

De data van het grootschalige survey zijn ook gebruikt om het hele theoretische model te toetsen, via structural equation modeling. Dominantie was daarbij de beste voorspeller voor acceptatie van beheersmaatregelen, gevolgd door mutualisme en risicoperceptie. Valentie was temidden van de andere voorspellers geen significante directe voorspeller, maar wel indirect via risicoperceptie.

Grofweg komen de bevindingen overeen met resultaten van eerder onderzoek onder Westerse populaties. De belangrijkste bijdrage aan kennis vormt de bevinding dat cognities (gerepresenteerd door waardeoriëntaties) goede voorspellers zijn voor acceptatie van maatregelen die leed berokkenen aan wilde dieren (zoals het doden van dieren die overlast veroorzaakten), terwijl emoties goede voorspellers zijn voor acceptatie van maatregelen die goed zijn voor wilde dieren (zoals beschermingsbeleid). Toekomstig onderzoek zal moeten uitwijzen in hoeverre deze bevindingen specifiek zijn voor Maleisië. Aan beleidsmakers en beheerders laat deze studie daarnaast zien dat deze waarop mensen denken over wilde dieren, en beleids- en beheersmaatregelen, divers is, zelfs in een relatief collectivistische cultuur. Omgaan met deze diversiteit is daarom een belangrijke uitdaging voor beheerders en beleidsmakers. 


\section{About the author}

\section{Z}

ulkhairi Azizi Zainal Abidin was born on Thursday $19^{\text {th }}$ December 1985 to Azizah Mat Hussin in Kuala Lumpur, Malaysia. He is the second of four siblings. He received his early education at Kampung Cheras Bharu Primary School and completed his secondary education at the Secondary Religious School Batu 10 Cheras. After finishing his Bachelor of Forestry Science at the Universiti Putra Malaysia in 2008, he continued his Master

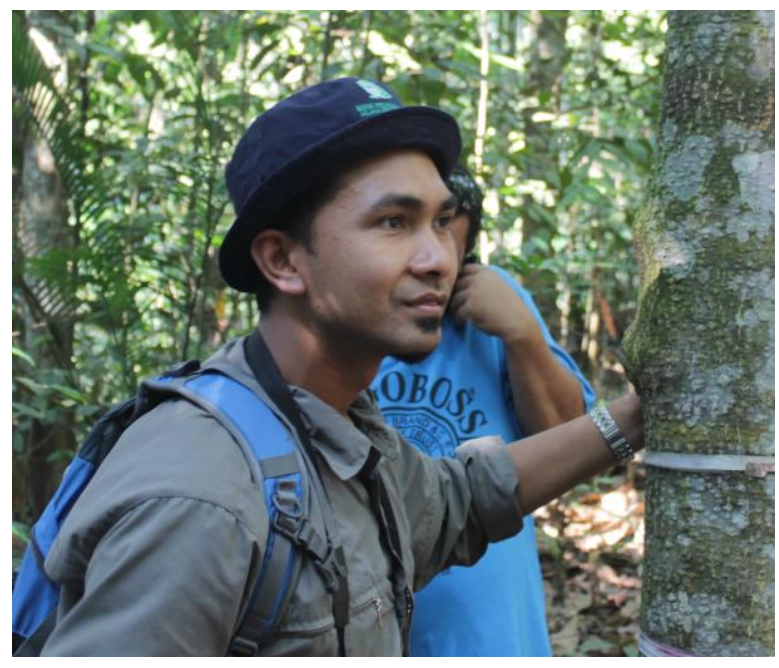
study at the University of South Australia in Environmental Management and Sustainability between 2010 and 2011, mainly focusing on topics of animal and plant species management in urban areas. During his master study, he wrote a minor dissertation that examined public perception of human-macaque conflicts at an urban-forest interface area. This is when he was first introduced to the social sciences. His PhD trajectory at Cultural Geography group in Wageningen began in October 2014. Over time, he got a strong interest and passion in his study topic. During the period of fieldwork, which he enjoyed the most, he learned many things about people's responses to wildlife issues and was given an opportunity to formally share his view on the importance of wildlife conservation to a group of primary school students. During his $\mathrm{PhD}$ work, he was involved in two conferences including the International Conference Centre for Space, Place and Society in 2017 and the Pathways Europe Conference in 2018 and is part of research team that investigate the cross-cultural comparison of wildlife value orientations. The results of his $\mathrm{PhD}$ study are presented in this thesis.

Zulkhairi's research interest focuses on the influence of psychological factors on individual thought and actions in nature-related issues. After his $\mathrm{PhD}$ graduation, he will rejoin the Department of Recreation and Ecotourism, Faculty of Forestry, Universiti Putra Malaysia as a lecturer. 


\section{Scientific contributions}

\section{Refereed scientific journals}

1. Zainal Abidin, Z. A., \& Jacobs, M. H. (2016). The applicability of wildlife value orientations scales to a Muslim student sample in Malaysia. Human Dimensions of Wildlife, 21(6), 555-566. doi: 10.1080/10871209.2016.1199745

2. Zainal Abidin, Z. A., \& Jacobs, M. H. (2019). Relationships between valence towards wildlife and wildlife value orientations. Journal for Nature Conservation, 49, 63-68. doi: https://doi.org/10.1016/j.jnc.2019.02.007

\section{Contributions to conferences and seminars}

1. Zainal Abidin, Z. A., \& Jacobs, M. H. (2017). Structure and predictive validity of human emotions to animals; Presented at the $1^{\text {st }}$ International Conference of Centre for Space, Place and Society (CSPS). Wageningen, The Netherlands, 28-30 June 2017. (Oral presentation).

2. Zainal Abidin, Z. A., \& Jacobs, M. H. (2017). Abstract wildlife is nice, concrete wildlife less so; Presented at the Pathways Conference 2017 - Human Dimensions of Wildlife. Colorado, USA, 17-20 September 2017. (Oral presentation).

3. Zainal Abidin, Z. A., \& Jacobs, M. H. (2018). Understanding public acceptability of wildlife management actions in Malaysia; Presented at the Pathways Europe 2018 Human Dimensions of Wildlife. Goslar, Germany, 16-19 September 2018. (Oral presentation). 
Zulkhairi Azizi Zainal Abidin

Wageningen School of Social Sciences (WASS)

Completed Training and Supervision Plan

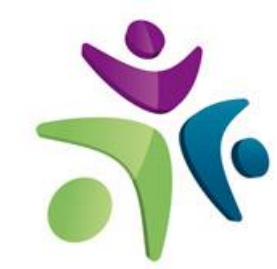

Wageningen School

of Social Sciences

\begin{tabular}{|c|c|c|c|}
\hline Name of the learning activity & Department/Institute & Year & ECTS* \\
\hline \multicolumn{4}{|l|}{ A) Project related competences } \\
\hline $\begin{array}{l}\text { GEO } 36306 \text { Environmental } \\
\text { Psychology }\end{array}$ & $\begin{array}{l}\text { Wageningen University and Research } \\
\text { (WUR) }\end{array}$ & 2015 & 6.0 \\
\hline $\begin{array}{l}\text { GEO } 34806 \text { Advanced Socio-Spatial } \\
\text { Research Methodology }\end{array}$ & WUR & 2015 & 3.0 \\
\hline $\begin{array}{l}\text { YRM } 50806 \text { Quantitative Data } \\
\text { Analysis - Multivariate Techniques }\end{array}$ & WUR & 2017 & 2.0 \\
\hline GEO PhD Day Symposium & WUR & $2015-2018$ & 1.5 \\
\hline Proposal writing & WUR & 2016 & 6.0 \\
\hline \multicolumn{4}{|c|}{ B) General research related competences } \\
\hline WASS Introduction course & WASS & 2014 & 1.0 \\
\hline $\begin{array}{l}\text { 'Structure and predictive validity of } \\
\text { human emotions to animals' }\end{array}$ & $\begin{array}{l}\text { Int. Conference, Centre for Space, } \\
\text { Place and Society (CSPS), WUR }\end{array}$ & 2017 & 1.0 \\
\hline $\begin{array}{l}\text { 'Public acceptance of wildlife } \\
\text { management interventions in } \\
\text { Malaysia' }\end{array}$ & $\begin{array}{l}\text { Pathway to Success Conference, } \\
\text { Alfred Toepfler Academy for Nature } \\
\text { Conservation, Germany and } \\
\text { Colorado State University, United } \\
\text { States of America }\end{array}$ & 2018 & 1.0 \\
\hline Efficient Writing Strategies & Wageningen in'to Languages & 2016 & 1.3 \\
\hline Wageningen Geography Lecture & GEO & $2014-2018$ & 2.0 \\
\hline Landscape Conservation seminars & GEO & $2014-2018$ & 2.0 \\
\hline Scientific Writing & Wageningen In'to Languages & 2017 & 1.8 \\
\hline $\begin{array}{l}\text { Research Ethics in the Social } \\
\text { Sciences }\end{array}$ & $\begin{array}{l}\text { Wageningen Graduate Schools } \\
\text { (WGS) }\end{array}$ & 2017 & 0.5 \\
\hline CSPS Writing Retreat & WASS \& CSPS & 2018 & 1.0 \\
\hline \multicolumn{4}{|c|}{ C) Career related competences/personal development } \\
\hline $\begin{array}{l}\text { Orientation on Teaching for PhD } \\
\text { Candidate }\end{array}$ & Educational Staff Development & 2017 & 1.0 \\
\hline Reviewing a Scientific Paper & WGS & 2018 & 0.1 \\
\hline Supervised BSc Thesis & $\begin{array}{l}\text { The Hague University of Applied } \\
\text { Sciences }\end{array}$ & 2016 & 2.0 \\
\hline Co-supervise MSc Thesis & GEO, WUR & 2018 & 1.0 \\
\hline Total & & & 34.2 \\
\hline
\end{tabular}

*One credit according to ECTS is on average equivalent to 28 hours of study load 
The research described in this thesis was financially supported by the Ministry of Higher Education of Malaysia and Universiti Putra Malaysia.

Financial support from Cultural Geography Group, Wageningen University for printing this thesis is gratefully acknowledged. 
